\title{
Desempenho de sistemas com dados georeplicados com consistência em momento indeterminado e na linha do tempo
}

Maurício José de Oliveira De Diana

\author{
DisSERTAÇÃO APRESENTADA \\ $\mathrm{AO}$ \\ Instituto DE MATEMÁticA E Estatística \\ DA \\ UniVERSIDADE DE SÃO PAULO \\ PARA \\ OBTENÇÃO DO TÍTULO \\ $\mathrm{DE}$ \\ Mestre em CiênCia da Computação
}

Programa: Mestrado em Ciência da Computação

Orientador: Prof. Dr. Marco Aurélio Gerosa 


\title{
Desempenho de sistemas com dados georeplicados com consistência \\ em momento indeterminado e na linha do tempo
}

\begin{abstract}
Esta versão da dissertação/tese contém as correções e alterações sugeridas pela Comissão Julgadora durante a defesa da versão original do trabalho, realizada em 21/03/2013. Uma cópia da versão original está disponível no Instituto de Matemática e Estatística da Universidade de São Paulo.
\end{abstract}

Comissão Julgadora:

- Prof. Dr. Marco Aurélio Gerosa (orientador) - IME-USP

- Prof. Dr. Daniel Macedo Batista - IME-USP

- Prof. Dr. Magnos Martinello - UFES 


\section{Agradecimentos}

Eu gostaria de agradecer:

Primeiramente, ao Prof. Dr. Marco Aurélio Gerosa, por me mostrar o caminho na academia, também pela confiança e paciência.

Aos Profs. Drs. Daniel Macedo Batista, José Eduardo Ferreira e Magnos Martinello pelas sugestões nas bancas de qualificação e de defesa.

A Adrien Lèbre, Gustavo Bervian Brand e Louis-Claude Canon pelos ensinamentos sobre sistemas distribuídos e análise de desempenho. A Adrien e Gabriel Antoniu por me darem oportunidades em seus grupos.

A Alfredo Goldman e Olivier Richard por viabilizarem a infraestrutura para os experimentos.

A Paulo Miotto, Fabio Akita e Gleicon Moraes pelas lições sobre computação e profissão.

A Gustavo Oliva e Mauricio Aniche pelos debates sobre a pesquisa. Ao Aniche, também pela parceria nas disciplinas.

A Adolfo Sousa pela logística de apoio em São Paulo.

A Daniel Prado pela companhia nos momentos de despressurização.

A família, pelo pelo apoio incondicional.

Os experimentos apresentados neste trabalho foram realizados utilizando a plataforma para experimentos Grid'5000, desenvolvida pela ação de desenvolvimento ALADDIN INRIA com o apoio do CNRS, RENATER e várias universidades, bem como outros organismos de financiamento (ver https://www.grid5000.fr). 


\section{Resumo}

DE DIANA, M. J. O. Desempenho de sistemas com dados georeplicados com consistência em momento indeterminado e na linha do tempo. 2013. 66 f. - Instituto de Matemática e Estatística, Universidade de São Paulo, São Paulo, 2013.

Sistemas web de larga escala são distribuídos em milhares de servidores em múltiplos centros de processamento de dados em diferentes localizações geográficas, operando sobre redes de longa distância (WANs). Várias técnicas são usadas para atingir os altos níveis de escalabilidade requeridos por esses sistemas. Replicação de dados está entre as principais delas, e tem por objetivo diminuir a latência, aumentar a vazão e/ou aumentar a disponibilidade do sistema. O principal problema do uso de replicação em sistemas georeplicados é a dificuldade de garantir consistência entre as réplicas sem prejudicar consideravelmente o desempenho e a disponibilidade do sistema. O desempenho do sistema é afetado pelas latências da ordem de centenas de milissegundos da WAN, enquanto a disponibilidade é afetada por falhas que impedem a comunicação entre as réplicas. Quanto mais rígido o modelo de consistência de um sistema de armazenamento, mais simples é o desenvolvimento do sistema que o usa, mas menores são seu desempenho e disponibilidade.

Entre os modelos de consistência mais relaxados e mais difundidos em sistemas web georeplicados está a consistência em momento indeterminado (eventual consistency). Esse modelo de consistência garante que em algum momento as réplicas convergem após as escritas terem cessado. Um modelo mais rígido e menos difundido é a consistência na linha do tempo. Esse modelo de consistência usa uma réplica mestre para garantir que não ocorram conflitos na escrita. Nas leituras, os clientes podem ler os valores mais recentes a partir da cópia mestre, ou optar explicitamente por ler valores possivelmente desatualizados para obter maior desempenho ou disponibilidade. A consistência na linha do tempo apresenta disponibilidade menor que a consistência em momento indeterminado em determinadas situações, mas não há dados comparando o desempenho de ambas.

O objetivo principal deste trabalho foi a comparação do desempenho de sistemas de armazenamento georeplicados usando esses dois modelos de consistência. Para cada modelo de consistência, foram realizados experimentos que mediram o tempo de resposta do sistema sob diferentes cargas de trabalho e diferentes condições de rede entre centros de processamento de dados. O estudo mostra que um sistema usando consistência na linha do tempo apresenta desempenho semelhante ao mesmo sistema usando consistência em momento indeterminado em uma WAN quando a localidade dos acessos é alta. Esse comparativo pode auxiliar desenvolvedores e administradores de sistemas no planejamento de capacidade e de desenvolvimento de sistemas georeplicados.

Palavras-chave: Sistemas distribuídos, modelos de consistência, sistemas web de larga escala, análise de desempenho. 


\section{Abstract}

DE DIANA, M. J. O. Performace of systems with geo-replicated data with eventual consistency and timeline consistency. 2013. 66 f. - Instituto de Matemática e Estatística, Universidade de São Paulo, São Paulo, 2013.

Large scale web systems are distributed among thousands of servers spread over multiple data centers in geographically different locations operating over wide area networks (WANs). Several techniques are employed to achieve the high levels of scalability required by such systems. One of the main techniques is data replication, which aims to reduce latency, increase throughput and/or increase availability. The main drawback of replication in geo-replicated systems is that it is hard to guarantee consistency between replicas without considerably impacting system performance and availability. System performance is affected by WAN latencies, typically of hundreds of miliseconds, while system availability is affected by failures cutting off communication between replicas. The more rigid the consistency model provided by a storage system, the simpler the development of the system using it, but the lower its performance and availability.

Eventual consistency is one of the more relaxed and most widespread consistency models among geo-replicated systems. This consistency model guarantees that all replicas converge at some unspecified time after writes have stopped. A model that is more rigid and less widespread is timeline consistency. This consistency model uses a master replica to guarantee that no write conflicts occur. Clients can read the most up-to-date values from the master replica, or they can explicitly choose to read stale values to obtain greater performance or availability. Timeline consistency has lower availability than eventual consistency in particular situations, but there are no data comparing their performance.

The main goal of this work was to compare the performance of a geo-replicated storage system using these consistency models. For each consistency model, experiments were conducted to measure system response time under different workloads and network conditions between data centers. The study shows that a system using timeline consistency has similar performance than the same system using eventual consistency over a WAN when access locality is high. This comparative may help developers and system administrators on capacity and development planning of geo-replicated systems.

Keywords: Distributed systems, consistency models, large scale web systems, performance analysis. 


\section{Sumário}

$\begin{array}{ll}\text { Lista de Abreviaturas } & \text { ix }\end{array}$

Lista de Figuras $\quad$ xi

Lista de Tabelas $\quad$ xiii

1 Introdução $\quad 1$

1.1 Organização do Trabalho . . . . . . . . . . . . . . . . . . . . 3

2 Consistência em Sistemas Georeplicados $\quad 5$

2.1 Estratégias para Escalabilidade de Aplicações Web . . . . . . . . . . . . . . . 5

2.2 Replicação de Dados e Seus Compromissos . . . . . . . . . . . . . . . . 6

2.2 .1 Replicação pessimista . . . . . . . . . . . . . . . . 6

2.2 .2 Replicação otimista . . . . . . . . . . . . . . . . . . 7

2.3 Modelos de Consistência para Replicação . . . . . . . . . . . . . . . . . . . 8

2.4 Consistência, Desempenho e Disponibilidade em Sistemas Georeplicados . . . . . . . 11

2.4.1 Propriedades ACID em sistemas distribuídos de larga escala . . . . . . . . . . 11

2.4.2 Consistência, disponibilidade, tolerância a particionamento (CAP - Consistency, Availability, Partition-tolerance $\ldots \ldots \ldots \ldots 11$

3 Planejamento $\quad 15$

3.1 Nomenclatura . . . . . . . . . . . . . . . . . . . . . . . 15

3.2 Metas do Estudo . . . . . . . . . . . . . . . . . . . . 16

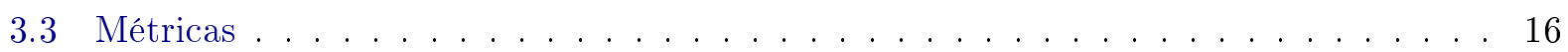

3.4 Técnica de Avaliação . . . . . . . . . . . . . . . . . . . . . . 17

3.5 Sistema de Armazenamento . . . . . . . . . . . . . . . . . . . . 17

3.6 Plataforma de Experimentação . . . . . . . . . . . . . . . . . . . . . 18

3.7 Fluxo de Trabalho dos Experimentos . . . . . . . . . . . . . 18

3.8 Experimentos Fatoriais . . . . . . . . . . . . . . . . . . 20

4 Parâmetros e Fatores $\quad 21$

4.1 Mecanismos do TCP e Parâmetros de Rede . . . . . . . . . . . . . . . . . 21

4.2 Lista de Parâmetros . . . . . . . . . . . . . . . . . . . . . . 23

4.2 .1 Parâmetros de sistema . . . . . . . . . . . . . . . . . . 24

4.2 .2 Parâmetros de rede . . . . . . . . . . . . . . . . . 25

4.2 .3 Parâmetros de carga de trabalho . . . . . . . . . . . . . 27 
4.3 Parâmetros Fixados . . . . . . . . . . . . . . . . . . . 28

4.3.1 Aglomerado e mecanismo de armazenamento . . . . . . . . . . . . 28

4.3 .2 Parâmetros restantes . . . . . . . . . . . . . . . . . . . 30

4.4 Seleção dos Fatores . . . . . . . . . . . . . . . . . . 31

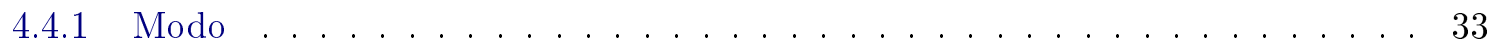

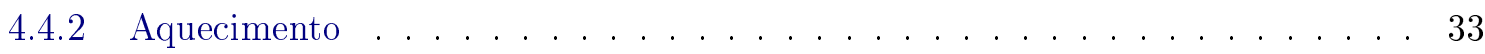

4.4.3 Fatores de tamanho do sistema e benchmark . . . . . . . . . . . . . 34

4.4.4 Fatores de banco de dados . . . . . . . . . . . . . . . . 35

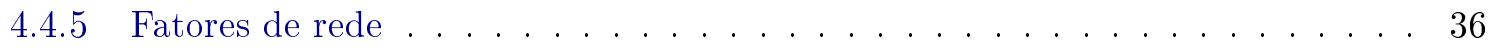

4.4 .6 Fatores de carga de trabalho . . . . . . . . . . . . . . 39

4.5 Fatores Selecionados . . . . . . . . . . . . . . . . . . . 40

5 Aspectos Técnicos $\quad 43$

5.1 Modificações no Riak . . . . . . . . . . . . . . . . . . . . . . . . . 43

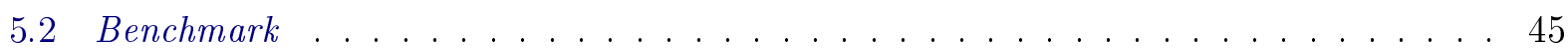

5.3 Ambiente e Imagem . . . . . . . . . . . . . . . . . . . . . . 46

5.4 Rede . . . . . . . . . . . . . . . . . . . . . . . 46

5.4 .1 Centros de processamento de dados . . . . . . . . . . . . . . 46

5.4 .2 Execução e análise dos experimentos . . . . . . . . . . . . . . . . . . . 47

6 Análise dos Resultados $\quad 49$

6.1 Nível de Confiança, Exatidão, Tamanho da Amostra e Replicações . . . . . . . . . . 49

6.2 Análise dos Tempos de Resposta . . . . . . . . . . . . . . . . . . 50

6.3 Análise dos Conflitos . . . . . . . . . . . . . . . . . . 53

6.4 Análise das Migrações . . . . . . . . . . . . . . . . . . . . 55

6.5 Ameaças à Validade . . . . . . . . . . . . . . . . . . . . 55

6.6 Trabalhos Relacionados . . . . . . . . . . . . . . . . . . . 55

7 Conclusões $\quad 57$

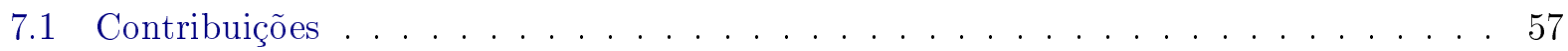

7.2 Lições Aprendidas . . . . . . . . . . . . . . . . . . . . . 58

7.3 Produções ao Longo do Mestrado . . . . . . . . . . . . . . . . . . . . . . 59

7.4 Trabalhos Futuros . . . . . . . . . . . . . . . . . . . . 59

$\begin{array}{ll}\text { Referências Bibliográficas } & 61\end{array}$ 


\section{Lista de Abreviaturas}

ACID Atomicidade, Consistência, Isolamento, Durabilidade

CAP Consistência, Disponibilidade, Tolerância a particionamento de rede (Consistency, Availability, Partition tolerance)

CRDT Tipos de Dados Replicados Livres de Conflito

(Conflict-free Replicated Data Type)

CV Coeficiente de Variação

DHT Tabela de Espalhamento Distribuída (Distributed Hash Table)

FDA Função Distribuição Acumulada

LAN Rede Local (Local Area Network)

PACELC Particionamento, Disponibilidade, Consistência. Senão, Latência, Consistência (Partition, Availability, Consistency. Else, Latency, Consistency)

SGBD Sistema Gerenciador de Bancos de Dados

SGBDD Sistema Gerenciador de Bancos de Dados Distribuído

WAN Rede de Longa Distância (Wide Area Network) 


\section{Lista de Figuras}

3.1 Fluxo de trabalho da execução do estudo. . . . . . . . . . . . . . . . . . . . . . 19

4.1 Aquecimento do sistema. . . . . . . . . . . . . . . . . . . . . . 34

6.1 Boxplot dos tempos de resposta para latência de rede de 200 ms. . . . . . . . . . . 51

6.2 FDAs dos tempos de resposta para latência de rede de $200 \mathrm{~ms}$. . . . . . . . . . . 52

6.3 Boxplot dos tempos de resposta para latência de rede de $200 \mathrm{~ms}$ com taxa de chegada máxima. . . . . . . . . . . . . . . . . . . . . . 54 


\section{Lista de Tabelas}

2.1 Sequência de operações válida para consistência estrita. . . . . . . . . . . . . . . . 8

2.2 Sequência de operações válida para consistência forte. . . . . . . . . . . . . . . 9

2.3 Sequências de operações válidas para consistência forte. . . . . . . . . . . . . . . 9

2.4 Sequência de operações válida para consistência sequencial. . . . . . . . . . . . . 9

2.5 Sequência de operações válida para consistência causal. . . . . . . . . . . . . . . . 10

2.6 Sequência de operações inválida para consistência causal. . . . . . . . . . . . . . . . 10

2.7 Sequência de operações válida para consistência em momento indeterminado. . . . . 10

4.1 Aglomerados do Grid'5000. . . . . . . . . . . . . . . . . . . . . . 28

4.2 Comparação de desempenho de acessos dos discos entre aglomerados. . . . . . . . . . 29

4.3 Estudo para quantidade de nós do sistema. . . . . . . . . . . . . . . . . 35

4.4 Estudo para quantidade e tamanho dos objetos armazenados. . . . . . . . . . . 36

4.5 Estudo para tamanho dos buffers de transmissão e recepção. . . . . . . . . . . . . . 37

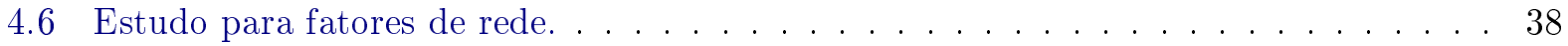

4.7 Estudo para fatores de carga de trabalho. . . . . . . . . . . . . . . . . . . 40

4.8 Fatores e níveis do estudo final. . . . . . . . . . . . . . . . . . . . . 41

6.1 Ganhos relativos entre modos. . . . . . . . . . . . . . . . . . 53 


\section{Capítulo 1}

\section{Introdução}

Para atender centenas de milhares de usuários ininterruptamente em sistemas web de larga escala, dados são replicados em milhares de servidores distribuídos em múltiplos centros de processamento de dados em diferentes localizações geográficas. A replicação de dados objetiva a redução da latência, o aumento da vazão e/ou disponibilidade [SS05]. O tempo de resposta de requisições torna-se menor devido à localidade dos dados, pois a réplica usada para fornecer a resposta é a mais próxima do usuário que faz a requisição. A vazão aumenta pois o sistema é capaz de receber uma quantidade maior de requisições simultâneas para o mesmo dado já que há mais servidores disponíveis para atendê-las. A disponibilidade aumenta pois caso um servidor ou até um centro de processamento de dados inteiro fique indisponível, outros ainda podem atender requisições. A durabilidade também é mais alta, pois os dados não se perdem no caso em que um nó fique permanentemente indisponível, o que pode acontecer devido a uma falha em um disco rígido ou até mesmo a destruição de um centro de processamento de dados inteiro.

O principal problema do uso de replicação em redes de longa distância (Wide Area Network WAN) é que manter as réplicas sempre consistentes entre si tipicamente implica em sacrificar outros requisitos também importantes, como desempenho ou disponibilidade. Um motivo para divergência entre réplicas é que a replicação entre centros de processamento de dados pode apresentar centenas de milissegundos de latência, período durante o qual as réplicas podem divergir. Essa latência é resultado não só das distâncias físicas entre os nós, mas também de limitações na largura de banda disponível, congestionamento de rede e perda de pacotes. Outro motivo de divergência entre réplicas é a falha temporária de um nó, que deixa de receber atualizações por um período de tempo. Um terceiro motivo é a falha em um equipamento ou enlace de rede que impeça a comunicação entre réplicas.

Com isso, desenvolvedores e administradores de sistemas web de larga escala buscam um balanço entre disponibilidade, desempenho e consistência dos dados. Uma decisão comum em vários desses sistemas é o relaxamento da consistência em troca de alta disponibilidade e baixa latência. Há diversos modelos de consistência propostos na literatura, cada um com diferentes garantias e condições em que as réplicas dos dados podem ficar inconsistentes. Os modelos mais rígidos, que oferecem mais garantias, são mais simples de serem usados pelos desenvolvedores. Modelos que oferecem menos garantias de consistência possibilitam réplicas com dados desatualizados e/ou o aparecimento de divergências e conflitos entre elas. Com isso, esses conflitos precisam ser detectados e corrigidos e ações de compensação podem ser necessárias devido a ações no sistema tomadas a partir de dados inconsistentes. Isso afeta negativamente a manutenibilidade do sistema, já que sua lógica torna-se mais complexa. Por outro lado, quanto mais garantias um modelo oferece, mais comunicação e estruturas de sincronização são necessárias entre as réplicas. Por isso, quanto mais rígido um modelo de consistência, mais baixo é o seu desempenho.

A consistência forte (linearibilidade) [HW90] garante que todas as réplicas são idênticas a qualquer momento. O problema desse modelo de consistência é que ele é pouco escalável. Por isso, os desenvolvedores dos sistemas web de larga escala georeplicados passaram a abrir mão de consistência forte em seus sistemas, e essa prática resultou em padrões arquiteturais baseados nesse relaxamento 
de consistência [GL02, Bre00, Vog09, HC09, $\mathrm{DHJ}^{+}$07].

A consistência em momento indeterminado (eventual consistency ${ }^{1}$ ) é um modelo mais relaxado e se tornou especialmente popular após a publicação sobre o Dynamo [DHJ $\left.{ }^{+} 07\right]$, sistema de armazenamento chave-valor usado tanto pela loja virtual quanto pela estrutura de computação em nuvem da Amazon ${ }^{2}$ [Vog07]. A consistência em momento indeterminado garante que as réplicas vão sempre convergir em algum momento no futuro desde que novas atualizações cessem. Enquanto atualizações estiverem acontecendo, existe a possibilidade de surgirem inconsistências entre as réplicas. Como a consistência em momento indeterminado permite conflitos entre réplicas, clientes podem acessar dados desatualizados ou divergentes dependendo da réplica acessada. Os conflitos que surgem precisam ser resolvidos por algoritmos de detecção e resolução de conflitos e caso ações tenham sido tomadas com base em valores inconsistentes, ações de compensação são necessárias. $\mathrm{O}$ uso de consistência em momento indeterminado em um sistema georeplicado resulta em baixa latência e alta disponibilidade, tendo como contraponto uma maior complexidade no desenvolvimento da aplicação, que precisa estar preparada para lidar com inconsistências. Após o Dynamo, diversos sistemas de armazenamento que lidam com consistência em momento indeterminado foram implementados e colocados em produção, como Cassandra [LM10] e Voldemort [Vol], implementados respectivamente pelo Facebook ${ }^{3}$ e LinkedIn ${ }^{4}$. Outras empresas web de larga escala utilizando Cassandra são Twitter ${ }^{5}$ [Kin10b], Reddit ${ }^{6}$ [Kin10a] e Rackspace ${ }^{7}$ [Hoo10].

Para algumas aplicações web, é importante que os usuários sempre encontrem a aplicação disponível, mesmo que isso cause algum tipo de inconveniente. Os sistema de armazenamento usado pela loja virtual Amazon apresenta disponibilidade de 99,995\% [DHJ+07]. A Amazon almeja esse nível de disponibilidade pois considera fundamental que seus usuários consigam adicionar itens em seus carrinhos de compras, mesmo que isso implique em problemas que precisem ser corrigidos depois, como itens previamente removidos do carrinho ressurgirem - algo que pode acontecer ao usar o Dynamo como sistema de armazenamento [ $\left.\mathrm{DHJ}^{+} 07\right]$. Os casos mais simples geram inconvenientes para o usuário, que precisa refazer uma operação por exemplo. Os casos mais complicados precisam de ações de compensação, como o estorno do valor de um item que o usuário não queria ter comprado.

Entretanto, nem todas as aplicações web de larga escala podem usar consistência em momento indeterminado. Existem aplicações que necessitam de modelos de consistência mais rígidos, embora não necessariamente consistência forte, para funcionar corretamente. Por exemplo, uma aplicação de leilão não pode permitir conflitos no histórico de lances de um produto. Num sistema que usa consistência em momento indeterminado, no caso de uma falha que divida a rede em duas partições, usuários em cada partição têm uma visão própria do histórico de lances. Isso seria equivalente a dois leilões simultâneos sobre o mesmo item, conflito que não tem como ser resolvido depois sem desprezar lances. Outro exemplo é um usuário de uma aplicação web de planilha, que não pode ver um valor que acabou de ser inserido desaparecer espontaneamente, mesmo que temporariamente algo que pode acontecer em um sistema usando consistência em momento indeterminado.

Além disso, existem aplicações que não precisam apresentar índices de disponibilidade tão altos. Em uma aplicação de rede social, por exemplo, uma indisponibilidade curta pode ser tolerada pelos

\footnotetext{
${ }^{1} \mathrm{O}$ termo eventual consistency às vezes é erroneamente traduzido para o português como consistência eventual. Mas eventual é um falso cognato: o dicionário de inglês Cambridge define essa palavra como "happening or existing at a later time or at the end, especially after a lot of effort, problems, etc.", cuja tradução para o português é "acontecendo ou existindo em um instante mais tarde ou ao fim, especialmente depois de muito esforço, problemas, etc." (http://dictionary.cambridge.org/dictionary/british/eventual?q=eventual). O dicionário de português Michaelis usa a definição como "dependente de evento incerto, casual, fortuito, variável" (http://michaelis.uol.com.br/moderno/ portugues/index.php?lingua=portugues-portugues\&palavra=eventual). Portanto, neste trabalho é usada a tradução "em momento indeterminado".

${ }^{2}$ http://www.amazon.com/ e http://aws.amazon.com/

${ }^{3}$ http://www.facebook.com/

${ }^{4}$ http://www.linkedin.com/

${ }^{5}$ http://twitter.com/

${ }^{6}$ http://www.reddit.com/

${ }^{7}$ http://www.rackspace.com/
} 
usuários.

Um modelo de consistência para sistemas georeplicados que busca um meio termo entre consistência forte e consistência em momento indeterminado é a consistência na linha do tempo, usada no PNUTS do Yahoo! [CRS ${ }^{+}$08]. Para cada objeto armazenado, esse modelo de consistência permite atualizações em apenas uma de suas réplicas, evitando assim a possibilidade de conflitos ao mesmo tempo em que evita o uso de bloqueios (locks) e propagação de atualizações síncrona. Com a propagação assíncrona, réplicas podem ter valores desatualizados devido à latência de rede ou falhas, mas a qualquer instante sabe-se qual é a réplica com o valor mais recente. Os clientes escolhem em cada acesso se aceitam como resposta apenas o valor mais recente ou se aceitam valores desatualizados. A principal desvantagem da consistência na linha do tempo é que a existência de uma réplica mestre implica que escritas e leituras consistentes (leituras do valor mais recente) ficam indisponíveis em caso de uma falha que impeça um cliente de acessar essa réplica.

Se esse modelo fosse usado para um carrinho de compras como o citado acima, o problema de itens ressurgirem não aconteceria. Por outro lado, um usuário poderia ser impedido de adicionar novos itens a seu carrinho de compras temporariamente caso a réplica mestre ficasse indisponível.

Portanto, um modelo de consistência oferece um balanço entre desempenho, disponibilidade e consistência. Considerando que usuários de algumas aplicações web toleram indisponibilidades, a consistência na linha do tempo pode ser uma opção interessante por oferecer um modelo de programação mais simples, desde que seu desempenho seja aceitável. O maior fator de impacto no desempenho da consistência na linha do tempo é o fato de que todas as escritas e leituras consistentes que não são feitas no centro de processamento de dados em que está a réplica mestre incorrem no custo de latência da WAN. Entretanto, em aplicações como redes sociais, por exemplo, é de se esperar que haja uma grande quantidade de acessos locais (a maioria dos usuários acessa o sistema de um único país e tem a maioria de seus contatos no mesmo país) e que a relação escrita/leitura seja baixa (cada item criado, como uma postagem ou um comentário, seja lido diversas vezes). De fato, os autores do PNUTS indicam que em sua rede social $60 \%$ dos acessos é local e a relação escrita/leitura observada é de 0,06 [KCCL11]. Eles indicam também que outras aplicações chegam a ter $85 \%$ dos acessos locais [CRS ${ }^{+} 08$ ]. Dado isso, eles usam a estratégia de sempre mover dinamicamente a réplica mestre para o centro de processamento de dados que processa a maior quantidade de requisições para dado objeto. Com isso, em uma aplicação na qual a quantidade de leituras é muito maior do que a quantidade de escritas, o custo de latência pode ser baixo, em especial se as leituras não precisarem necessariamente do valor mais recente.

Consistência em momento indeterminado é bastante difundida em sistemas web de larga escala. Ela é item de destaque em padrões arquiteturais usados por esse tipo de sistema [Vog09, HC09], e é possível encontrá-la em vários sistemas de armazenamento apresentados na literatura e em projetos de software livre [DHJ ${ }^{+}$07, LM10, Vol, Ria]. Enquanto isso, a consistência na linha do tempo é pouco usada e reconhecida [Aba10] - em julho de 2012, foram encontrados apenas dois sistemas na literatura e nenhum projeto de software livre usando esse tipo de consistência [CRS $\left.{ }^{+} 08, \mathrm{RST} 11\right]$. Mas a consistência na linha do tempo pode ser uma opção interessante por oferecer um modelo de programação mais simples, desde que seu desempenho seja próximo ao da consistência em momento indeterminado e a aplicação tolere níveis mais baixos de disponibilidade.

Há diversos estudos experimentais sobre desempenho de modelos de consistência $\left[\mathrm{DHJ}{ }^{+} 07\right.$, $\mathrm{CRS}^{+} 08$, LFKA11, $\mathrm{BKS}^{+} 11$ ], mas não foi encontrada uma comparação quantitativa entre esses dois modelos mostrando como cada um se comporta em diferentes condições de latência de rede e carga de trabalho. Dados sobre essa comparação são úteis para desenvolvedores e administradores de sistemas estimarem melhor os custos de desenvolvimento e fazerem um planejamento de capacidade mais eficaz.

\subsection{Organização do Trabalho}

Este trabalho está dividido em cinco capítulos. O Capítulo 2 apresenta os fundamentos para o entendimento da motivação, dos problemas e das soluções oferecidas pela replicação de dados em 
sistemas georeplicados. Os três capítulos seguintes seguem a ordem em que as atividades do estudo experimental foram realizadas. O Capítulo 3 contempla o planejamento dos experimentos. A seguir, o Capítulo 4 descreve o processo usado para definir quais características do sistema, do ambiente e da carga de trabalho foram consideradas e quais foram desconsideradas no estudo. Depois, o Capítulo 5 trata dos aspectos técnicos da implementação dos experimentos. O Capítulo 6 aborda a análise dos resultados obtidos nos experimentos. Por fim, o Capítulo 7 traz as conclusões deste trabalho. 


\section{Capítulo 2}

\section{Consistência em Sistemas Georeplicados}

Este capítulo apresenta os conceitos relacionados à replicação de dados em sistemas georeplicados, as motivações para seu uso e os compromissos resultantes. Embora alguns conceitos descritos não sejam exclusivos de sistemas georeplicados, eles são necessários para um entendimento mais profundo do contexto em que opera o tipo de sistema estudado neste trabalho.

Este trabalho usa o termo "sistemas de armazenamento" para se referir de forma geral a sistemas distribuídos que armazenam e gerenciam dados, como SGBDDs, tabelas de espalhamento distribuídas (Distributed Hash Table - DHT) e sistemas de arquivos distribuídos. Um motivo para isso é que às vezes a distinção entre esses tipos de sistemas não é clara. Além disso, eles lidam com questões semelhantes, como replicação, por exemplo, o que faz com que muitas técnicas surgidas em um contexto sejam aplicadas em outro.

A Seção 2.1 apresenta conceitos de escalabilidade de aplicações web. Uma estratégia comum para escalabilidade é o uso de replicação, a Seção 2.2 mostra diferentes tipos de replicação e as vantagens e desvantagens de cada um. Um sistema apresenta diferentes garantias de consistência dependendo da forma como replica seus dados, a Seção 2.3 descreve diversos tipos de modelos de consistência, incluindo os dois que são alvo deste trabalho. A Seção 2.4 mostra algumas implicações dos diferentes modelos de consistência na arquitetura de sistemas de larga escala.

\subsection{Estratégias para Escalabilidade de Aplicações Web}

Uma aplicação web potencialmente precisa lidar com quantidades crescentes de dados e tráfego. A quantidade de dados cresce com o uso do sistema ao longo do tempo e o aumento do tráfego costuma estar associado a um aumento do número de usuários. São três as estratégias de escalabilidade existentes: escalabilidade vertical, escalabilidade horizontal e escalabilidade diagonal.

Escalabilidade vertical é o aumento da capacidade de um sistema por meio do aumento dos recursos (CPU, memória, disco, etc.) de um servidor [All08]. Esse tipo de escalabilidade não é uma opção para sistemas que lidam com grandes volumes de dados. Uma razão comumente citada é o crescimento exponencial do custo do hardware relativo à sua capacidade [BDH03]. Outra é o surgimento de pontos únicos de falha [Al108]. Brewer sugere que a razão é de fato mais simples: não existe solução de escalabilidade vertical que atenda às demandas de sistemas web de larga escala [Bre01].

Escalabilidade horizontal é o aumento da capacidade de um sistema por meio da adição de mais servidores de igual capacidade aos já existentes [Al108]. Ao tratar de escalabilidade horizontal, devese distinguir o processo de escalar os componentes com e os sem estado [Hen06]. Escalar as camadas do sistema que não guardam estado é relativamente simples, dado que todos os seus componentes são idênticos e intercambiáveis. As dificuldades são maiores ao escalar os componentes com estado, como SGBDDs, por exemplo.

Particionamento de dados é a técnica de distribuir dados por diversas partições (nós, discos, etc.) para o aumento do desempenho de um sistema de armazenamento (por meio de paralelização das operações) ou para aumentar sua capacidade [LO09]. Existem basicamente três técnicas 
de particionamento para escalar horizontalmente um banco de dados [LO09, Pri08]. A primeira técnica é o particionamento vertical, que consiste na distribuição das colunas das tabelas pelas partições, e é usada normalmente apenas por SGBDs relacionais orientados a colunas. A segunda é o particionamento funcional, que consiste em distribuir os dados pelas partições de acordo com as funcionalidades do sistema. Por exemplo, um banco de dados relacional é particionável funcionalmente colocando as tabelas relacionadas a usuários em uma partição e as tabelas relacionadas a produtos em uma segunda partição. Por último, o particionamento horizontal (ou fragmentação ou sharding, como ficou particularmente conhecido entre desenvolvedores de aplicações web) é a técnica de particionamento que distribui as coleções de dados do mesmo tipo (usuários, por exemplo) pelas partições. O particionamento horizontal é feito de acordo com alguns critérios de particionamento. Por exemplo, o particionamento por faixa distribui os objetos de acordo com o valor de determinado atributo dos objetos, como o país de origem dos usuários. Outro exemplo é o particionamento por espalhamento (hashing), pelo qual os objetos são particionados de acordo com um índice de espalhamento calculado para cada um deles.

Uma terceira estratégia de escalabilidade é a escalabilidade diagonal [All08], que consiste em escalar verticalmente um conjunto de nós que já está preparado para escalar horizontalmente. Isso acontece, por exemplo, quando o hardware usado se torna obsoleto. Ao escalar diagonalmente é possível consolidar servidores ${ }^{1}$, diminuindo assim o custo operacional do sistema. Do ponto de vista dos desenvolvedores e administradores, pouca coisa muda com escalabilidade diagonal dado que a arquitetura do sistema deve ter sido criada para escalar horizontalmente.

Para escalar um sistema horizontalmente, além do particionamento dos dados, outra técnica importante é a replicação de dados. As diferentes estratégias de replicação, suas vantagens e consequências são apresentadas na seção seguinte.

\subsection{Replicação de Dados e Seus Compromissos}

Replicação de dados é o processo de criar cópias de uma coleção de dados [LO09] e é usada em sistemas distribuídos por três razões [SS05]. A primeira é a diminuição da latência por meio da replicação de dados para localizações mais próximas de onde esses dados são usados - especialmente válido no caso de longas distâncias, como é o caso de centros de processamento de dados em diferentes localizações geográficas [DHJ ${ }^{+} 07, \mathrm{CRS}^{+} 08$ ]. A segunda razão para replicar dados é aumentar a vazão do sistema por meio do balanceamento de carga entre diferentes servidores, possibilitando que o mesmo dado seja acessado em mais de um servidor simultaneamente. Finalmente, a terceira razão é o aumento da disponibilidade do sistema, pois determinado dado continua sendo acessado pelos clientes mesmo quando algumas das réplicas encontram-se indisponíveis.

A replicação pode usar um esquema mestre-escravo (ou cópia primária), em que apenas uma das réplicas é responsável por receber atualizações e distribuí-las para as outras, ou mestre-mestre (ou múltiplos mestres), em que qualquer uma das réplicas recebe atualizações e depois as distribui [LO09]. Além disso, a replicação pode ser pessimista ou otimista [LO09]. Essas estratégias são discutidas nas subseções a seguir.

\subsubsection{Replicação pessimista}

Replicação pessimista (também chamada síncrona ou adiantada) é a estratégia de replicação que garante a consistência mútua entre réplicas, dando para os clientes do sistema a impressão de que existe uma única réplica. Consistência mútua (ou coerência) ${ }^{2}$ é a garantia oferecida por um sistema de que em um dado momento todas as réplicas de um determinado objeto possuem um mesmo

\footnotetext{
${ }^{1}$ Consolidação é o processo de diminuição do número de servidores usados por uma organização devido a um aumento na eficiência de sua utilização.

${ }^{2}$ Apesar de relacionadas, consistência mútua e a consistência representada pelo "C" de ACID são conceitos diferentes. A primeira se refere à garantia de que todas as réplicas de um objeto são idênticas entre si a qualquer momento, enquanto a segunda se refere à propriedade de um banco de dados sempre ir de um estado válido para outro estado válido (mais sobre ACID pode ser visto na Subseção 2.4.1).
} 
valor do ponto de vista de quem o acessa [SS05, GHOS96, DGMS85, PPR $\left.{ }^{+} 83\right]$. Isso significa que ao alterar uma réplica, todas as outras também são alteradas antes de qualquer acesso independente posterior.

Uma desvantagem da replicação pessimista em sistemas de larga escala é uma diminuição da disponibilidade do sistema. Isso porque uma operação que atualiza as réplicas X1 e X2 de um objeto X nos nós N1 e N2 só é bem sucedida caso ambas as réplicas estejam disponíveis. É comum que sistemas usando replicação pessimista apresentem modos de degradação que possibilitam maior disponibilidade na presença de falhas, como por exemplo continuar permitindo operações de leitura, recusando apenas as de escrita. Existem soluções, como o uso de quóruns, que proporcionam um aumento da disponibilidade de um sistema replicado [Gif79, Tho79, EpNm03]. Uma discussão mais aprofundada dos problemas de disponibilidade da replicação pessimista pode ser vista na Seção 2.4.

Outra desvantagem de replicação pessimista é o seu desempenho, especialmente em WANs. Esse tipo de rede pode causar um aumento no tempo de resposta de requisições devido a alta latência, limitações na largura de banda disponível, congestionamento, perda de pacotes e rajadas de tráfego [FM05, $\mathrm{FML}^{+}$10, JD05]. Caso replicação pessimista seja usada nesse cenário, qualquer escrita fica sujeita a latências da ordem de dezenas ou centenas de milissegundos. Isso é inaceitável em aplicações web, já que muitas vezes cada requisição web resulta em diversos acessos ao sistema de armazenamento. Por exemplo, o Yahoo! considera que $100 \mathrm{~ms}$ é o máximo de tempo que pode ser gasto para acessos ao sistema de armazenamento durante o processamento de uma requisição web $\left[\mathrm{CRS}^{+} 08\right]$.

Por esses motivos a replicação otimista, explicada na próxima subseção, costuma ser a solução mais viável para sistemas de larga escala.

\subsubsection{Replicação otimista}

Ao contrário da replicação pessimista, a replicação otimista é assíncrona [SS05, GHOS96, DGMS85]. Um sistema usando replicação otimista apresenta maiores escalabilidade, desempenho e disponibilidade que um outro usando replicação pessimista [SS05, GN95]. O contraponto da replicação otimista é que um sistema que a use pode apresentar dados desatualizados e conflitantes em caso de falhas de nós ou particionamento da rede.

Quando esse tipo de replicação é utilizado são necessários mecanismos de resolução de conflitos. Esses mecanismos podem ser simples como a regra de escrita de Thomas [JT75], em que o sistema implementa uma semântica de "a última escrita ganha". Mas existem mecanismos de identificação e resolução de conflitos mais sofisticados, como é o caso de relógios vetoriais (Vector clocks) [Fid88, $\left.\mathrm{PPR}^{+} 83\right]$, que mantêm um histórico de quais nós foram responsáveis por quais atualizações em determinado objeto, tornando assim possível definir o(s) nó(s) que possui(em) o valor correto em caso de conflito. Em casos mais extremos, a complexidade semântica dos conflitos impossibilita que a resolução seja realizada pelo sistema de armazenamento - por exemplo, caso um mesmo objeto tenha sido atualizado simultaneamente com valores divergentes em duas réplicas. Nesses casos, as respostas do sistema de armazenamento para leituras feitas pela aplicação contêm os valores divergentes. Isso implica que, para resolver os conflitos, os desenvolvedores precisam prever que eles podem acontecer e preparar a aplicação para resolvê-los [DGMS85].

Um problema que torna uma aplicação ainda mais complexa na presença de conflitos acontece quando não é possível perceber os conflitos imediatamente, e ações são tomadas na aplicação baseadas em valores inconsistentes. Esse é o caso de um particionamento de rede seguido de escritas divergentes em um mesmo objeto em cada partição. Nesse caso, clientes em cada partição podem realizar ações inválidas baseadas nesses valores desatualizados ou conflitantes. Por exemplo, podem acontecer duas vendas de um mesmo produto que possui um único item em estoque, uma venda ocorrendo em cada partição. Ao perceber o conflito posteriormente, o sistema precisa usar uma ação de compensação ou correção para resolver o problema [Hoh04]. No caso desse exemplo, seria necessário estornar o valor cobrado no cartão de crédito de um dos clientes e enviar um email para ele avisando do problema. 
Uma outra alternativa para lidar com conflitos na replicação otimista é o uso de tipos de dados replicados livres de conflito (Conflict-free replicated data type - CRDT) [Sha11, SPBZ], que garantem a convergência entre réplicas. Um exemplo de CRDT é um conjunto cuja única operação disponível é adição. No caso de um particionamento, o sistema continua recebendo adições vindas de cada partição, e quando o particionamento é resolvido, o sistema realiza a união de todos os elementos de todas as réplicas daquele conjunto.

O tipo de replicação escolhido impacta as expectativas que o desenvolvedor de um sistema tem sobre os estados resultantes das operações de leitura e escrita. As garantias sobre os resultados de leituras e escritas que um sistema replicado oferece são dadas por seu modelo de consistência, assunto discutido na próxima seção.

\subsection{Modelos de Consistência para Replicação}

Um modelo de consistência define o momento em que os resultados de determinada escrita serão retornados por leituras subsequentes em sistemas de memória compartilhada distribuída [TS06]. Do ponto de vista do desenvolvedor, um modelo de consistência define a ordem global em que as operações sobre os dados parecem ser executadas [TS06, AG95]. O modelo de consistência funciona como a especificação do que o sistema deve realizar, enquanto o protocolo de consistência define a implementação do modelo de consistência.

Modelos de consistência mais rígidos favorecem a manutenibilidade de um sistema, pois são mais simples de usar pelo desenvolvedor. A rigidez de um modelo de consistência é dada pelas restrições com relação à ordem em que as operações sobre os dados são executadas. Quanto maiores as restrições sobre a ordem das operações, mais complexo é o protocolo de consistência para garantilas. Protocolos que garantem modelos de consistência mais rígidos possuem desempenhos mais baixos [Mos93].

Modelos de consistência são estudados amplamente pelas áreas de programação paralela e sistemas distribuídos. Os modelos mais comuns no contexto de replicação, ordenados do mais para o menos rígido, são: consistência estrita, forte (linearibilidade), sequencial, causal e em momento indeterminado. Um modelo não tão difundido, mas de interesse particular para este trabalho, é a consistência na linha do tempo, que é menos rígida que a consistência sequencial e mais forte que a consistência em momento indeterminado ${ }^{3}$. Além desses, outros modelos de consistência são encontrados na literatura [TS06, AG95, Mos93]. Nos diagramas de modelos de consistência a seguir, $R_{1}, R_{2}, \ldots, R_{n}$ representam as réplicas $1,2, \ldots, \mathrm{n} ; t_{0}, t_{1}, \ldots, t_{n}$ representam os instantes de tempo 0 , $1, \ldots, \mathrm{n} ; \mathrm{E}(\mathrm{x}, \mathrm{a})$ é a operação de escrita do objeto $\mathrm{x}$ com o valor $\mathrm{a} ; \mathrm{a}=\mathrm{L}(\mathrm{x})$ é a operação de leitura do objeto $\mathrm{x}$ que retorna o valor a e $0=\mathrm{L}(\mathrm{x})$ é a operação de leitura do objeto $\mathrm{x}$ que retorna nulo pois o objeto $\mathrm{x}$ não existe (nunca foi escrito).

Consistência estrita (ou atômica) [Mos93] é o modelo mais rígido. Ele define que toda leitura deve sempre retornar o valor definido pela escrita mais recente. A sequência de operações na Tabela 2.1 é válida, mas a da Tabela 2.2 não. Consistência estrita representa o comportamento esperado em um sistema de um único processador, em que não há replicação de dados nem acesso concorrente. Como o "mais recente" da definição implica que os resultados de qualquer operação são visíveis instantaneamente em todo o sistema, a consistência estrita precisa que o sistema apresente latência nula. Como qualquer sistema distribuído apresenta latência, consistência estrita é impossível nesses sistemas.

Consistência forte (ou linearibilidade) [HW90, AW94] define que as operações são executadas em uma ordem serial de acordo com o instante em que foram emitidas e por isso depende de tempo global. Esse modelo relaxa as condições em que o resultado de uma operação é visível, permitindo que isso aconteça em um momento qualquer entre a emissão da operação e a recepção da resposta no emissor. Com isso, a sequência de operações da Tabela 2.2 é válida. Quando existem escritas concorrentes, a consistência forte garante que uma única ordem das operações será vista.

\footnotetext{
${ }^{3}$ Consistência na linha do tempo e causal não são comparáveis, mas ambas são menos rígidas que a consistência sequencial e mais rígidas que a consistência em momento indeterminado.
} 


\begin{tabular}{c|c|c} 
& $t_{0}$ & $t_{1}$ \\
\hline$R_{1}$ & $\mathrm{E}(\mathrm{x}, \mathrm{a})$ & \\
\hline$R_{2}$ & & $\mathrm{a}=\mathrm{L}(\mathrm{x})$
\end{tabular}

Tabela 2.1: Sequência de operações válida para consistência estrita.

A Tabela 2.3 mostra duas sequências de operações válidas, a Tabela 2.4 mostra uma sequência inválida. Como o resultado de uma operação deve aparecer em todas as réplicas ao mesmo tempo, um sistema replicado linearizável precisa usar algum mecanismo de sincronização entre réplicas.

\begin{tabular}{c|c|c|c} 
& $t_{0}$ & $t_{1}$ & $t_{2}$ \\
\hline$R_{1}$ & $\mathrm{E}(\mathrm{x}, \mathrm{a})$ & & \\
\hline$R_{2}$ & & $0=\mathrm{L}(\mathrm{x})$ & $\mathrm{a}=\mathrm{L}(\mathrm{x})$
\end{tabular}

Tabela 2.2: Sequência de operações válida para consistência forte.

\begin{tabular}{c|c|c} 
& $t_{0}$ & $t_{1}$ \\
\hline$R_{1}$ & $\mathrm{E}(\mathrm{x}, \mathrm{a})$ & $\mathrm{a}=\mathrm{L}(\mathrm{x})$ \\
\hline$R_{2}$ & $\mathrm{E}(\mathrm{x}, \mathrm{b})$ & $\mathrm{a}=\mathrm{L}(\mathrm{x})$ \\
\hline$R_{3}$ & \multicolumn{3}{|c}{$\mathrm{a}=\mathrm{L}(\mathrm{x})$} \\
& $t_{0}$ & $t_{1}$ \\
\hline$R_{1}$ & $\mathrm{E}(\mathrm{x}, \mathrm{a})$ & $\mathrm{b}=\mathrm{L}(\mathrm{x})$ \\
\hline$R_{2}$ & $\mathrm{E}(\mathrm{x}, \mathrm{b})$ & $\mathrm{b}=\mathrm{L}(\mathrm{x})$ \\
\hline$R_{3}$ & & $\mathrm{~b}=\mathrm{L}(\mathrm{x})$
\end{tabular}

Tabela 2.3: Sequências de operações válidas para consistência forte.

Um modelo mais relaxado que consistência forte é a consistência sequencial [Lam97, Mos93]. Ela define que as operações são executadas em uma ordem serial qualquer, abrindo mão assim da restrição sobre a ordenação no tempo da linearibilidade. A consistência sequencial define que a ordem de execução vista por todas as réplicas é a mesma, mas essa ordem não precisa seguir um tempo global (pode seguir tempo lógico [Lam78]). A sequência de operações da Tabela 2.4 é válida, mas a da Tabela 2.5 não. Esse modelo de consistência é equivalente ao critério de correção em bancos de dados replicados chamado seriabilidade de cópia única [BG83], pelo qual a execução intercalada de múltiplas transações em um banco de dados distribuído deve ser equivalente à execução serial dessas transações em um banco de dados não-distribuído.

\begin{tabular}{c|c|c|c|c} 
& $t_{0}$ & $t_{1}$ & $t_{2}$ & $t_{3}$ \\
\hline$R_{1}$ & $\mathrm{E}(\mathrm{x}, \mathrm{a})$ & & & \\
\hline$R_{2}$ & & $\mathrm{E}(\mathrm{x}, \mathrm{b})$ & & \\
\hline$R_{3}$ & & & $\mathrm{~b}=\mathrm{L}(\mathrm{x})$ & $\mathrm{a}=\mathrm{L}(\mathrm{x})$
\end{tabular}

Tabela 2.4: Sequência de operações válida para consistência sequencial.

A consistência causal [ANB $\left.{ }^{+} 95\right]$ define que operações que potencialmente possuem causas relacionadas devem ser executadas em todas as réplicas na mesma ordem, caso contrário, elas podem ser executadas em ordens diferentes. Por exemplo, um processo que escreveu $x$ após ler $y$ pode ter realizado essa escrita como o resultado de uma computação sobre o valore de $x$, portanto a escrita foi potencialmente causada pela leitura. Mas se a leitura ocorreu em um processo e a escrita em outro, mesmo que da mesma variável, não existe relação potencial de causa. A sequência de 
operações da Tabela 2.5 é válida, mas a da Tabela 2.6 não. A implementação de consistência causal necessita que um grafo de operações seja mantido em toda réplica para que seja possível saber que operações potencialmente influenciaram cada escrita. A consistência causal acomoda conflitos de atualização, permitindo que réplicas divirjam indefinidamente, de modo que um cliente leia valores diferentes dependendo da réplica acessada.

\begin{tabular}{c|c|c|c|c} 
& $t_{0}$ & $t_{1}$ & $t_{2}$ & $t_{3}$ \\
\hline$R_{1}$ & $\mathrm{E}(\mathrm{x}, \mathrm{a})$ & & & \\
\hline$R_{2}$ & & $\mathrm{E}(\mathrm{x}, \mathrm{b})$ & $\mathrm{a}=\mathrm{L}(\mathrm{x})$ & $\mathrm{b}=\mathrm{L}(\mathrm{x})$ \\
\hline$R_{3}$ & & & $\mathrm{~b}=\mathrm{L}(\mathrm{x})$ & $\mathrm{a}=\mathrm{L}(\mathrm{x})$
\end{tabular}

Tabela 2.5: Sequência de operações válida para consistência causal.

\begin{tabular}{c|c|c|c|c|c} 
& $t_{0}$ & $t_{1}$ & $t_{2}$ & $t_{3}$ & $t_{4}$ \\
\hline$R_{1}$ & $\mathrm{E}(\mathrm{x}, \mathrm{a})$ & & & & \\
\hline$R_{2}$ & & $\mathrm{a}=\mathrm{L}(\mathrm{x})$ & $\mathrm{E}(\mathrm{x}, \mathrm{b})$ & & \\
\hline$R_{3}$ & & & & $\mathrm{~b}=\mathrm{L}(\mathrm{x})$ & $\mathrm{a}=\mathrm{L}(\mathrm{x})$
\end{tabular}

Tabela 2.6: Sequência de operações inválida para consistência causal.

A consistência em momento indeterminado é um modelo de consistência mais relaxado [Vog09, $\mathrm{FGL}^{+}$99]. Ela garante que se nenhuma nova escrita ocorrer, após um período de tempo indeterminado, chamado janela de inconsistência, todas as leituras retornarão o último valor escrito. Assim, a sequência de operações na Tabela 2.7 é válida. É possível surgirem conflitos entre réplicas na consistência em momento indeterminado, portanto um sistema que use esse modelo de consistência precisa implementar um mecanismo de resolução de conflitos. Detalhes do funcionamento desse modelo de consistência estão na Subseção 2.4.2.

\begin{tabular}{c|c|c|c|c|c} 
& $t_{0}$ & $t_{1}$ & $t_{2}$ & $t_{3}$ & $t_{4}$ \\
\hline$R_{1}$ & $\mathrm{E}(\mathrm{x}, \mathrm{a})$ & & & $\mathrm{b}=\mathrm{L}(\mathrm{x})$ & $\mathrm{b}=\mathrm{L}(\mathrm{x})$ \\
\hline$R_{2}$ & & $\mathrm{E}(\mathrm{x}, \mathrm{b})$ & $\mathrm{a}=\mathrm{L}(\mathrm{x})$ & & $\mathrm{b}=\mathrm{L}(\mathrm{x})$ \\
\hline$R_{3}$ & & & $\mathrm{~b}=\mathrm{L}(\mathrm{x})$ & $\mathrm{a}=\mathrm{L}(\mathrm{x})$ & $\mathrm{b}=\mathrm{L}(\mathrm{x})$
\end{tabular}

Tabela 2.7: Sequência de operações válida para consistência em momento indeterminado.

Por último, a consistência na linha do tempo $\left[\mathrm{CRS}^{+} 08, \mathrm{AD} 76\right]$ define que as escritas acontecem na mesma ordem em todas as réplicas e existem três possibilidades de leituras. A leitura da "versão mais recente" (Read-latest no original) lê o último valor escrito. A leitura por versão específica (Readcritical no original) recebe a versão mais antiga aceitável como parâmetro. A leitura de "versão qualquer" (Read-any no original) não oferece garantias sobre quão atual é o valor lido. Do ponto de vista da escrita, a consistência na linha do tempo se comporta como a consistência sequencial. Do ponto de vista da leitura, o seu comportamento depende do tipo de leitura: com leitura da "versão mais recente", ela se comporta como a consistência forte, com leituras de "versão qualquer" ou uma versão específica, ela se comporta como a consistência em momento indeterminado. Esse modelo de consistência permite que existam réplicas desatualizadas, mas garante que não existem divergências que precisem de mecanismos de resolução de conflitos [SS05], pois todas as escritas obedecem uma ordem serial. Detalhes do funcionamento desse modelo de consistência estão na Subseção 2.4.2.

O modelo de consistência de um sistema replicado impacta o seu desempenho, disponibilidade e manutenibilidade. Sistemas web georeplicados normalmente usam os modelos de consistência mais relaxados para atingir maiores desempenho e disponibilidade. Conceitos que ajudam os desenvolvedores a entender a relação entre esses requisitos são discutidos na seção seguinte. 


\subsection{Consistência, Desempenho e Disponibilidade em Sistemas Geo- replicados}

A maioria dos sistemas georeplicados têm fortes requisitos de escalabilidade, desempenho e disponibilidade. Nesse contexto, alguns conceitos usados em arquiteturas de sistemas menores deixam de ser válidos. Esta seção trata dos problemas enfrentados pelos desenvolvedores de sistemas de larga escala georeplicados e de algumas soluções para eles. Conhecer esses problemas e soluções é importante para entender a motivação e os compromissos envolvidos em diferentes modelos de consistência.

\subsubsection{Propriedades ACID em sistemas distribuídos de larga escala}

ACID se refere a Atomicidade, Consistência, Isolamento e Durabilidade [Gra81, HR83]. Transações ACID simplificam o projeto e desenvolvimento de um sistema, pois oferecem garantias que livram o desenvolvedor de se preocupar com a integridade dos dados. Atomicidade é a propriedade de uma transação de ter os efeitos de todas ou de nenhuma de suas operações aplicados ao banco de dados, não sendo assim permitida uma execução parcial. Consistência é a propriedade de uma transação de levar o banco de dados de um estado válido para outro estado válido. Isolamento é a propriedade pela qual uma transação executa como se não existissem outras transações sendo executadas simultaneamente. Durabilidade é a propriedade que garante que os efeitos de uma transação são permanentes após sua execução, estando disponíveis para todas as futuras transações.

A garantia de que essas propriedades são sempre válidas em um sistema tem um preço em termos de escalabilidade, desempenho e disponibilidade. Por isso, sistemas web de larga escala costumam abrir mão de propriedades ACID. Isso acontece pois implementações de transações distribuídas são dependentes de técnicas de sincronização que são pouco escaláveis [Hel07]. A maioria dos SGBDs usa algum protocolo de bloqueio (como bloqueio em 2 fases [BG81], por exemplo). Gray et al. mostram as limitações de escalabilidade desse tipo de protocolo por meio de um modelo analítico [GHOS96]. Essa análise mostra que a quantidade de bloqueios mútuos cresce cubicamente com a quantidade de nós do sistema, fato que torna esse tipo de sincronização inviável para sistemas de larga escala.

Além disso, o uso de transações distribuídas impacta na disponibilidade do sistema [Hel07], uma vez que um nó inalcançável pelos outros (seja por falha no nó ou particionamento na rede) torna todos os objetos armazenados nele indisponíveis para escrita, mesmo que esses objetos estejam replicados. Isso acontece pois independente do número de réplicas, o sistema fica impossibilitado de garantir consistência mútua [DGMS85]. As consequências de abandonar as propriedades ACID impactam fortemente na forma como sistemas web de larga escala são projetados e implementados, algo que pode ser visto em mais detalhes na subseção seguinte.

\subsubsection{Consistência, disponibilidade, tolerância a particionamento (CAP - Con- sistency, Availability, Partition-tolerance)}

O teorema CAP ou conjectura de Brewer diz que é impossível um sistema distribuído prover consistência, disponibilidade e tolerância a particionamento de rede simultaneamente, sendo necessário escolher quaisquer duas propriedades em detrimento da terceira [Bre00, GL02]. A consistência a que o teorema se refere é a consistência mútua. A disponibilidade é definida como a garantia de resposta de uma requisição recebida por qualquer nó que não apresente falha. A tolerância a particionamento é a capacidade do sistema continuar atendendo requisições mesmo quando uma quantidade arbitrária de mensagens entre os nós é perdida, o que representa a divisão do sistema em duas ou mais partições. A perda de mensagem pode ocorrer pela falha de qualquer equipamento ou estrutura de rede, como um roteador ou um enlace, ou por problemas comuns em redes de longa distância, como perda de pacotes, por exemplo.

A possibilidade de particionamento da rede não é uma característica do sistema, mas sim da rede na qual ele opera - particionamentos em redes locais são raros, mas são comuns em WANs 
$\left[\mathrm{DHJ}^{+}\right.$07, Hal10, AW96]. Assim, em sistemas georeplicados, boa parte da rede está fora do controle dos administradores do sistema. Essa é a essência do teorema CAP: em um sistema no qual há a possibilidade de particionamento da rede, resta aos desenvolvedores escolher entre disponibilidade e consistência.

Dessa forma, desenvolvedores de sistemas web georeplicados costumam escolher disponibilidade e tolerância a particionamento. O caso de indisponibilidade de uma réplica é menos complexo, o sistema continua funcionando normalmente, mesmo que com alguma degradação no desempenho. O maior problema é a "síndrome do cérebro dividido", em que um particionamento na rede ocorre e com isso abre-se a possibilidade de clientes de cada lado do particionamento continuarem lendo e escrevendo nas réplicas a que têm acesso. Quando isso acontece, escritas vindas dos clientes de cada partição podem levar as réplicas de um mesmo objeto a estados diferentes.

Há diversos modelos de consistência usados em sistemas que escolhem disponibilidade e tolerância a particionamento, sendo a consistência em momento indeterminado um exemplo. Esse modelo de consistência permite inconsistências entre réplicas, mas garante que elas são sempre expostas e resolvidas, apesar de não haver garantias de tempo para tal. Quando consistência em momento indeterminado é usada, algoritmos de detecção e resolução de conflitos precisam ser implementados para forçar a convergência dos valores das réplicas após um nó se recuperar de uma falha ou o particionamento da rede ser resolvido. Um exemplo de algoritmo de deteç̧ão de conflitos é a correção na leitura $\left[\mathrm{DHJ}^{+} 07\right]$. Por esse algoritmo, todas as réplicas de um objeto são acessadas a cada requisição de leitura para o objeto, e ao perceber divergência entre elas, o sistema ativa mecanismos de resolução de conflitos (comentados na Subseção 2.2.2).

Os compromissos apresentados pelo teorema CAP são complexos, não representando apenas situações binárias (disponível $\mathrm{x}$ indisponível, consistente $\mathrm{x}$ inconsistente). Um exemplo disso é o uso de quóruns, bastante utilizados na implementação do controle de consistência em sistemas distribuídos. Esse protocolo é utilizado para evitar ou diminuir a possibilidade de conflitos, com diminuição da disponibilidade do sistema sempre que o quórum para determinada operação não for atingido [Gif79, Vog09, YV01]. Por esse protocolo, um sistema usa um subconjunto das réplicas disponíveis para um balanço entre consistência e disponibilidade ao atender as requisições dos clientes. Seja o fator de replicação $\mathrm{N}$ a quantidade de réplicas existentes de um determinado objeto, $\mathrm{R}$ a quantidade de réplicas que precisam concordar com o mesmo valor para que uma leitura seja bem sucedida e $\mathrm{W}$ a quantidade de réplicas que precisam confirmar a execução da escrita para que ela seja bem sucedida. Nas situações em que $N>=R+W$, existe a possibilidade do surgimento de conflitos. Seja um exemplo em que um sistema é composto dos nós N1, N2 e N3, e $N=3, R=1$ e $W=2$. Nesse caso é possível que um cliente escreva em um determinado objeto em N1, e esse valor seja replicado para N2, mas ocorra um particionamento na rede antes da escrita atingir N3. Dado que $R=1$, um cliente solicitando a leitura desse objeto em N3 lerá o valor anterior do objeto. Uma opção para evitar o conflito é definir $N, R$ e $W$ tal que $N<R+W$, de forma que sempre haja intersecção entre os subconjuntos de nós usados para leitura e escrita. Essa leitura seria mal sucedida se $R=2$, por exemplo. O contraponto nesse caso é que a disponibilidade do sistema foi diminuída. A questão sobre que valores de $N, R$ e $W$ escolher se torna ainda mais complexa ao se considerar outros fatores, como durabilidade. Por exemplo, ao usar $W=1$, a durabilidade fica comprometida caso ocorra uma falha permanente em um nó que recebeu uma escrita mas falhou antes de enviá-la para as outras réplicas.

Outro exemplo de balanço entre consistência e disponibilidade é a consistência na linha do tempo $\left[\mathrm{CRS}^{+} 08, \mathrm{AD} 76\right]$. Esse modelo usa o conceito de cópia primária, mas em vez de aplicá-lo ao banco de dados como um todo, cada objeto replicado no sistema possui sua cópia primária (réplica mestre). Todas as escritas são feitas na réplica mestre, que usa replicação assíncrona para propagar o valor das atualizações [GHOS96]. Como existe uma única réplica em que uma escrita pode ocorrer, caso uma requisição precise necessariamente ler o valor mais recente do objeto, a réplica mestre é lida. Mas caso a aplicação possa ler valores desatualizados de um objeto, ela pode acessar qualquer outra réplica. Assim, a falha da réplica mestre torna o objeto indisponível para escritas e para leituras que exijam o valor mais recente do objeto. No caso de um particionamento da rede, o objeto permanece 
disponível para escrita e leitura para os clientes que ficaram na partição com acesso à réplica mestre. Para clientes nas outras partições, o objeto fica disponível apenas para leituras que explicitamente tolerem valores desatualizados.

O teorema CAP não cobre todas as trocas envolvidas no projeto de sistemas distribuídos de larga escala. O teorema PACELC fala sobre uma outra razão para um sistema relaxar a consistência, já comentada anteriormente: a obtenção de ganhos de desempenho [Aba10]. PACELC significa "se houver particionamento $(\mathrm{P})$, troque disponibilidade $(\mathrm{A})$ por consistência $(\mathrm{C})$, caso contrário $(\mathrm{E}-$ else), troque latência (L) por consistência (C)". Em uma rede local, a latência da rede é muitas vezes desprezível, mas em um sistema geograficamente distribuído as latências entre diferentes centros de processamento de dados são grandes. Garantir consistência mútua por meio de replicação pessimista nesse contexto implica que toda operação apresentará um tempo de resposta relacionado com a latência do enlace mais lento entre as réplicas, algo muitas vezes inaceitável por sistemas desse porte $\left[\mathrm{DHJ}^{+} 07, \mathrm{CRS}^{+} 08\right]$.

A partir da observação dos teoremas CAP e PACELC é possível criar heurísticas para otimização de um modelo de consistência. Por exemplo, uma heurística implementada no PNUTS [CRS $\left.{ }^{+} 08\right]$ que favorece tanto disponibilidade quanto desempenho da consistência na linha do tempo é a migração do mestre de um objeto para o centro de processamento de dados no qual ele é escrito mais frequentemente.

Este trabalho lidou com a questão da troca feita entre desempenho e consistência em sistemas georeplicados. Para isso, foram realizados experimentos com um sistema usando consistência em momento indeterminado e na linha do tempo em diferentes condições. O capítulo a seguir trata do planejamento dos experimentos e de como foram implementados. 


\section{Capítulo 3}

\section{Planejamento}

Este trabalho usa como principal referência metodológica o livro The Art of Computer Systems Performance Analysis (A Arte da Análise de Desempenho de Sistemas de Computação) [Jai91], de Raj Jain. Esse livro trata da análise de desempenho de sistemas de software e/ou hardware, e apresenta conceitos de estudos experimentais e o ferramental estatístico necessário nesse tipo de estudo. Além disso, ele propõe uma abordagem sistemática para fazer um estudo experimental. A segunda referência usada sobre análise de desempenho foi [Li105].

A definição do estudo seguiu os passos da abordagem de Jain em [Jai91], com exceção do levantamento de parâmetros e a seleção de fatores, que ocorreram após a definição da técnica de avaliação. Isso foi feito pois essa foi a fase de maior complexidade do estudo e está descrita no Capítulo 4.

A Seção 3.1 apresenta definições de termos usados em experimentação. A Seção 3.2 apresenta as metas do estudo. As métricas são definidas na Seção 3.3 e a técnica de avaliação é definida na Seção 3.4. A seguir, a Seção 3.5 descreve o processo de escolha do sistema usado no estudo, a Seção 3.6 descreve a plataforma de experimentação e a Seção 3.7 descreve as etapas de cada experimento. Por fim, a Seção 3.8 apresenta os tipos de experimentos usados neste trabalho.

\subsection{Nomenclatura}

A literatura sobre experimentos apresenta alguns termos importantes para a comunicação de objetivos, procedimentos e resultados [Jai91]. Termos usados frequentemente neste e nos próximos capítulos são:

Estudo: Um conjunto de experimentos relacionados. O plural "experimentos" também é usado no lugar de "estudo" ao longo deste trabalho.

Variáveis de resposta: Resultados de um experimento (variáveis dependentes). No caso deste estudo, as variáveis de resposta são as métricas de desempenho.

Parâmetros: Características do sistema (hardware e software) e da carga de trabalho (requisições para o sistema) que afetam o desempenho do sistema. Exemplos de parâmetros são CPU, latência da rede e relação leitura/escrita.

Fatores: Parâmetros que são variados nos experimentos (variáveis independentes) e cujo efeito no desempenho é analisado. Parâmetros que não são fatores possuem um único valor em todos os experimentos (variáveis fixas e constantes).

Níveis: Valores assumidos pelos fatores nos experimentos. 
Interação entre fatores: Dois ou mais fatores interagem se a influência que um deles tem no desempenho depende do nível dos outros. Por exemplo, um software é testado nas combinações das CPUs A e B e 4 GB e 8 GB de memória. Se ao mudar a CPU de A para B o desempenho sempre aumenta em $10 \%$, por exemplo, independente do tamanho da memória, é dito que CPU e memória não interagem. Mas se ao mudar a CPU de A para B o desempenho aumenta em $10 \%$ quando o sistema tem $4 \mathrm{~GB}$, mas $30 \%$ quando tem $8 \mathrm{~GB}$, é dito que CPU e memória interagem.

Ordem de uma interação entre fatores: A quantidade de fatores envolvidos na interação por exemplo, uma interação de terceira ordem é uma interação entre três fatores.

Projeto dos experimentos: Especificação do número de experimentos e das combinações de fatores e níveis usados.

\subsection{Metas do Estudo}

A meta deste estudo foi comparar o desempenho de um sistema de armazenamento georeplicado usando consistência em momento indeterminado e consistência na linha do tempo.

A principal hipótese deste trabalho era que um sistema georeplicado usando consistência na linha do tempo apresentaria um desempenho competitivo com a consistência em momento indeterminado para algumas cargas de trabalho, como uma que apresentasse localidade alta, por exemplo. Essa hipótese se baseava em uma segunda hipótese, a de que os tempos de resposta das requisições para o sistema seriam dominados pela latência e pelo jitter (variação da latência) da WAN. Um exemplo de fenômeno que poderia invalidar a hipótese seria a réplica mestre se comportar como gargalo na consistência na linha do tempo. Essa hipótese é verificada pela distribuição acumulada dos tempos de resposta para cada modo usado no estudo.

Outra hipótese é que as proporções de conflitos identificados durante as leituras em ambos os modelos de consistência seriam próximas. Conflitos na consistência na linha do tempo aparecem pois atualizações são enfileiradas na réplica mestre. Há um intervalo de tempo em que a atualização foi aplicada na réplica mestre mas ainda não foi enviada para as outras réplicas, esse intervalo é a janela de inconsistência. A consistência em momento indeterminado apresenta conflitos por motivo semelhante, com a diferença que a atualização pode ser aplicada em qualquer réplica. Desse fato resulta que a consistência em momento indeterminado permite atualizações simultâneas e divergentes, o que não é permitido pela consistência na linha do tempo. Assim, os conflitos no caso da consistência em momento indeterminado são mais graves.

Por limitações de escopo e recurso, este estudo analisa o sistema apenas do ponto de vista do desempenho. Isso significa que o estudo não considera outros requisitos como disponibilidade e manutenibilidade. Por isso, o comportamento do sistema não foi estudado com relação a presença de falhas em nós, por exemplo. Além disso, também foi considerada a operação do sistema em estado estacionário, sua operação em sobrecarga não foi estudada. Essas outras condições de operação podem ser estudadas em trabalho futuros (Seção 7.4).

\subsection{Métricas}

A principal métrica é o tempo de resposta das requisições (em s). Quanto menor o tempo de resposta, melhor é o desempenho de um modelo de consistência. Além do tempo de resposta, outras métricas observadas foram quantidade de migrações e quantidade de conflitos (ambas dadas pela porcentagem com relação ao total de operações do experimento). A quantidade de migrações, exclusiva da consistência na linha do tempo, oferece uma visão da dinâmica de um sistema usando esse modelo de consistência. A quantidade de conflitos proporciona uma noção da frequência com que clientes acessam valores desatualizados. Uma diferença entre conflitos nos dois modelos é que na consistência na linha do tempo eles são causados apenas por atualizações que ainda não chegaram a todas as réplicas, portanto serão automaticamente resolvidos em algum momento no futuro. Já na 
consistência em momento indeterminado eles podem ser mais graves, dado que esse modelo permite que duas atualizações simultâneas ocorram em réplicas diferentes, criando assim uma situação em que um mecanismo de resolução de conflitos precisa atuar.

\subsection{Técnica de Avaliação}

A escolha da técnica de avaliação depende em parte dos parâmetros e fatores [Jai91]. Apesar de o levantamento de parâmetros e a seleção de fatores terem sido completados depois desse passo, a escolha da técnica de avaliação foi feita com base em uma lista preliminar. Essa lista era composta por parâmetros diretamente ligados à meta deste trabalho, como os relacionados a carga de trabalho e rede.

Três técnicas são comumente usadas na análise de desempenho de sistemas: simulação, modelagem analítica e medição [Jai91]. Dada a complexidade dos sistemas considerados neste estudo e do ambiente em que operam, é difícil criar simuladores ou modelos que considerem muitos dos parâmetros que afetam seu desempenho. Para serem viáveis nesse contexto, essas técnicas fazem uso de diversas simplificações que afetam a precisão dos resultados do estudo. Por outro lado, as principais dificuldades para o uso de medição são a necessidade de um sistema pronto para ser usado, o tempo disponível para o estudo e as ferramentas disponíveis. No caso deste estudo, nenhum dos três representava empecilho, portanto medição foi escolhida.

\subsection{Sistema de Armazenamento}

Considerando que medição foi a técnica de avaliação escolhida, era necessária a escolha do sistema que seria o objeto do estudo (chamado de sistema sob teste por [Jai91]). Uma opção para a comparação dos dois modelos de consistência seria o uso de um sistema de armazenamento já existente que implementasse ambos, mas tal sistema não foi encontrado. A partir disso, outra opção seria o uso de sistemas diferentes, cada um implementando um modelo de consistência. Apesar de existirem experimentos que fizeram essa opção [CRS $\left.{ }^{+} 08, \mathrm{SMA}^{+} 07, \mathrm{PPR}^{+} 09\right]$, dois problemas foram identificados. O primeiro é que o desempenho de cada sistema é afetado por parâmetros particulares do sistema que não o modelo de consistência, como a tecnologia utilizada, detalhes de configuração, entre outros. No caso de uso de mais de um sistema, esses fatores, pouco importantes para este estudo, precisariam ser levados em conta. O segundo problema é que apesar de existirem sistemas de armazenamento de software livre que implementam consistência em momento indeterminado, não foram encontrados sistemas que implementassem consistência na linha do tempo.

Assim, decidiu-se usar um único sistema para os experimentos. Uma opção para tal era implementar um sistema de armazenamento distribuído específico para os experimentos. O problema é que esse tipo de sistema é bastante complexo, já que precisa prover funcionalidades como controle de entrada e saída dos nós no aglomerado, algoritmos de particionamento, etc.

Para evitar a implementação completa de um sistema de armazenamento e tornar este trabalho mais realista, algumas opções de software livre foram analisadas. A seleção das opções foi feita considerando modelos de consistência, estabilidade da solução e simplicidade de desenvolvimento. Como não foram encontrados sistemas de armazenamento de software livre que implementavam consistência na linha do tempo, as soluções avaliadas foram aquelas que implementavam consistência em momento indeterminado. Os sistemas encontrados foram Dynomite [Dyn], Cassandra [LM10], Voldemort [Vol] e Riak [Ria]. Todos eles usam basicamente a mesma arquitetura do Dynamo, provendo gerenciamento de entrada e saída de nós no aglomerado, relógios vetoriais para identificação e resolução de conflitos entre diferentes réplicas dos objetos [Lam78] e espalhamento consistente para o particionamento dos objetos [KLL $\left.{ }^{+} 97\right]$.

O Dynomite foi descartado pois o projeto foi abandonado pela comunidade em um estado ainda instável. O Cassandra por outro lado possui estabilidade e uma comunidade bastante ativa, mas é mais complexo que os outros sistemas dado que também implementa características de SGBDs 
orientados a colunas [CDG $\left.{ }^{+} 06\right]$. Dos dois sistemas restantes, o Riak foi escolhido por ser implementado em Erlang, linguagem voltada para o desenvolvimento de sistemas distribuídos, apresentando assim maior facilidade para o desenvolvimento do modelo de consistência na linha do tempo. Um indício dessa facilidade é que o riak_kv, o módulo do Riak usado na implementação do novo modelo de consistência, apresenta aproximadamente 20 mil linhas de código contra aproximadamente 85 mil do Voldemort. Além disso, o Riak já tinha um benchmark implementado, o Basho Bench [Bas].

Detalhes das modificações feitas no Riak encontram-se na Seção 5.1.

\subsection{Plataforma de Experimentação}

Os experimentos foram executados no Grid' $5000^{1}$, uma plataforma para criação, execução e monitoramento de experimentos de sistemas paralelos e distribuídos. Em janeiro de 2013, a plataforma possuía mais de 5000 núcleos de processamento distribuídos em 10 sítios na França e um no Brasil.

Outras plataformas como o OpenCirrus ${ }^{2}$ e PlanetLab ${ }^{3}$ também foram consideradas, mas foram descartadas por uma questão de conveniência, já que o autor deste trabalho utilizou o Grid'5000 em dois estágios de mestrado de respectivamente quatro meses e um mês pelo INRIA na França. A experiência no ambiente adquirida nesse período foi reutilizada neste trabalho, tornando o projeto e a execução dos experimentos mais produtivos. O Amazon Web Services (AWS) ${ }^{4}$ também foi considerado, mas foi descartado por se tratar de ambiente virtualizado compartilhado. Nesses ambientes, o desempenho de um sistema em uma máquina virtual pode ser afetado por outras máquinas virtuais que compartilham o mesmo hardware físico, o que dificulta a análise dos resultados e a reprodutibilidade dos experimentos.

Os sítios do Grid'5000 são conectados por redes de alta velocidade. Suas redes apresentam latências da ordem de centenas de microssegundos entre nós de um mesmo aglomerado e da ordem de $20 \mathrm{~ms}$ entre sítios, e portanto não caracterizam uma WAN convencional. De qualquer forma, mesmo que caracterizassem, ter controle sobre esses valores era necessário para medir o desempenho do sistema em diferentes condições de rede e possibilitar a reprodutibilidade dos experimentos. Por isso, a WAN foi emulada nos experimentos (ver Seção 5.4).

\subsection{Fluxo de Trabalho dos Experimentos}

A execução de um estudo compreendia diversas etapas. Cada uma delas compunha o fluxo de trabalho, apresentado na Figura 3.1.

Reserva dos nós Nessa etapa, escolhe-se o aglomerado, a quantidade de nós, o período da reserva e o instante em que ela ocorrerá (pode ser imediatamente ou em algum momento futuro).

Implantação da imagem nos nós Essa etapa usa a lista de nós definida na reserva e lida com situações em que os nós não foram corretamente implantados, algo relativamente comum.

Configuração dos nós Essa etapa consiste em separar os nós reservados entre nós de Riak e instâncias do benchmark, a partir das quantidades de cada um definidas para o estudo.

Configuração do Riak Essa etapa consiste no envio dos arquivos de configuração do Riak para cada nó. Nesse momento ocorre a configuração do modelo de consistência a ser usado em um dado experimento.

\footnotetext{
${ }^{1}$ http://www.grid5000.fr/

${ }^{2}$ http://opencirrus.org/

${ }^{3}$ http://www.planet-lab.org/

${ }^{4}$ http://aws.amazon.com/
} 


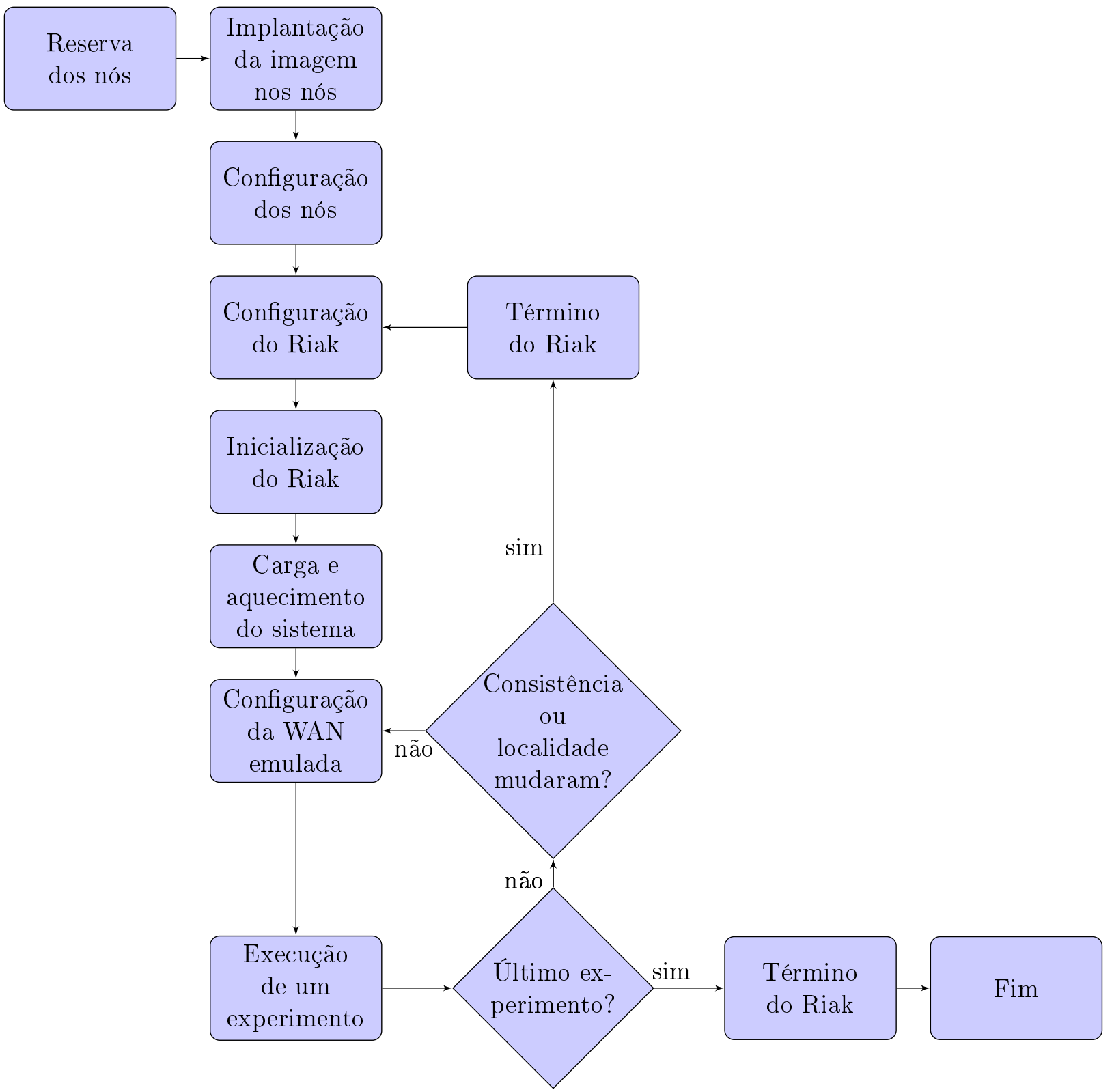

Figura 3.1: Fluxo de trabalho da execução do estudo.

Inicialização do Riak Essa etapa corresponde à inicialização das instâncias de Riak em cada nó e à entrada de cada uma no aglomerado de Riaks.

Carga e aquecimento do sistema Essa etapa consiste em popular o banco de dados do Riak antes dos experimentos. Para a consistência na linha do tempo, a fase de aquecimento do sistema é necessária (detalhes na subseção 4.4.2).

Configuração da WAN emulada Nessa etapa as interfaces de rede dos nós são configuradas com latência de rede, perda de pacotes, etc. para a WAN emulada. Além disso, as otimizações para WAN são aplicadas.

Execução de um experimento Essa etapa começa pela aquisição de informações do sistema, como as condições de memória e disco dos nós e latência da LAN. Após isso, a execução do benchmark propriamente dita ocorre. Por fim, arquivos com os resultados dos experimentos, logs e arquivos de configuração são salvos para serem usados na análise dos resultados posteriormente. 
Término do Riak Essa etapa é responsável por encerrar o Riak.

\subsection{Experimentos Fatoriais}

Experimentos fatoriais consistem da combinação de dois ou mais fatores em cada experimento que compõe o estudo. Um projeto que considere todos os fatores em todos os níveis é chamado completo, caso contrário é chamado fracionado [Jai91].

Um projeto de experimentos fatoriais completo é constituído por experimentos com todas as combinações possíveis de fatores e seus níveis. Assim, a quantidade total de experimentos é dada por:

$n=\prod_{i=1}^{k} n_{i}$,

onde $\mathrm{k}$ é o número de fatores e $n_{i}$ é a quantidade de níveis do iésimo fator.

Esse tipo de projeto de experimentos tem a vantagem de identificar com precisão a influência de todos os fatores e suas interações nas variáveis de resposta. Mas quanto maior a quantidade de fatores e de níveis em um estudo experimental, mais recursos (tempo, dinheiro, etc) são necessários para sua execução. Normalmente os fatores não afetam igualmente as variáveis de resposta, pelo contrário, é comum alguns poucos fatores explicarem a maior parte dos efeitos na resposta [Jai91]. Para esses casos, um projeto de experimentos fatoriais $2^{\mathrm{k}}$, que é um tipo de projeto de experimentos completo, é utilizado para fazer uma triagem dos fatores, identificando quais deles são os mais influentes.

Em um projeto de experimentos fatoriais $2^{\mathrm{k}}$, todos os fatores inicialmente selecionados são usados, mas apenas com dois níveis cada (normalmente o mínimo e o máximo), resultando em um total de $2^{\mathrm{k}}$ experimentos. O desempenho em função dos fatores é expresso por um modelo de regressão linear múltipla da forma:

$y=q_{0}+q_{A} x_{A}+q_{B} x_{B}+q_{C} x_{C}+\ldots+q_{A B} x_{A} x_{B}+q_{A C} x_{A} x_{C}+q_{B C} x_{B} x_{C} \ldots+q_{A B C} x_{A} x_{B} x_{C}+\ldots$,

onde $y$ é o desempenho medido, $q_{0}, q_{A}, q_{B}$, etc. são os coeficientes do modelo e $x_{A}, x_{B}, x_{C}$, etc. representam respectivamente os níveis dos fatores A, B, C, etc. Os termos compostos pela multiplicação de dois ou mais fatores representam as interações entre eles.

Usando as respostas dos $2^{\mathrm{k}}$ experimentos, é possível calcular o valor dos coeficientes por meio de um sistema de $2^{\mathrm{k}}$ equações em que os $2^{\mathrm{k}}$ coeficientes são as variáveis. Para tal, define-se uma relação entre os níveis dos fatores e os valores -1 ou 1 . Por exemplo, pode-se definir que a latência de 100 ms valerá -1 e a latência de 300 ms valerá 1 .

Com os coeficientes, é possível fazer a alocação de variação dos fatores, que é o cálculo da importância de cada um deles na resposta. A importância de cada um é dada pela proporção da variação total pela qual ele é responsável. A variação total da resposta (ou soma total dos quadrados) é dada por:

$S T Q=\sum_{i=1}^{n}\left(y_{i}-\bar{y}\right)^{2}$

onde $n$ é a quantidade de respostas, $y_{i}$ é resposta medida e $\bar{y}$ é a média das respostas.

Para um projeto de experimentos $2^{\mathrm{k}}$, a soma total dos quadrados é dada por (para a derivação dessa equação a partir da anterior, ver [Jai91]):

$S T Q=S Q A+S Q B+S Q C+\ldots+S Q A B+S Q A C+S Q B C+\ldots+S Q A B C+\ldots$, onde cada $S Q X$ é dado por:

$S Q X=2^{k} q_{X}$

Cada $S Q X$ é a porção da variação total explicada pelo fator ou pela interação entre fatores X. A partir disso, é possível finalmente calcular a fração da variação explicada por cada X por:

$F S Q X=S Q X / S T Q$

Ordenando os $F S Q X$ s é possível descobrir quais são os fatores e interações entre eles que mais afetam os resultados dos experimentos. 


\section{Capítulo 4}

\section{Parâmetros e Fatores}

A etapa seguinte à definição do estudo e dos aspectos técnicos tratou dos parâmetros e fatores usados nos experimentos finais. Primeiramente, a lista de parâmetros foi levantada. Dessa lista, alguns parâmetros já foram imediatamente fixados por limitação de recursos ou por não serem foco do estudo. A seleção inicial de fatores foi formada pelos parâmetros restantes. Como essa seleção era grande, experimentos foram usados para identificar os fatores mais influentes para o estudo. Os fatores menos influentes foram tratados como parâmetros e tiveram seus valores fixados. Os fatores mais influentes foram usados nos experimentos finais.

A fim de caracterizar a WAN, as principais características de uma rede são evidenciadas pelos mecanismos presentes no protocolo TCP, explicado na Seção 4.1. A lista de parâmetros inicialmente levantada é apresentada na Seção 4.2. Os parâmetros fixados e seus valores estão na Seção 4.3. A seleção dos fatores e os experimentos que levaram a ela estão na Seção 4.4. Por fim, um sumário dos fatores selecionados e as configurações do estudo final são apresentados na Seção 4.5.

\subsection{Mecanismos do TCP e Parâmetros de Rede}

Uma das principais diferenças entre redes de longa distância (WANs) e redes locais (LANs), além da área pela qual se estendem, diz respeito à confiabilidade do meio. LANs costumam usar topologias simples com poucos dispositivos e segmentos entre os nós, enquanto o oposto acontece em WANs. Além disso, LANs costumam ser mais homogêneas e terem um único administrador. No caso de WANs, um pacote de dados normalmente atravessa diversas redes compostas por dispositivos e administradores diferentes. Do ponto de vista deste trabalho, um centro de processamento de dados corresponde a uma LAN, enquanto a georeplicação ocorre na WAN.

TCP/IP é a pilha de protocolos comumente utilizada em sistemas georeplicados. O protocolo IP provê os mecanismos de endereçamento e roteamento. O TCP provê comunicação fim-a-fim confiável. Para tal, usa diversos mecanismos relacionados e dependentes entre si para lidar com controle de fluxo, controle de congestionamento, perdas, corrupção, reordenação e duplicação de pacotes.

No TCP, o controle de fluxo é feito por mecanismos usados nas pontas de uma conexão com o objetivo de usar a rede de forma eficiente e evitar o envio de mais dados do que o receptor pode tratar. O controle de congestionamento controla o tráfego em uma conexão para evitar sobrecarregar elementos de rede intermediários. Perdas acontecem quando um dispositivo na rede descarta pacotes, o que pode ser causado por corrupção de pacotes ou congestionamento da rede, como buffers esgotados em um roteador, por exemplo. Reordenação ocorre quando pacotes de uma mesma conexão TCP enviados nos instantes $t_{1}$ e $t_{2}$ seguem caminhos diferentes na rede, e o pacote enviado em $t_{2}$ chega ao receptor antes do enviado em $t_{1}$. Duplicação normalmente é relacionada a retransmissões do TCP, mas também acontece devido a balanceamento de carga ou problemas de hardware ou software em dispositivos intermediários.

Os principais mecanismos adotados no TCP para prover comunicação confiável são descritos a seguir [SW93, RFC09]: 
Reconhecimento positivo com retransmissão O TCP garante a entrega de dados pelo uso de números de sequência e reconhecimento dos pacotes e de mensagens de reconhecimento enviadas pelo receptor. Cada pacote enviado pelo transmissor carrega um número de sequência que representa a posição do primeiro byte de dados desse pacote no fluxo de dados. Ao receber um pacote, o receptor envia para o transmissor um pacote ACK com número de reconhecimento informando qual é o próximo byte que espera receber. Por exemplo, se um transmissor envia um pacote de 10 bytes de dados de carga e número de sequência 1, o receptor responderá com um ACK com número de reconhecimento 11. Um temporizador de transmissão é ativado para cada pacote enviado. Se o temporizador expirar antes do recebimento do ACK, o pacote é reenviado.

Controle de fluxo A janela de recebimento é a quantidade de bytes que o receptor está disposto a receber, baseada no espaço livre de seu buffer de recepção. O receptor envia o valor da janela em todas as suas respostas para o transmissor. Esse mecanismo evita que o transmissor envie mais dados do que o receptor pode tratar.

Partida lenta Ao contrário da janela de recebimento, a janela de congestionamento é mantida pelo transmissor, e é uma estimativa do congestionamento da rede. O transmissor calcula o tamanho da janela (cwnd - Congestion window) a partir dos ACKs recebidos. O mecanismo de partida lenta atua no início de uma conexão, quando o transmissor ainda não recebeu ACKs. No primeiro pacote, cwnd é igual a 1 ou 2 vezes o tamanho máximo de segmento TCP (MSS-Maximum Segment Size). Para cada ACK recebido, cwnd é incrementada em 1 MSS. Assim, a janela dobra de tamanho a cada tempo de ida e volta até que atinja o tamanho da janela de recebimento ou uma perda aconteça. Quando uma perda acontece, um segundo valor passa a ser levado em consideração, o limiar da partida lenta (ssthresh - Slow start threshold onde ssthresh $=$ cwnd/2) e o processo começa de novo, com cwnd igual a 1 ou $2 M S S$, até atingir ssthresh. A partir desse ponto, o TCP entra em modo de prevenção de congestionamento.

Prevenção de congestionamento As diferentes variações do TCP usam diferentes algoritmos de prevenção de congestionamento. Um dos primeiros algoritmos de prevenção de congestionamento implementados no TCP aumenta a janela de congestionamento em 1/cwnd a cada ACK recebido [Jac88]. Assim, durante essa fase, o aumento da janela de transmissão é linear, e não mais exponencial como na partida lenta. Variantes de TCP oferecem outras opções de algoritmos de prevenção de congestionamento, inclusive algumas delas sendo focadas em redes com latência e largura de banda grandes (ver Subseção 4.4.5).

Retransmissão rápida O receptor envia um ACK para todo pacote recebido, mesmo que fora de ordem. Por exemplo, se os pacotes de 10 bytes com números de sequência 1, 21 e 31 chegam ao receptor, ele responde com três ACKs com número de reconhecimento 11. O transmissor trata os primeiros ACKs em duplicata como reordenação de pacotes e apenas os ignora. Mas ao receber o terceiro, ele considera que um pacote foi perdido (o de número 21 no exemplo). Em vez de esperar o temporizador, o mecanismo de retransmissão rápida retransmite o pacote imediatamente.

Recuperação rápida $\mathrm{O}$ mecanismo de retransmissão rápida ter sido acionado indica que uma perda aconteceu, portanto algum mecanismo de prevenção de congestionamento deve atuar. Mas o recebimento de ACKs de pacotes posteriores ao perdido indica que o congestionamento foi uma situação pontual, já que o fluxo de dados entre transmissor e receptor não foi totalmente cortado. Por isso, reduzir drasticamente a janela de transmissão pelo uso da partida lenta implicaria em perda de vazão desnecessária. Assim, a recuperação rápida atua juntamente com a retransmissão rápida. Quando o terceiro ACK em duplicata é recebido, ssthresh assume o valor de cwnd/2, o pacote é retransmitido e a janela de congestionamento assume o valor cwnd $=$ ssthresh $+3 * M S S$. Se outros ACKs chegam em duplicata, a janela é incrementada em 1 MSS para cada um. Quando um ACK diferente chega, reconhecendo todos os pacotes recebidos fora de ordem (o de número 41 
no exemplo), a janela assume o valor cwnd $=$ ssthresh - metade do seu tamanho no momento em que o terceiro ACK em duplicata foi recebido.

Pacotes duplicados Pacotes duplicados são simplesmente descartados no receptor.

Pacotes corrompidos O TCP tem um campo com uma soma de verificação que é usada no receptor para verificar se o pacote foi corrompido em trânsito. Em caso positivo, ele é descartado. Do ponto de vista do transmissor, o pacote foi perdido, então os mecanismos usuais de controle de fluxo são acionados.

\subsection{Lista de Parâmetros}

Os parâmetros foram divididos em três categorias: parâmetros de sistema, de rede e de carga de trabalho. As justificativas para a escolha de um parâmetro nem sempre consideraram todas as situações possíveis em que ele afeta o desempenho do sistema, em alguns casos uma única razão foi considerada suficiente para tratá-lo como parâmetro.

Os 15 parâmetros de sistema levantados foram:

- Configuração de hardware (CPU, memória, disco e placa de rede)

- Mecanismo de armazenamento - memória ou disco

- Quantidade de nós do sistema

- Capacidade dos centros de processamento de dados

- Quantidade de instâncias do benchmark

- Quantidade de threads por instância do benchmark

- Quantidade de objetos armazenados

- Tamanho dos objetos armazenados

- Algoritmo de particionamento

- Modelo de consistência

- Fator de replicação $(N)$

- Configuração de replicação - $R$ e $W$ (para consistência em momento indeterminado)

- Limiar de migração (para consistência na linha do tempo)

- Protocolo de acesso

- Nível de $\log$

Os 13 parâmetros de rede levantados foram:

- Configuração de hardware dos dispositivos de rede intermediários

- Topologia da rede

- Largura de banda da LAN

- Latência da LAN

- Jitter da LAN 
- Largura de banda da WAN

- Latência da WAN

- Jitter da WAN

- Taxa de perda de pacotes na WAN

- Taxa de duplicação de pacotes na WAN

- Taxa de reordenação de pacotes na WAN

- Variante do TCP

- Quantidade de enlaces de WAN

Os 5 parâmetros de carga de trabalho levantados foram:

- Relação leitura/escrita

- Popularidade dos objetos

- Localidade

- Taxa de chegada de requisições

- Versão requisitada nas leituras (para consistência na linha do tempo)

Cada um desses parâmetros é explicado nas subseções a seguir. Os parâmetros que foram fixados, as justificativas para tal e seus valores estão descritos na Seção 4.3. Os restantes foram considerados fatores e o tratamento dado a eles está na Seção 4.4.

Uma última observação é que todos valores de latência relatados referem-se à latência de ida e volta.

\subsubsection{Parâmetros de sistema}

Os parâmetros de sistema levantados foram:

Configuração de hardware (CPU, memória, disco e placa de rede) O tempo de resposta de uma requisição é dado pela soma dos seus tempos de envio, de processamento e de recebimento. CPU, memória e disco afetam o tempo de processamento, a placa de rede afeta os tempos de envio e recebimento.

Mecanismo de armazenamento - memória ou disco O desempenho da memória é ordens de grandeza maior que o desempenho de um disco ${ }^{1}$. Em um sistema de armazenamento, o desempenho de leituras em disco pode ser próximo do desempenho de leituras em memória dependendo do tamanho do cache de disco e do conjunto de dados armazenados. Para escritas, o desempenho em disco é sempre menor.

Quantidade de nós do sistema A menos que um sistema distribuído apresente escalabilidade linear, quanto mais nós ele tiver, menor será o desempenho por nó.

Capacidade dos centros de processamento de dados A menos que todos os centros de processamento de dados possuam as mesmas capacidades agregadas de processamento, armazenamento e largura de banda, a vazão de cada centro de processamento de dados é diferente, o que se reflete no desempenho das requisições.

\footnotetext{
${ }^{1}$ SSDs são uma exceção, mas eles não estavam disponíveis no ambiente dos experimentos.
} 
Quantidade de instâncias do benchmark Considerando que cada instância do benchmark gere a mesma taxa de requisições, uma quantidade mínima é necessária para evitar gargalos no benchmark.

Quantidade de threads por instância do benchmark A mesma justificativa usada para quantidade de instâncias do benchmark é válida para quantidade de threads por instância.

Quantidade de objetos armazenados A quantidade de objetos armazenados influencia o volume de dados no disco e no cache de disco (caso disco seja o mecanismo de armazenamento utilizado). Além disso, dada uma taxa de chegada de requisições constante, a quantidade de objetos armazenados também afeta a probabilidade de conflitos, já que quanto menos objetos estiverem armazenados no sistema, maior a chance de um dado objeto ser requerido.

Tamanho dos objetos armazenados O tamanho dos objetos armazenados influencia o volume de dados no cache de disco, caso seja esse o mecanismo de armazenamento utilizado. No caso de armazenamento em memória, o tamanho dos objetos influencia a fragmentação da memória, o que também afeta o desempenho. Além disso, o tamanho dos objetos afeta o comportamento da comunicação TCP, dado que objetos muito grandes precisam ser divididos em mais de um pacote e objetos muito pequenos resultam em uma carga paga (payload) proporcionalmente menor. Isso tende a se refletir como redução da vazão e/ou aumento do tempo de resposta das requisições.

Algoritmo de particionamento $\mathrm{O}$ algoritmo de particionamento define a distribuição dos objetos pelos nós. No caso de uma distribuição desbalanceada, nós com mais objetos tendem a receber uma maior quantidade de requisições e ter seu desempenho prejudicado com relação a outros.

Modelo de consistência Objeto do estudo.

Fator de replicação $(N)$ Quanto maior o fator de replicação, maior o tráfego de rede, o que tende a causar uma diminuição do desempenho do sistema.

Configuração de replicação - $R$ e $W$ (para consistência em momento indeterminado) Em um ambiente com mais de um centro de processamento de dados, a configuração de replicação afeta a proporção entre requisições locais e remotas. Por exemplo, se todo centro de processamento de dados possui uma e apenas uma réplica de cada objeto, todas as leituras são locais para $\mathrm{R}=$ 1 e remotas para $R=2$. Dessa forma, a configuração de replicação afeta o tempo de resposta das requisições.

Limiar de migração (para consistência na linha do tempo) O limiar de migração é o valor no qual uma réplica mestre migra de um centro de processamento de dados para outro. Dependendo da carga de trabalho, valores diferentes do limiar resultam em proporções entre requisições locais e remotas diferentes, afetando assim o tempo de resposta médio das requisições.

Protocolo de acesso Um protocolo mais eficiente, que envia menos metadados, por exemplo, resulta em desempenho das requisições mais alto.

Nível de log O nível de log afeta a quantidade de escritas em disco, o que por sua vez afeta o desempenho do sistema.

\subsubsection{Parâmetros de rede}

Os parâmetros de rede levantados foram: 
Configuração de hardware dos dispositivos de rede intermediários (comutadores, roteadores, etc.) A configuração dos dispositivos de rede intermediários relaciona-se à largura de banda disponível, tamanho dos buffers de transmissão e recepção, capacidade de processamento de requisições, entre outros. Dessa forma, gargalos nesses dispositivos causam congestionamento na rede, com perda de desempenho do sistema.

Topologia da rede Várias características da topologia de rede afetam o desempenho do sistema, por exemplo, a quantidade de segmentos de rede pelos quais uma requisição passa para chegar ao destino afeta o seu tempo de resposta.

Quantidade de enlaces de WAN Se os diferentes enlaces tiverem diferentes características de rede, o tempo de resposta de uma dada requisição depende de sua origem e destino.

Largura de banda da LAN A largura de banda limita a vazão máxima do sistema em bits/s.

Latência da LAN O tempo de resposta de uma requisição é dado pela soma dos seus tempos de envio, de processamento e de recebimento. A latência afeta os tempos de envio e recebimento.

Jitter da LAN A latência em uma rede não é constante, dado que dentre suas causas está a dinâmica da rede [Gur01, KPFM12]. Por exemplo, rajadas de tráfego aumentam a fila de pacotes a serem processados em um roteador, o que se manifesta como aumento de latência nas conexões passando por ele. Quando o roteador volta à sua operação normal, a latência diminui. A latência não varia aleatoriamente, ela tem períodos de aumento e de diminuição gradual. No exemplo, a latência diminui em função da diminuição da fila no roteador, ela não cai imediatamente para o seu valor médio.

Largura de banda da WAN A mesma justificativa usada para largura de banda da LAN é válida para largura de banda da WAN.

Latência da WAN A mesma justificativa usada para latência da LAN é válida para latência da WAN. Um agravante é que latências em WANs são ordens de grandeza maiores que em LANs já que as distâncias percorridas pelos pacotes são muito maiores.

Jitter da WAN Mesma justificativa que para jitter da LAN. Um agravante é que requisições em uma WAN atravessam mais segmentos de rede e dispositivos intermediários, portanto são mais suscetíveis ao jitter. Quando a variação é muita e a latência torna-se maior que o tempo de expiração do temporizador de transmissão, o transmissor interpreta a demora na recepção de ACKs como perda de pacotes, o que diminui a vazão do sistema (a seguir).

Taxa de perda de pacotes na WAN Após uma perda ${ }^{2}$, o transmissor aciona o mecanismo de partida lenta (no caso de expiração do temporizador de transmissão) ou o mecanismo de prevenção de congestionamento (no caso do recebimento de ACKS em duplicata). Com isso, a janela de transmissão é diminuída, com consequente diminuição da vazão.

Taxa de duplicação de pacotes na WAN Duplicação de pacotes gera tráfego e processamento desnecessários, o que pode causar diminuição de vazão e/ou aumento do tempo de resposta das requisições.

\footnotetext{
${ }^{2}$ Perdas acontecem por corrupção de pacotes ou congestionamento. A ocorrência de corrupção de pacotes é um fenômeno mais frequente em redes sem fio ou via satélite, [Stevens] cita que esse valor é muito menor que $1 \%$ normalmente. Além disso, o tratamento dado pelo TCP para perda de pacotes é o mesmo independente do motivo da perda, por isso este trabalho apenas considera perdas por congestionamento.
} 
Taxa de reordenação de pacotes na WAN Pacotes fora de ordem acionam o mecanismo de recuperação rápida, com consequente diminuição da janela de transmissão. Além disso, pacotes fora de ordem ocupam espaço no buffer do receptor, o que pode afetar seu desempenho [WLL04].

Variante do TCP Variantes do TCP oferecem diferentes algoritmos de prevenção de congestionamento, responsável pelo dimensionamento da janela de congestionamento. Quanto maior a janela de congestionamento, maior a quantidade de dados em trânsito e maior a vazão do sistema.

Taxas de perda, de duplicação e reordenação de pacotes não foram consideradas para LAN pois ocorrem com menor frequência e geram pouco impacto nesse tipo de rede. Em WANs, esses fenômenos são relacionados a uma maior quantidade de nós intermediários (incluindo roteadores e proxies) e redes heterogêneas que os pacotes atravessam.

O Produto Banda-Latência (Bandwidth Delay Product - BDP) representa a quantidade máxima de dados em trânsito em uma conexão TCP e é comumente usado como medida de capacidade de enlaces de WANs em vez de latência e largura de banda separadamente. Neste trabalho a opção foi tratar latência e largura de banda separadamente pois a principal métrica do estudo é o tempo de resposta das requisições (Seção 3.3), que é comparável diretamente com a latência da rede, ao contrário do BDP. Além disso, foi considerado para estudo um cenário de implantação em que uma nuvem semelhante ao EC2 da Amazon fosse usada, então a largura de banda foi fixada nos estudos com base em valores relatados (ver Seção 4.3).

Por último, a variante do TCP usada é definida na configuração nos nós, e portanto poderia ser considerada um parâmetro de sistema. Mas como uma única variação foi usada em todos os nós e a análise do parâmetro fazia mais sentido no contexto da rede, a opção foi por classificá-lo como parâmetro de rede.

\subsubsection{Parâmetros de carga de trabalho}

Os parâmetros de carga de trabalho levantados foram:

Relação leitura/escrita Escritas normalmente são mais lentas que leituras, portanto a relação leitura/escrita afeta o tempo de resposta médio das requisições. Além disso, a consistência na linha do tempo pode apresentar desempenho mais baixo em um cenário de escrita intensiva, pois a réplica mestre pode se tornar um gargalo. Outro ponto a considerar é que a probabilidade de haver conflitos entre réplicas aumenta com o aumento da taxa de escritas em um sistema que usa consistência em momento indeterminado, que pode sofrer um impacto no seu desempenho devido à execução de seus algoritmos de resolução de conflitos.

Popularidade dos objetos Em muitas aplicações a popularidade dos objetos não é uniforme, alguns são mais acessados do que outros. Um exemplo é uma loja virtual em que o interesse dos clientes pelos produtos tende a obedecer uma lei de potência [And06]. A existência de objetos muito populares pode prejudicar o desempenho de um modelo de consistência como a consistência na linha do tempo, em que a réplica mestre pode se tornar um gargalo nas escritas.

Localidade Cooper et al. notam um alto índice de localidade nos acessos aos objetos dos sistemas no Yahoo! [CRS $\left.{ }^{+} 08\right]$. Em uma análise feita no período de uma semana, foi observado que em média $85 \%$ das escritas a determinado objeto vinham do mesmo centro de processamento de dados. Isso acontece por exemplo em uma rede social, em que os usuários costumam tanto acessar a aplicação quanto ter a maior parte de seus contatos na mesma localização geográfica - usuários brasileiros tendem a acessar o sistema do Brasil e a maioria de seus contatos é brasileira. Nesse caso, é possível evitar requisições entre centros de processamento de dados se os objetos são particionados no sistema considerando a localização geográfica dos acessos mais recentes. A implementação de consistência na linha do tempo usada neste estudo implementa migração de réplica mestre por esse motivo. 
Taxa de chegada de requisições A mesma justificativa usada para quantidade de instâncias do benchmark é válida para a taxa de chegada de requisições.

Versão requisitada nas leituras (para consistência na linha do tempo) Leituras de "qualquer versão" apresentam tempo de resposta menor que leituras de "versão mais recente" pois têm maior probabilidade de serem atendidas localmente. No caso em que existe garantia de haver ao menos uma réplica por centro de processamento de dados, as leituras de "qualquer versão" só não são atendidas localmente em caso de falha.

\subsection{Parâmetros Fixados}

Um motivo para fixar um parâmetro é a limitação de recursos. Por exemplo, um estudo pode estar limitado apenas às configurações de hardware disponíveis para o pesquisador. Um outro motivo é saber de antemão que, apesar de afetar o desempenho do sistema, o parâmetro é pouco relevante para o estudo.

Favorecer simetria e homogeneidade nos experimentos foi um princípio que guiou algumas das decisões, para simplificar a implementação e a análise dos experimentos. A desvantagem é a possível perda de realismo, dado que sistemas distribuídos de larga escala não costumam ser totalmente simétricos nem homogêneos.

Como o foco do estudo era a operação do sistema sobre uma WAN, fatores relacionados à rede e à carga de trabalho eram prioridade. Por isso, sempre que possível, parâmetros de sistema foram fixados, mesmo quando se sabia que eles afetavam o desempenho.

A configuração de hardware e o mecanismo de armazenamento são os únicos parâmetros cuja decisão envolveu experimentos, descritos na Subseção 4.3.1. Os outros parâmetros estão descritos na Subseção 4.3.2.

\subsubsection{Aglomerado e mecanismo de armazenamento}

As configurações de hardware estavam limitadas às oferecidas pelo Grid'5000. Cada aglomerado do Grid'5000 possui todos os nós com mesma configuração de hardware, e aglomerados diferentes são compostos por hardware com configurações diferentes. Com isso, decidiu-se restringir os experimentos a um único aglomerado, de forma a garantir homogeneidade de hardware. Além disso, do ponto de vista operacional, o uso de um único aglomerado simplificou a execução dos experimentos. Dado isso, alguns experimentos foram feitos para decidir qual aglomerado seria usado.

Os aglomerados do Grid'5000 considerados foram parapluie, sol e suno. A descrição do hardware e a quantidade de nós de cada um deles se encontra na Tabela 4.1.

\begin{tabular}{|c|c|c|c|c|}
\hline Aglomerado & CPU & Memória & Disco & Nós \\
\hline parapluie & AMD Opteron 6164 HE 1.7 Ghz & $48 \mathrm{~GB}$ & SATA / 250 GB & 40 \\
\hline sol & AMD Opteron 2218 2.6 GHz & $4 \mathrm{~GB}$ & SATA / 250 GB & 50 \\
\hline suno & Intel Xeon E5520 $2.26 \mathrm{GHz}$ & $32 \mathrm{~GB}$ & SAS/RAID-0 / 2x300 GB & 45 \\
\hline
\end{tabular}

Tabela 4.1: Aglomerados do Grid'5000.

Os experimentos mostraram diferenças consideráveis no desempenho do Riak nesses aglomerados. Considerando que os experimentos eram limitados por E/S (e não por CPU) e que não havia gargalo de rede, decidiu-se verificar o desempenho dos discos em cada aglomerado. A especificação do hardware mostrava tipos de discos diferentes entre aglomerados. Dada essa diferença, experimentos foram realizados para quantificá-la e tomar uma decisão mais informada.

Testes de desempenho de disco foram realizados em cada aglomerado. Para medição do desem- 
penho, os experimentos usaram o hdparm ${ }^{3}$ para acesso sequencial e o seeker ${ }^{4}$ para acesso aleatório. As médias obtidas confirmaram as grandes diferenças de desempenho, como pode ser visto na Tabela 4.2 .

\begin{tabular}{|c|c|c|c|}
\hline Aglomerado & Sequencial (MB/s) & Aleatório (buscas/s) & Aleatório (em ms) \\
\hline parapluie & 103,9 & 77 & 13,0 \\
\hline sol & 59,8 & 78 & 12,7 \\
\hline suno & 242,7 & 131 & 7,6 \\
\hline
\end{tabular}

Tabela 4.2: Comparação de desempenho de acessos dos discos entre aglomerados.

Além do tipo de disco, um outro ponto considerado foi o cache de disco. Em sistemas Linux, todo a memória livre é automaticamente usada como cache de disco. Dado isso, existiam três opções para a execução dos experimentos com relação ao mecanismo de armazenamento, considerando que um tamanho do banco de dados podia ser escolhido de forma a manter todos os dados em memória:

1. Dados em disco e cache limpo no início dos experimentos: O cenário seria mais real, mas mais difícil de analisar pois os efeitos do disco e da memória sobre o desempenho do sistema se misturariam. Além disso, o efeito do preenchimento do cache seria dependente da duração do experimento, quanto mais longo o experimento maiores as chances de as leituras encontrarem os objetos no cache.

2. Dados em cache no início dos experimentos: O disco seria predominantemente usado apenas para escritas e as leituras seriam servidas a partir do cache. Com isso, o desempenho das escritas seria dependente do disco, enquanto o das leituras não.

3. Dados em memória: O Riak podia ser configurado para funcionar como um banco de dados em memória, eliminando definitivamente o efeito do disco.

A terceira opção foi a escolhida. Realizar os experimentos com banco de dados em memória geraria resultados mais precisos e de interpretação mais simples por descartar a influência de desempenho do disco. Em princípio, os resultados podem parecer menos realistas e aplicáveis, mas na prática eles são tão limitados quanto com o uso de disco, já que nesse caso os resultados seriam afetados pelo tipo de disco e pela relação entre o tamanho do banco de dados e a memória livre. Um exemplo é a comparação de suno com parapluie, em que o primeiro aglomerado possui discos com taxas de acesso maiores que a largura de banda da rede $(1 \mathrm{~Gb} / \mathrm{s})$ - o gargalo em um caso seria a rede, em outro caso seria o disco. Efeitos do cache de disco tornariam os resultados ainda mais particulares e difíceis de serem generalizados. Dessa forma, ao adotar memória como mecanismo de armazenamento, eliminou-se os efeitos das interações entre rede, disco e cache de disco e a análise foi focada apenas na rede. Trabalhos futuros podem estudar o efeito de disco e cache de disco no desempenho (Seção 7.4).

Ao definir que o sistema usaria memória como mecanismo de armazenamento, a configuração de hardware do aglomerado passou a ser menos relevante, dado que todos os aglomerados oferecem nós com capacidade de processamento (CPU) razoável, ao menos 4 GB de memória e placas de rede de $1 \mathrm{~Gb} / \mathrm{s}$. O aglomerado sol foi escolhido predominantemente por questões operacionais - ele tem um tamanho suficiente (47 nós) e a concorrência pela reserva de seus nós é baixa.

Dessa forma, os valores fixados foram:

- Aglomerado: sol

- Mecanismo de armazenamento: memória

O aglomerado escolhido usa topologia em estrela com cada nó ligado diretamente a um comutador Foundry FastIron Super X.

\footnotetext{
${ }^{3}$ http://linux.die.net/man/8/hdparm

${ }^{4}$ http://www.linuxinsight.com/how_fast_is_your_disk.html
} 


\subsubsection{Parâmetros restantes}

Os parâmetros inicialmente levantados que não foram considerados fatores foram fixados. O valores definidos foram:

Capacidade dos centros de processamento de dados: Os centros de processamento de dados têm a mesma capacidade, com a mesma quantidade de nós e os nós têm a mesma configuração de hardware, resultando em um sistema simétrico e homogêneo.

Algoritmo de particionamento das chaves: O algoritmo padrão do Riak foi usado (espalhamento consistente), configurado com 512 partições. Esse valor satisfaz as duas condições descritas na documentação do Riak: ser uma potência de 2 e resultar em ao menos 10 partições por nó (caso os experimentos finais usassem mais do que 64 nós esse valor teria sido aumentado).

Fator de replicação $(N)$ : 3. Valor que resulta em um balanço razoável entre desempenho, disponibilidade e durabilidade em aplicações reais $\left[\mathrm{DHJ}^{+} 07\right]$.

Limiar de migração (para consistência na linha do tempo): 3. Valor padrão usado pelo PNUTS [CRS $\left.{ }^{+} 08\right]$.

Interface de acesso: HTTP. O Riak também dá suporte a Protocol Buffers ${ }^{5}$, mais eficiente que a interface HTTP. Apesar disso, a opção foi pelo uso de HTTP pois eficiência da interface não era tão relevante para os experimentos dado que a carga sobre o sistema era controlada, e implementar os parâmetros da consistência na linha do tempo na interface HTTP era mais simples.

Nível de log: WARN. Alguns experimentos exploratórios mostraram perda de desempenho quando o nível de log estava em INFO, que resulta em muito mais escritas no log que WARN. De qualquer forma, como a carga sobre o sistema era controlada, esse parâmetro era pouco relevante.

Configuração de hardware dos dispositivos de rede intermediários (comutadores, roteadores, etc.) O único dispositivo de rede no aglomerado usado no estudo era um comutador (ver Subseção 4.3.1). Testes mostraram que não existiam gargalos no comutador mesmo nos experimentos com maior consumo de banda.

Topologia da rede: Topologia da rede em estrela do aglomerado usado nos experimentos.

Quantidade de enlaces de WAN: 1. Um único enlace significa que o estudo usou dois centros de processamento de dados. Esse valor simplificou a modificação do algoritmo de particionamento do Riak (ver Seção 3.5) e a análise dos resultados, que precisou considerar heterogeneidade da rede.

Largura de banda da LAN: $1 \mathrm{~Gb} / \mathrm{s}$. Essa é a largura de banda disponível nas placas de rede dos nós do aglomerado e não foram encontrados indícios de que o comutador seria um gargalo. Tomando o AWS como base, estudos informais indicam que é essa a largura de banda observada dentro de um mesmo centro de processamento de dados por instâncias com perfil de E/S "Alto" (por exemplo, uma instância M1 Grande) [Tho07, Puj12].

Latência da LAN: Latência do aglomerado utilizado no estudo. Um teste com ping com 60 amostras espaçadas em $5 \mathrm{~s}$ no aglomerado mediu $167 \mu$ s de latência média.

\footnotetext{
${ }^{5}$ http://code.google.com/p/protobuf/
} 
Jitter da LAN: Jitter do aglomerado utilizado no estudo. A mesma medição feita para a latência mostrou desvio padrão de $90 \mu$ s.

Largura de banda da WAN: $100 \mathrm{Mb} / \mathrm{s}$. Um estudo informal entre os serviços EC2 e S3 da Amazon com 9 segmentos de rede entre eles (indício de que estão em centros de processamento de dados diferentes) mediu $400 \mathrm{Mb} / \mathrm{s}$ [Tho07]. Outro estudo cita que é comum medir $100 \mathrm{Mb} / \mathrm{s}$ como largura de banda entre zonas de disponibilidade [Puj12].

Taxa de chegada de requisições 15 operações/s para cada thread de cada instância do benchmark. Esse valor foi usado pois esse parâmetro se relaciona diretamente com a quantidade de threads por instância do benchmark. Assim, considerando que threads por instância foi inicialmente considerado um fator, a taxa de chegada foi fixada.

Vale notar que a LAN nos experimentos foi definida pela infraestrutura do Grid'5000 usada, mas a WAN foi emulada (ver Seção 5.4). Dessa forma, os parâmetros da LAN estavam limitados pela infraestrutura do estudo, enquanto os da WAN foram usados como configuração do emulador.

\subsection{Seleção dos Fatores}

Os parâmetros que não foram fixados consequentemente eram candidatos a fatores nos experimentos finais. Como a lista precisava ser reduzida pois ainda era grande, experimentos fatoriais $2^{\mathrm{k}}$ foram realizados. Dada a meta do estudo, fatores de rede e de carga de trabalho foram priorizados, portanto havia intenção de desconsiderar os fatores de sistema desde o início. Mesmo assim, estudos fatoriais foram feitos para eles por dois motivos. Primeiro, para verificar quais fatores eram mais influentes e portanto representavam ameaças à validade se desconsiderados. Depois, para ter mais informações sobre os valores a serem usados para eles.

Os fatores de sistema eram:

- Quantidade de nós do sistema

- Quantidade de instâncias do benchmark

- Quantidade de threads por instância do benchmark

- Quantidade dos objetos armazenados

- Tamanho dos objetos armazenados.

Os fatores de rede eram:

- Modelo de consistência

- Latência da WAN

- Jitter da WAN

- Taxa de perda de pacotes na WAN

- Taxa de duplicação de pacotes na WAN

- Taxa de reordenação de pacotes na WAN

- Variante do TCP

Os fatores de carga de trabalho eram:

- Relação leitura/escrita 
- Popularidade dos objetos

- Localidade

Uma abordagem possível para a seleção final de fatores seria agrupar todos os fatores levantados em um único projeto de experimentos fatoriais $2^{\mathrm{k}}$. O problema é que mesmo com apenas dois níveis por fator, a quantidade final de experimentos seria proibitiva, dado que a quantidade de fatores era 15.

A opção adotada para lidar com o excesso de fatores foi dividi-los em grupos menores e realizar experimentos para cada grupo. O principal problema de fazer essa separação é o fato de a comparação da influência de fatores de grupos diferentes ser perdida. Por exemplo, localidade e quantidade de nós de sistema foram tratados em estudos diferentes e cada um apareceu como o fator mais influente do estudo de que fez parte. Como eles não fizeram parte do mesmo estudo, a informação de qual deles é o mais influente foi perdida, bem como a informação sobre a influência da interação entre eles. Se um fosse muito mais influente do que o outro e a interação entre eles fosse baixa, a decisão de fixar o menos influente não teria consequências. Mas sem essa informação, fixar um deles representava ameaça à validade do estudo.

A maioria desses fatores era suscetível a interações com fatores de rede, como o tamanho dos objetos armazenados, por exemplo. A latência de rede em particular havia se mostrado muito influente em estudos exploratórios, fato confirmado posteriormente pelo estudo para fatores de rede. Dado isso, a abordagem adotada foi usar a latência como um representante da rede nos outros estudos fatoriais. A partir disso foi possível concluir, por exemplo, que apesar de o tamanho dos objetos armazenados aparecer como fator influente no estudo fatorial para ele, desconsiderá-lo no estudo final não era uma ameaça à validade pois a latência era um fator bem mais influente.

Existem outras situações em que desconsiderar um fator que aparece como influente não implica necessariamente em ameaça à validade. O método de análise de variação de um estudo $2^{\mathrm{k}}$ mostra a importância relativa de cada fator, o que não significa que esses fatores sejam de fato influentes. Por exemplo, ao testar o desempenho de um software com duas CPUs e dois tamanhos de memória diferentes (quatro experimentos), um estudo fatorial vai indicar a influência de um ou dos dois fatores mesmo que a maior diferença entre as respostas seja de $0,001 \%$. Nesse caso, a variação é pouco significativa, mas o estudo fatorial vai indicar qual a influência relativa de cada fator nesses $0,001 \%$ de variação. Para tratar esses casos, também foram calculados os coeficientes de variação ${ }^{6}$ $(\mathrm{CVs})$ das respostas para estimar qual a influência daquele conjunto de fatores e interações como um todo. Assim, quando o CV era baixo (1\%, por exemplo), nenhum dos fatores usados no estudo era influente, já que nenhuma combinação de fatores e níveis resultou em variação significativa da resposta.

Os tempos de resposta das requisições remotas dominam a média dos tempos de resposta pois são ordens de grandeza maiores que os das requisições locais. Por isso, a análise da maioria dos estudos é feita por percentis em vez de médias - percentis baixos representam requisições locais e percentis altos representam requisições remotas. Também é feita a distinção entre escritas e leituras dada a diferença de natureza dessas operações.

Três fatores receberam um tratamento diferente ao longo do experimento: modelo de consistência, configuração de replicação (para consistência em momento indeterminado) e versão requisitada nas leituras (para consistência na linha do tempo). Isso foi feito pois as combinações entre esses fatores definem configurações do sistema de armazenamento que resultam em proporções de requisições locais e remotas diferentes. Assim, esses fatores foram tratados como um único fator chamado modo, descrito na Subseção 4.4.1. Os fatores localidade e popularidade na consistência na linha do tempo impuseram a necessidade de uma fase de aquecimento após a carga do sistema, o processo é explicado na Subseção 4.4.2. Experimentos fatoriais $2^{\mathrm{k}}$ foram realizados para estimar a influência dos fatores restantes e são descritos nas subseções subsequentes. Nas tabelas de influência nessas

\footnotetext{
${ }^{6} \mathrm{O}$ coeficiente de variação é a divisão do desvio padrão pela média e é uma maneira de representar a variabilidade dos dados desconsiderando sua ordem de grandeza
} 
subseções, células mais escuras indicam valores de influência mais altos. Os valores estão divididos em quatro faixas: 0 a $20 \%$ (sem cor), $21 \%$ a $50 \%, 51 \%$ a $80 \%$ e $81 \%$ a $100 \%$.

\subsubsection{Modo}

Os modos adotados foram:

- ind1: Consistência em momento indeterminado com $W=1$ e $R=1$

- ind2: Consistência em momento indeterminado com $W=2$ e $R=1$

- lt_qqer: Consistência na linha do tempo com leituras de qualquer versão

- lt_rec: Consistência na linha do tempo com leituras da versão mais recente

Todas as configurações usam $N=3$ (ver Seção 4.3). O algoritmo de particionamento garante que existe ao menos uma réplica em cada centro de processamento de dados (ver Subseção 3.5). Assim, existem sempre duas situações possíveis com relação à localização das réplicas do ponto de vista do coordenador: uma local e duas remotas ou duas locais e uma remota. Dado isso, o modo ind1 resulta em todas as leituras e escritas locais. O modo ind2 resulta em todas as leituras locais e metade das escritas local e a outra metade remota. O modo lt_qqer resulta em todas as leituras locais e a quantidade de escritas dependente da localidade dos acessos. Finalmente, o modo $l t_{-} r e c$ resulta tanto em leituras quanto escritas dependentes da localidade.

Os modos foram escolhidos de forma a representar situações encontradas em aplicações web e ao mesmo tempo limitar a quantidade de níveis. Assim, consistência na linha do tempo com leituras de versões específicas não foi considerada já que ela é um meio termo entre leituras de "versão mais recente" e leituras de "qualquer versão". Consistência em momento indeterminado com $W=1$ e $R=2$ não foi considerada pois sua semântica é similar a $W=2$ e $R=1$, mas teria seu desempenho prejudicado considerando que leituras predominam nas relações leitura/escrita usadas nos experimentos (ver Subseção 4.4.6).

Esses modos implicam em trocas além de desempenho e consistência. A principal é durabilidade, que para ind2 é mais alta do que para os outros casos, em que a confirmação de escrita de uma única réplica é suficiente.

\subsubsection{Aquecimento}

Como localidade era um fator, apenas a inserção de objetos na etapa de carga (Seção 5.4.2) não era suficiente para que o sistema operasse no seu estado estacionário durante os experimentos para a consistência na linha do tempo. Isso porque ao final da carga, cada objeto no banco de dados tinha recebido apenas um acesso de cada centro de processamento de dados, nenhuma réplica mestre teria migrado por efeito da localidade até esse momento. Por isso, o aquecimento era necessário após a carga para a consistência na linha do tempo. Já a consistência em momento indeterminado não era sujeita à influência direta de localidade, portanto não precisava de aquecimento.

A influência da popularidade também foi considerada pois ela afetava a probabilidade de um determinado objeto ser acessado. Foram feitos testes com os dois valores de popularidade usados nos experimentos (ver Subseção 4.4.6). Na popularidade uniforme os objetos armazenados têm chances iguais de serem acessados, enquanto na concentrada os acessos obedecem uma distribuição Pareto.

Dado isso, um estudo foi realizado para saber quantas escritas eram necessárias até que o sistema atingisse o regime estacionário para cada combinação de localidade e popularidade. O estudo foi feito com 20.000 objetos armazenados. A quantidade de escritas necessárias era proporcional à quantidade total de objetos, comportamento verificado por meio de testes com outros valores de objetos armazenados e no estudo final (ver Seção 6.4).

A Figura 4.1 mostra que, independente da popularidade, o sistema atinge o regime estacionário para localidade de $50 \%$ em aproximadamente 60 mil escritas ( 3 vezes o total de objetos armazenados). No início existe um aumento das migrações enquanto os objetos ainda não receberam em média três acessos, após esse ponto as migrações estabilizam. 


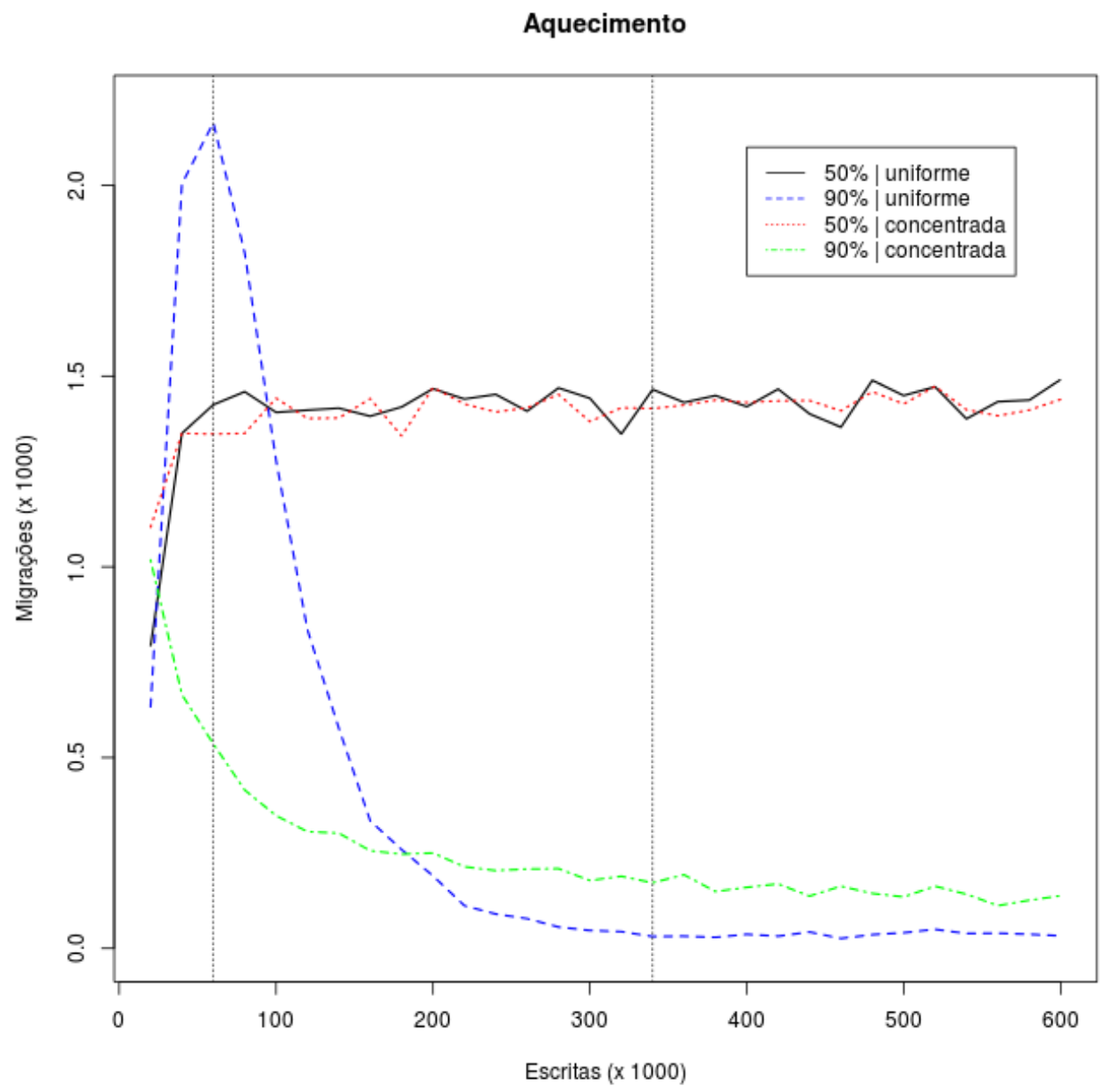

Figura 4.1: Aquecimento do sistema. As linhas tracejadas indicam o ponto onde o sistema atinge o regime estacionário.

A mesma figura mostra que, independente de popularidade, o sistema atinge o regime estacionário para localidade de $90 \%$ em aproximadamente 340 mil escritas (17 vezes o total de objetos armazenados). A popularidade concentrada significa que poucos objetos precisam migrar para atingir o regime estacionário, e a quantidade logo cai pois a localidade alta significa que eles são "atraídos" para seu centro de processamento de dados preferencial rapidamente e nele ficam. No caso da popularidade uniforme, muitos objetos precisam migrar para atingir o regime estacionário, mas uma vez que receberam em média três acessos, as migrações caem rapidamente pois a alta localidade significa que estão no seu centro de processamento de dados "preferencial".

O aquecimento teve apenas a função de acertar a localização das réplicas pois o mecanismo de armazenamento usado foi memória (ver Seção 4.3.1). Caso fosse disco, essa fase também seria usada para aquecer o cache de disco.

\subsubsection{Fatores de tamanho do sistema e benchmark}

As quantidade de nós de sistema e benchmark não só influenciam as respostas, como também afetam questões operacionais, dado que quanto mais nós são usados, maiores as dificuldades de conseguir reservá-los no Grid'5000. Portanto, um estudo foi feito para definir a influência desses fatores e achar valores que representassem um compromisso razoável entre tamanho dos experimentos e as questões operacionais.

Os níveis selecionados para o estudo foram:

- Quantidade de nós do sistema: 8 e 16 
- Quantidade de instâncias do benchmark: 2 e 4

- Quantidade de threads em cada instância do benchmark: 32 e 64

A quantidade de partições usadas pelo Riak deve ser uma potência de 2 (ver Seção 4.3). Uma forma de manter a simetria do sistema foi adotar potências de 2 para os níveis da quantidade de nós do sistema, garantindo assim a mesma quantidade de partições por nó. Fazer o mesmo para quantidade de instâncias do benchmark e quantidade de threads por instância foi uma forma de balancear a carga média tanto por nó quanto por partição.

O estudo usou modo $l t_{-} r e c$, localidade de $50 \%$ e latência de rede de $100 \mathrm{~ms}$. Esses valores foram escolhidos pois por meio deles obtém-se uma quantidade balanceada de leituras e escritas locais e remotas. O resultado do estudo está na Tabela 4.3.

\begin{tabular}{|c|c|c|c|c|c|c|c|c|}
\hline Operação & Percentil & N & B & T & NB & NT & BT & NBT \\
\hline leitura & 10 & 30 & 18 & 22 & 10 & 8 & 7 & 4 \\
\hline leitura & 90 & 65 & 13 & 15 & 3 & 4 & 0 & 0 \\
\hline escrita & 10 & 96 & 2 & 1 & 0 & 0 & 0 & 0 \\
\hline escrita & 90 & 65 & 15 & 13 & 3 & 3 & 0 & 0 \\
\hline
\end{tabular}

Tabela 4.3: Estudo para quantidade de nós do sistema. $N$ representa a quantidade de nós do sistema, $B$ representa a quantidade de instâncias do benchmark e $T$ representa a quantidade de threads usadas em cada instância do benchmark.

Na maioria dos casos, o tamanho do sistema tem a maior influência nos resultados e a quantidade de instâncias do benchmark e a quantidade de threads não são desprezíveis, ainda mais ao se considerar as interações entre elas. Apesar disso, esses fatores foram desconsiderados devido ao excesso de fatores. Dessa forma, os valores fixados foram:

- Quantidade de nós do sistema: 16 (maior valor)

- Quantidade de instâncias do benchmark: 4 (maior valor)

- Quantidade de threads em cada instância do benchmark: 32 (menor valor)

Esses valores foram selecionados pois resultaram em uma configuração "leve", evitando gargalos de rede e não sobrecarregando o sistema. Ao mesmo tempo, a quantidade total de nós necessária para os experimentos se enquadrava nas limitações de recursos do aglomerado.

Uma opção semelhante seriam 32 nós do sistema e 8 instâncias do benchmark, resultando em um total de 40 nós. Isso não foi feito por questões operacionais. Apesar de o aglomerado ter mais do que 40 nós, é muito comum alguns poucos nós já estarem reservados por outros pesquisadores, além de alguns nós apresentarem falhas no momento da implantação da imagem. Esse último problema levou o autor a sempre reservar alguns nós além dos necessários para garantir a quantidade mínima de nós para executar os experimentos. Além disso, alguns limites de uso do Grid'5000 são relativos ao tamanho do aglomerado usado. Por exemplo, uma das regras diz que, entre 9:00 e 19:00, a quantidade de nós reservados multiplicada pelo período da reserva deve ser menor ou igual a quantidade total de nós do aglomerado multiplicada por 2 horas. Dessa forma, experimentos que precisassem de 40 nós seriam mais difíceis de serem executados.

\subsubsection{Fatores de banco de dados}

Um estudo foi feito para dimensionar o tamanho do banco de dados, que afeta o uso de memória e de banda. Os experimentos consideraram a latência como fator para verificar a importância relativa entre esses fatores e a rede.

Os níveis selecionados foram: 
- Quantidade de objetos armazenados: 64.000 e 256.000

- Tamanho dos objetos armazenados (bytes): 100 e 10.000

O estudo usou modo $l t_{-}$rec e localidade de $50 \%$. Esses valores foram escolhidos pois através deles obtém-se uma quantidade balanceada de leituras e escritas locais e remotas. O resultado do estudo está na Tabela 4.4.

\begin{tabular}{|c|c|c|c|c|c|c|c|c|}
\hline Operação & Percentil & $\mathrm{Q}$ & $\mathrm{T}$ & $\mathrm{L}$ & $\mathrm{QT}$ & $\mathrm{QL}$ & $\mathrm{TL}$ & $\mathrm{QTL}$ \\
\hline leitura & 10 & 0 & 100 & 0 & 0 & 0 & 0 & 0 \\
\hline leitura & 90 & 0 & 0 & 100 & 0 & 0 & 0 & 0 \\
\hline escrita & 10 & 0 & 100 & 0 & 0 & 0 & 0 & 0 \\
\hline escrita & 90 & 0 & 0 & 100 & 0 & 0 & 0 & 0 \\
\hline
\end{tabular}

Tabela 4.4: Estudo para quantidade e tamanho dos objetos armazenados. Q representa a quantidade de objetos armazenados, $T$ representa o tamanho dos objetos armazenados e $L$ representa a latência.

A quantidade de objetos não afeta o desempenho do sistema. O tamanho dos objetos não afeta o desempenho das requisições remotas, mas com relação às requisições locais aparece com $100 \%$ de influência. Apesar disso, o CV das requisições locais indica que sua influência na prática não é tão grande $-19 \%$ para leituras e $16 \%$ para escritas. Assim, os valores fixados foram:

- Quantidade de objetos armazenados: 128.000

- Tamanho dos objetos armazenados (bytes): 500

Como o tempo de aquecimento depende da quantidade de objetos armazenados, quanto menor essa quantidade, mais rápida é a execução dos experimentos. Por outro lado, a opção foi por um número intermediário de modo a evitar um excesso de conflitos. Já no caso do tamanho dos objetos armazenados, o valor foi escolhido baseado em um estudo dos sistemas de caching distribuído no Facebook, que relata que $90 \%$ dos objetos nesses sistemas são menores do que 500 bytes [AXF12].

\subsubsection{Fatores de rede}

Dado o objetivo do trabalho, o estudo para fatores de rede era um dos mais importantes da etapa de seleção de fatores. Mas antes dele, um estudo preliminar foi feito para verificar as recomendações de otimização para WAN do tamanho dos buffers de transmissão e recepção.

Pelo BDP de um enlace, quanto maior a latência da rede, maior é a quantidade de pacotes em trânsito. Um gargalo comum em WANs é o tamanho dos buffers de transmissão e recepção das pontas serem menores que o BDP. Recomendações sugerem a configuração de buffers com tamanho em bytes igual ao dobro do BDP [Jon06, ESN]. Em princípio essa otimização seria aplicada aos estudos, mas experimentos com a ferramenta para medição de largura de banda iperf ${ }^{7}$ mostraram ganhos de desempenho para buffers de até quatro vezes o BDP, portanto um estudo fatorial foi feito para verificar esse fato. O estudo usou latência e reordenação de pacotes para criar cenários que pressionassem os buffers de forma diferente.

Os níveis selecionados foram:

- Proporção entre tamanho dos buffers e BDP: 2 e 4

- Latência da WAN (ms): 100 e 300

- Taxa de reordenação de pacotes na WAN (\%): 0 e 5

\footnotetext{
${ }^{7}$ http://iperf.sourceforge.net/
} 
O estudo usou modo $l t_{-}$rec e localidade de $50 \%$. Esses valores foram escolhidos pois por meio deles obtém-se uma quantidade balanceada de leituras e escritas locais e remotas. Para a rede, o jitter foi de $50 \%$. A alta variabilidade ajuda a criar um cenário que pressiona os buffers de transmissão e recepção. O resultado do estudo está na Tabela 4.5.

\begin{tabular}{|c|c|c|c|c|c|c|c|c|}
\hline Operação & Percentil & L & O & B & LO & LB & OB & LOB \\
\hline leitura & 10 & 92 & 0 & 3 & 0 & 0 & 2 & 3 \\
\hline leitura & 90 & 98 & 0 & 1 & 0 & 0 & 0 & 0 \\
\hline escrita & 10 & 87 & 11 & 0 & 1 & 1 & 0 & 0 \\
\hline escrita & 90 & 99 & 0 & 0 & 0 & 0 & 0 & 0 \\
\hline
\end{tabular}

Tabela 4.5: Estudo para tamanho dos buffers de transmissão e recepção. L representa a latência, $O$ representa a taxa de reordenação de pacotes e B representa o tamanho dos buffers.

Como o tamanho dos buffers não afetou o desempenho, a opção foi por configurá-los seguindo as recomendações, assim o valor fixado foi:

- Proporção entre tamanho dos buffers e BDP: 2

Feito isso, o procedimento de otimização da WAN estava finalizado e os experimentos para rede foram executados. Este estudo usou a mesma configuração de modo e localidade que o estudo para tamanho de buffers, pelo mesmo motivo. Os níveis inicialmente selecionados para fatores de rede foram:

- Latência da WAN (ms): 100 e 300

- Jitter da WAN (\%): 1 e 60

- Taxa de perda de pacotes na WAN (\%): 0,01 e 0,3

- Taxa de duplicação de pacotes na WAN (\%): 0,05 e 5

- Taxa de reordenação de pacotes na WAN (\%): 0,05 e 5

- Variante do TCP: CUBIC e H-TCP

Os níveis de latência foram baseados em um estudo que relata as latências entre os centros de processamento de dados dos Amazon Web Services [SPAL11]. Os centros de processamento de dados considerados são Califórnia (EUA - Costa Oeste), Virginia (EUA - Costa Leste), Irlanda e Singapura. A menor latência observada foi $82 \mathrm{~ms}$ entre os centros de processamento de dados dos EUA e a maior foi $277 \mathrm{~ms}$ entre Irlanda e Singapura.

O mesmo estudo usado para latência apresenta um gráfico com grandes variações de latência, chegando a máximos de até 3 ordens de grandeza em alguns períodos curtos. O projeto PingER ${ }^{8}$ [Pin13], por sua vez, mostra em janeiro de 2013 uma média de latência de 238,062 ms com desvio padrão de 142,996 , o que resulta em uma variação de $60 \%$. Os 11 meses anteriores apresentavam valores semelhantes.

As taxas de perda também foram escolhidas com base em medidas pelo projeto PingER. A mediana das perdas medidas em janeiro de 2013 foi $0,119 \%$ e a mediana do último ano foi $0,178 \%$. O mesmo relatório mostra perdas bem mais altas em medições específicas, mas este trabalho considerou que a WAN entre os dois centros de processamento de dados é de boa qualidade, portanto não apresentaria taxas de perda muito altas.

\footnotetext{
${ }^{8}$ Ping End-to-end Reporting (Relatório de Ping Fim-a-fim) é um projeto de Stanford que monitora o desempenho fim-a-fim de enlaces de Internet, em 700 sítios e 160 países.
} 
O mesmo estudo mostra taxas de duplicação de pacotes muitos baixas (0\%). Embora os valores usados neste estudo tenham sido muito grandes, duplicação de pacotes não influenciou a resposta (ver abaixo).

Duas referências sobre reordenação de pacotes foram encontradas. A primeira, o projeto PingER, mostra taxas muito baixas - em janeiro de 2013, média de 0,006\% e mediana de 0\%. Estudo realizado em 2003 entre sítios na China mostra taxas de reordenação de pacotes de 3,187\% [WLL04]. Os valores usados no experimento foram maiores, mas mesmo assim reordenação de pacotes não influenciou a resposta (ver abaixo).

Tanto H-TCP [LS04] quanto CUBIC [HRX08] foram projetados com foco em redes com largura de banda e latências grandes (BDP alto). Ambos já estavam disponíveis no Linux usado nos experimentos, sendo que o TCP CUBIC é o padrão do kernel do Linux a partir da versão 2.6.19. Eles foram escolhidos pois são citados nas referências sobre otimizações da pilha TCP para WANs [Jon06, ESN].

No emulador de rede, a latência define o mínimo e a variação o máximo a que ela pode chegar. Por exemplo, ao fazer a configuração de $100 \mathrm{~ms}$ de latência e $60 \%$ de variação, o emulador vai gerar valores entre $100 \mathrm{~ms}$ e $160 \mathrm{~ms}$ aleatoriamente. Mas redes não apresentam uma variação aleatória de latência e é possível configurar uma distribuição da latência no emulador. No caso deste estudo, foi usada a distribuição normal. Além disso, o emulador foi configurado com $100 \mathrm{Mb} / \mathrm{s}$ como largura de banda da WAN (ver Subseção 4.3.2).

O resultado do estudo está na Tabela 4.6. Com exceção dos fatores e da interação entre latência e jitter, todas as outras colunas apresentavam valores nulos e foram suprimidas. As respostas das requisições locais apresentaram $\mathrm{CVs}$ de $1 \%$, portanto as respectivas linhas também foram suprimidas.

\begin{tabular}{|c|c|c|c|c|c|c|c|c|}
\hline Operação & Percentil & L & J & P & D & O & C & LJ \\
\hline leitura & 90 & 72 & 21 & 1 & 0 & 0 & 0 & 6 \\
\hline escrita & 90 & 69 & 23 & 1 & 0 & 0 & 0 & 6 \\
\hline
\end{tabular}

Tabela 4.6: Estudo para fatores de rede. L representa a latência, $J$ representa o jitter, $P$ representa as taxa de perdas, $D$ representa a taxa de pacotes duplicados, $O$ representa a taxa de pacotes fora de ordem e $C$ representa o algoritmo de congestionamento. A soma para escritas não é $100 \%$ devido a arredondamento.

A latência, o jitter e a interação de primeira ordem entre eles respondem por $100 \%$ dos resultados. Assim, os níveis escolhidos para esses fatores nos experimentos foram:

- Latência da WAN (ms): 0, 100, 200 e 300

- Jitter da WAN (\%): 0 e 60

Níveis nulos de latência e jitter equivalem a ter todo o sistema operando em uma rede local. Os resultados obtidos para esses casos foram usados como auxílio na interpretação dos resultados, mas não foram considerados na análise final dado que sistemas georeplicados, por definição, não operam nessas condições.

Os valores fixados dos fatores desconsiderados foram:

- Taxa de perda de pacotes na WAN (\%): 0

- Taxa de duplicação de pacotes na WAN (\%): 0

- Taxa de reordenação de pacotes na WAN (\%): 0

- Variante de TCP: CUBIC 
Taxas de perda, duplicação e reordenação de pacotes foram ignoradas no estudo final. O algoritmo de congestionamento foi fixado como CUBIC, pois esse é o padrão no sistema Linux utilizado nos experimentos.

Apesar da taxa de reordenação de pacotes ser fixada, a ocorrência de alguns pacotes fora de ordem é possível dada o jitter. Por exemplo, com uma latência de $100 \mathrm{~ms}$ e jitter de $50 \%$, é possível que o emulador aplique atrasos de $120 \mathrm{~ms}$ para um pacote e $80 \mathrm{~ms}$ para um outro no mesmo milissegundo, o que faz com que o segundo pacote seja transmitido antes do primeiro.

Um comentário final é que o mesmo estudo havia sido realizado anteriormente com níveis de perda de pacotes $0,01 \%$ e $1 \%$. Nesse estudo, a perda de pacotes era mais influente até do que o jitter. Mas como redes normalmente não apresentam taxas de perda de pacotes tão altas quanto $1 \%$, o estudo foi refeito com nível máximo de $0,1 \%$ e a perda de pacotes não afetou o resultado nesse caso.

\subsubsection{Fatores de carga de trabalho}

Juntamente com o estudo para fatores de rede, o estudo para fatores de carga de trabalho era um dos mais importantes, dado o objetivo deste trabalho. Os experimentos também consideraram a latência como fator para verificar a importância relativa entre os fatores de carga de trabalho e a rede.

A partir disso, os níveis selecionados para carga de trabalho foram:

- Relação leitura/escrita: 2:1 e 10:1

- Popularidade dos objetos: uniforme (a taxa de chegada de requisições média para cada objeto é a mesma) e concentrada (a taxa de chegada segue uma distribuição Pareto)

- Localidade (\%): 50 e 90

A relação leitura/escrita 2:1 representa uma carga balanceada entre os dois tipos de operações e a 10:1 representa uma carga intensiva de leituras. A consistência na linha do tempo pode tornar um sistema sob cargas com um maior número de escritas inviável pois as escritas se tornam indisponíveis em caso de falha. Assim, este estudo considera situações em que ela é competitiva quando comparada com a consistência em momento indeterminado, por isso as relações leitura/escrita usadas resultavam em mais leituras que escritas. Além disso, ao atualizar um objeto na consistência em momento indeterminado, é necessário o envio do relógio vetorial, por isso uma leitura ${ }^{9}$ é realizada pelo benchmark antes de toda atualização. Isso restringe a quantidade de escritas a um máximo de $50 \%$ da carga de trabalho.

A popularidade dos objetos uniforme representa uma taxa de chegada de requisições média igual entre os objetos e concentrada representa uma taxa de chegada que segue uma distribuição Pareto.

Os níveis de localidade foram escolhidos de modo a ter situações sem influência de localidade $(50 \%)$ e com localidade alta (90\%). O valor de localidade alta é baseado no relatado em estudo feito pelo Yahoo! em seus sistemas de produção [CRS $\left.{ }^{+} 08\right]$.

Como os modos possuem comportamentos diferentes para requisições locais e remotas, os experimentos foram executados para cada modo. O resultado para requisições locais apresentaram CVs em torno de 0,02 para todos os modos. Isso indica que requisições locais não sofrem influência de nenhum dos fatores. Já requisições remotas apresentaram CVs de aproximadamente $50 \%$ e influência da latência de $100 \%$ para ind2, $l t_{-}$qqer e $l t_{-} r e c$ (ind1 não tem requisições remotas).

A análise da relação leitura/escrita e localidade não usou percentis, mas sim a média do tempo de resposta de todas as requisições (leituras e escritas). Isso porque o primeiro fator diz respeito à composição entre leituras e escritas e o segundo à composição entre requisições locais e remotas, portanto esses fatores não fazem sentido nos percentis separados por tipo de requisição. Por exemplo, com localidade de $50 \%$ percebe-se que o percentil 70 representa requisições remotas, enquanto com

\footnotetext{
${ }^{9}$ É possível fazer atualizações sem relógio vetorial, mas isso cria versões concorrentes do mesmo objeto.
} 
localidade de $90 \%$ o mesmo percentil representa requisições locais. Se a análise fosse feita por percentis, essa informação se perderia e localidade nunca teria influência. O resultado do estudo está na Tabela 4.7

\begin{tabular}{|c|c|c|c|c|c|c|c|c|c|c|c|c|c|c|c|}
\hline Modo & $\mathrm{R}$ & $\mathrm{X}$ & $\mathrm{P}$ & $\mathrm{L}$ & $\mathrm{RX}$ & $\mathrm{RP}$ & $\mathrm{RL}$ & $\mathrm{XP}$ & $\mathrm{XL}$ & $\mathrm{PL}$ & $\mathrm{RXP}$ & $\mathrm{RXL}$ & $\mathrm{RPL}$ & XPL & RXPL \\
\hline ind1 & 19 & 12 & 2 & 31 & 0 & 3 & 2 & 4 & 6 & 6 & 4 & 0 & 0 & 8 & 1 \\
\hline ind2 & 50 & 0 & 0 & 39 & 0 & 0 & 11 & 0 & 0 & 0 & 0 & 0 & 0 & 0 & 0 \\
\hline lt_qqer & 25 & 30 & 0 & 19 & 9 & 0 & 6 & 0 & 8 & 0 & 0 & 3 & 0 & 0 & 0 \\
\hline lt_rec & 0 & 53 & 0 & 34 & 0 & 0 & 0 & 0 & 13 & 0 & 0 & 0 & 0 & 0 & 0 \\
\hline
\end{tabular}

Tabela 4.7: Estudo para fatores de carga de trabalho. $R$ representa a relação leitura/escrita, $X$ representa a localidade, $P$ representa a popularidade e $L$ representa a latência de rede.

Como esperado, localidade e latência influenciam as respostas em geral. Uma observação é o fato de inclusive ind1 ser afetada por latência. Isso provavelmente é resultado dos mecanismos de replicação e correção de leituras serem afetados pela latência.

O impacto de popularidade dos objetos é praticamente nulo. Talvez em uma situação em que o sistema recebesse uma carga maior, como no caso de um teste de sobrecarga, esse fator passasse a ser influente. Como não é o caso, ele foi desconsiderado e fixado no valor que simplifica o entendimento dos resultados. Em trabalhos futuros, experimentos podem ser realizados com o sistema sob carga mais alta para verificar se a influência de popularidade aumenta.

Apesar de alguns modos aparentemente sofrerem impacto considerável da relação leitura/escrita, esse impacto é consequência da relação entre requisições locais e remotas. Para ind1, tanto leituras quanto escritas são locais e a relação leitura/escrita e suas interações com outros fatores impacta pouco esse modo. Para $l t_{-}$rec, leituras e escritas são locais ou remotas dependendo da localidade e a relação leitura/escrita não impacta esse modo. Para ind2, todas as leituras são locais e metade das escritas é remota, portanto quando a relação leitura/escrita muda, a relação entre requisições locais e remotas muda proporcionalmente - como esperado, esse modo é impactado pela relação leitura/escrita. A mesma observação vale para lt_qqer, que tem todas as leituras locais e escritas dependendo da localidade, e também sofre impacto da relação leitura/escrita.

Caso o mecanismo de armazenamento fosse disco em vez de memória, a relação leitura/escrita provavelmente sofreria impacto de fato. Isso porque escritas seriam afetadas pelo tempo de escrita no disco, enquanto leituras poderiam ser mais rápidas pois parte delas seriam servidas a partir do cache de disco. Mas como não é esse o caso, a diferença relevante é a relação entre requisições locais e remotas.

Dessa forma, só foram escolhidos níveis para localidade:

- Localidade (\%): 50 e 90

Os valores fixados dos fatores desconsiderados foram:

- Relação leitura/escrita: 2:1

- Popularidade dos objetos: uniforme

O valor da relação leitura/escrita é um balanço razoável entre leituras e escritas. O valor de popularidade é o mais simples para a interpretação dos resultados.

\subsection{Fatores Selecionados}

Os fatores selecionados nos estudos $2^{\mathrm{k}}$ compuseram o estudo final e são apresentados junto com seus níveis na Tabela 4.8 .

Esse número de fatores e níveis resultou em um total de 64 experimentos. 


\begin{tabular}{|l|c|c|}
\hline \multicolumn{1}{|c|}{ Fator } & Níveis & Total de níveis \\
\hline Modo & ind1, ind2, t_ $_{-} q q e r$ e $l t_{-}$rec & 4 \\
\hline Latência da WAN (ms) & $0,100,200$ e 300 & 4 \\
\hline Jitter da WAN $(\%)$ & 0 e 60 & 2 \\
\hline Localidade & 0,5 e 0,9 & 2 \\
\hline
\end{tabular}

Tabela 4.8: Fatores e níveis do estudo final. 


\section{Capítulo 5}

\section{Aspectos Técnicos}

A preparação dos experimentos envolveu predominantemente atividades de programação e administração de sistemas, como implementação da consistência na linha do tempo e de scripts para a execução e análise dos experimentos. A reprodutibilidade do estudo foi um ponto levado em consideração em diversos momentos da implementação, em especial no caso dos scripts.

A Seção 5.1 trata da implementação da consistência na linha do tempo e de outras modificações no Riak. A Seção 5.2 descreve as modificações feitas no Basho Bench, benchmark usado nos experimentos. A Seção 5.3 apresenta o ambiente em que os experimentos foram executados. A Seção 5.4 trata da emulação da WAN. Por fim, a Seção 5.4.2 trata dos scripts usados na automatização e análise dos experimentos.

\subsection{Modificações no Riak}

Consistência na linha do tempo foi implementada no Riak pelo autor deste trabalho, no módulo riak_kv. Para os experimentos, a distinção entre leituras e escritas era importante. Mas a distinção entre os tipos de escrita (inserção, atualização ou remoção) não era tão importante dado que eles se comportam basicamente da mesma forma do ponto de vista de tráfego de rede local versus remoto. Assim, apenas atualizações foram implementadas de forma completa e eficiente, distinguindo a localização de cada nó com relação aos centros de processamento de dados. As inserções para uma dada chave ocorrem sempre pela mesma réplica, mesmo que isso signifique encaminhar para outro centro de processamento de dados uma requisição que, em princípio, poderia ser tratada localmente. Esse procedimento eliminou a necessidade de implementação de um mecanismo para evitar conflitos de inserção. Apesar de inserções serem ineficientes, isso não afetou os resultados, dado que os experimentos usam inserção apenas na carga e aquecimento do sistema (ver o fluxo de trabalho na Subseção 5.4.2). Remoções não foram implementadas.

O PNUTS conta com uma heurística que explora a localidade de requisições, simples mas importante para o desempenho da consistência na linha do tempo: a réplica mestre migra para o centro de processamento de dados de onde vieram as últimas escritas. Essa heurística foi implementada no Riak para este estudo.

A implementação da consistência na linha do tempo foi baseada na da consistência em momento indeterminado já disponível no Riak. Durante a implementação houve a preocupação em manter o código das duas o mais próximo possível de forma a eliminar diferenças dos tempos de execução dos dois modelos.

Por último, outras alterações menores no riak_kv foram o tratamento de parâmetros extras na interface HTTP, necessários para a consistência na linha do tempo, e a implementação de estatísticas de migrações.

A versão do riak_kv usada como base foi a 1.1. Durante a fase inicial de desenvolvimento as modificações feitas não estavam em um sistema de controle de versão. A partir do momento em que o git passou a ser usado, foram 2011 linhas inseridas e 222 removidas nos seguintes 11 arquivos: 
- riak_client.erl

- riak_kv_get_fsm.erl

- riak_kv_get_fsm_sup.erl

- riak_kv_put_fsm_sup.erl

- riak_kv_put_fsm.erl

- riak_kv_stat.erl

- riak_kv_timeline_get_core.erl

- riak_kv_timeline_get_fsm.erl

- riak_kv_timeline_put_fsm.erl

- riak_kv_wm_raw.hrl

- riak_kv_wm_worker.erl

Desses arquivos, os únicos que não estavam originalmente no riak_kv são os três com a implementação da consistência na linha do tempo: riak_kv_timeline_get_core.erl (237 linhas), riak_kv_timeline_get_fsm.erl (528 linhas) e riak_kv_timeline_put_fsm.erl (900 linhas). A maior parte dessas linhas foi retirada da implementação original da consistência em momento indeterminado. As modificações feitas no riak_kv se encontram em https://github.com/mdediana/riak_kv. git.

Além do riak_kv, outro módulo alterado foi o riak_core, responsável pelo roteamento de requisições em um aglomerado de Riak. Quando o Riak recebe uma requisição, ele define qual o nó responsável por tratá-la por meio do algoritmo de espalhamento consistente, que se baseia no valor da chave do objeto. O Riak foi projetado para ser implantado em um único centro de processamento de dados ${ }^{1}$, portanto o algoritmo não leva em consideração os centros de processamento de dados no momento de decidir para qual das réplicas a requisição deve seguir. Dessa forma, algumas modificações foram necessárias no riak_core para que ele priorizasse nós do mesmo centro de processamento de dados em que a requisição chegou. Além disso, modificações foram feitas para garantir que existisse ao menos uma réplica de cada objeto em cada centro de processamento de dados. A implementação é muito simples e pouco versátil, funcionando apenas para o cenário do estudo, de apenas dois centros de processamento de dados (ver seção 4.3) e baseada nos nomes dos nós para saber em qual centro de processamento de dados cada um deles se encontra.

A partir do momento em que o git passou a ser usado para controle de versão, foram 106 linhas inseridas e 17 removidas nos seguintes 5 arquivos:

- riak_core.app (diretório ebin)

- riak_core_apl.erl

- riak_core_claim_2_dcs.erl

As modificações feitas no riak_core se encontram em https://github.com/mdediana/riak_core. git.

Por fim, os testes foram executados manualmente. Os principais cenários testados (CPD se refere a centro de processamento de dados) foram:

- Requisição de inserção a partir do CPD1 ocorrendo no CPD1

\footnotetext{
${ }^{1}$ A versão Enterprise do Riak implementa replicação entre centros de processamento de dados, mas é paga.
} 
- Requisição de inserção a partir do CPD1 sendo redirecionada para o CPD2

- Verificação de que inserções resultavam em ao menos uma réplica em cada centro de processamento de dados

- Requisição de leitura/atualização a partir do CPD1 sempre ocorrendo no CPD1 para consistência em momento indeterminado (local)

- Requisição de leitura de "qualquer versão" a partir do CPD1 sempre ocorrendo no CPD1 para consistência na linha do tempo (local)

- Requisição de leitura da "versão mais recente"/atualização a partir do CPD1 sendo redirecionada para a réplica mestre no CPD1 para consistência na linha do tempo (local)

- Requisição de leitura da "versão mais recente"/atualização a partir do CPD1 sendo redirecionada para a réplica mestre no CPD2 para consistência na linha do tempo (remota)

- $L M$ requisições de atualização a partir do CPD1 de um objeto no CPD2 resultando em migração da réplica mestre para o CPD2, onde $L M$ é o limiar de migração

- Requisição de atualização sendo redirecionada para uma réplica mestre ao mesmo tempo em que a réplica mestre migra (a requisição é redirecionada para a nova réplica mestre)

\subsection{Benchmark}

O benchmark usado foi o Basho Bench [Bas], específico para o Riak. Ele provê configurações para quantidade de clientes concorrentes (threads), relação leitura/escrita, popularidade dos objetos acessados, entre outras. O benchmark originalmente não era distribuído, portanto foi modificado pois mais de uma instância precisava ser executada simultaneamente nos experimentos. Além de evitar gargalos no benchmark, isso era importante para a implementação de localidade. Além disso, foi necessária a implementação de um pequeno programa em Erlang (basho_bench_dist) para a consolidação dos dados obtidos pelas diversas instâncias do Basho Bench. Parte dessa consolidação envolveu a fusão de histogramas usados pelo Basho Bench, que por sua vez usavam o projeto basho_stats, que também precisou ser modificado.

Outro benchmark considerado foi o $\mathrm{YCSB}^{2}\left[\mathrm{CST}^{+} 10\right]$. Apesar de possuir mais flexibilidade que o Basho Bench nas suas configurações, ele não estava preparado para acessar o Riak, acesso esse que precisaria ser implementado. Além disso, ele também não oferecia muitas das funcionalidades necessárias para os experimentos, que precisariam ser implementadas.

A partir do momento em que o git passou a ser usado para controle de versão, foram 90 linhas inseridas e 17 removidas nos seguintes 3 arquivos do Basho Bench:

- basho_bench.app.src

- basho_bench_driver_http_raw.erl

- basho_bench_keygen.erl

- basho_bench_stats.erl

- basho_bench_worker.erl

No basho_stats, foram 77 linhas inseridas e 35 removidas nos seguintes 2 arquivos:

- basho_stats_histogram.erl

- basho_stats_sample.erl

\footnotetext{
${ }^{2}$ git://github.com/brianfrankcooper/YCSB.git
} 
Por último, o basho_bench_dist é composto por um único arquivo (basho_bench_dist.erl) de 149 linhas, muitas das quais foram copiadas do Basho Bench.

As alteração feitas no Basho Bench estão em https://github.com/mdediana/basho_bench.git, o basho_bench_dist se encontra em https://github.com/mdediana/basho_bench_dist.git e as modificações do basho_stats em https://github.com/mdediana/basho_stats.git.

\subsection{Ambiente e Imagem}

A operação no Grid'5000 se dá através do acesso ssh ao frontend de cada sítio. Nele o usuário encontra seu diretório home, onde ele armazena seus scripts e dados dos experimentos, e tem acesso a ferramentas específicas da infraestrutura. Como o Grid'5000 é compartilhado por diversos pesquisadores, ele oferece um conjunto de ferramentas $\left(\mathrm{OAR}^{3}\right)$ e regras para que um pesquisador reserve nós físicos por um determinado período de tempo. Além dos nós, é possível reservar IPs para compor sub-redes, recurso utilizado nos experimentos (ver Subseção 5.4). Outra ferramenta bastante utilizada é o kadeploy ${ }^{4}$, responsável pela implantação de imagens nos nós reservados pelo usuário.

A imagem usada nos experimentos foi um Debian GNU/Linux 6.0 (Squeeze) com kernel 2.6.325-amd64 baseado em uma imagem pré-configurada disponibilizada pelo Grid'5000 (squeeze-x64base). Além do conteúdo da imagem base, a imagem usada nos experimentos possui o Erlang R14B04 instalado a partir do fonte, o Riak e o Basho Bench modificados e algumas ferramentas de monitoração e análise de desempenho como sysstat ${ }^{5}$, bwm-ng ${ }^{6}$ e iperf ${ }^{7}$. Uma única imagem foi usada, sendo que a distinção entre nós executando instâncias do Riak ou do Basho Bench foi feita pelos scripts que gerenciam os experimentos (subseção 5.4.2).

Pesquisadores com acesso ao Grid'5000 podem acessar essa imagem, que se encontra no sítio Sophia em /home/madediana/images/squeeze-x64-riak.tgz.

\subsection{Rede}

Os experimentos emularam uma WAN pelo uso da ferramenta traffic control ${ }^{8}$ (tc). Essa ferramenta é usada para manipulação das filas de saída de pacotes de uma interface de rede em sistemas Linux, priorizando um determinado tipo de tráfego, por exemplo. Mais especificamente para emulação da WAN, o netem ${ }^{9}$ foi usado. Ele provê funcionalidade para inserção de latência de rede, variação da latência, perda de pacotes, pacotes duplicados, corrompidos e/ou fora de ordem. Outras ferramentas, como o dummynet ${ }^{10}$ [CR10] e o NISTNet ${ }^{11}$, foram desconsideradas dado que o netem já vem integrado ao tc e satisfazia os requisitos funcionais dos experimentos.

Existem recomendações sobre otimizações de sistemas Linux para quando esses se comunicam por meio de WANs [Jon06, ESN]. Durante os experimentos, sempre que os parâmetros da WAN foram alterados, um script para ajuste da pilha TCP foi usado (para mais detalhes, ver Seção 4.4.5).

\subsubsection{Centros de processamento de dados}

Os experimentos foram planejados para usar dois centros de processamento de dados simulados (ver Seção 4.3). Para simular os centros de processamento de dados, em cada experimento os nós que compunham o sistema eram divididos em dois conjuntos CPD1 e CPD2, cada um representando

\footnotetext{
${ }^{3}$ http://oar.imag.fr/

${ }^{4}$ http://kadeploy.imag.fr/

${ }^{5}$ http://sebastien.godard.pagesperso-orange.fr/

${ }^{6} \mathrm{http}: / /$ www.gropp.org/?id=projects\&sub=bwm-ng

${ }^{7}$ http://iperf.sourceforge.net/

${ }^{8}$ http://linux.die.net/man/8/tc

${ }^{9}$ http://www.linuxfoundation.org/collaborate/workgroups/networking/

${ }^{10} \mathrm{http}: / /$ info.iet.unipi.it/ luigi/dummynet/

${ }^{11}$ http://snad.ncsl.nist.gov/itg/nistnet/
} 
um centro de processamento de dados. Além dos nós, duas sub-redes SR1 e SR2 eram reservadas. Cada nó de CPD1 recebia, além de seu IP da rede do Grid'5000, um IP de SR1, o mesmo valendo para CPD2 e SR2.

Sistemas Linux usam o arquivo /etc/hosts como fonte primária para resolução de nomes, consultando um DNS apenas quando não encontram um nome definido ali (o que é a situação mais comum). Todos os nós no Grid'5000 possuem um nome registrado no DNS que aponta para o seu IP da rede do Grid'5000. Nos experimentos, dois arquivos hosts1 e hosts2 eram criados e substituíam o /etc/hosts dos nós de CPD1 e CPD2 respectivamente. O conteúdo de hosts1 eram os nomes dos nós de CPD2 sendo resolvidos para os IPs de SR2, o mesmo valendo para hosts2, CPD1 e SR1. Com isso, os nós de CPD1 resolviam os nomes dos nós de CPD2 para os IPs de SR2 e vice-versa. O resultado dessa configuração é que todas as requisições que saíam de um centro de processamento de dados para o outro usavam o IP da sub-rede de destino, enquanto as requisições para o mesmo centro de processamento de dados usavam o IP da rede do Grid'5000.

A partir dessa configuração foi possível adicionar um filtro baseado em sub-redes ao tc de modo que as características de WAN eram aplicadas às requisições que saíam para o outro centro de processamento de dados, enquanto as requisições para o mesmo centro de processamento de dados saíam inalteradas. Esse processo é executado pelo script net (ver Subseção 5.4.2).

\subsubsection{Execução e análise dos experimentos}

A automatização dos experimentos foi feita com dois conjuntos de scripts. O primeiro $(\mathrm{cmb})$ foi usado para gerenciamento e execução dos experimentos - reserva de nós, implantação da imagem, gerenciamento do sistema de armazenamento, configuração e execução do benchmark e coleta dos resultados. Os scripts se localizavam no frontend do Grid'5000 e foram escritos em bash. Esses scripts implementavam o fluxo de trabalho do estudo (ver Seção 3.7). O segundo conjunto (cmblocal) foi usado na análise dos dados, se localizava no computador do autor deste trabalho e era composto por scripts em bash, Ruby e R.

Os scripts em cmb se encontram em https://github.com/mdediana/cmb.git e os em cmb-local se encontram em https://github.com/mdediana/cmb-local.git. 


\section{Capítulo 6}

\section{Análise dos Resultados}

O estudo final foi um estudo fatorial completo (ver Subseção 3.8). A sua execução foi rápida e usou poucos recursos devido aos estudos fatoriais $2^{\mathrm{k}}$ feitos para triagem dos fatores - a execução de uma repetição do estudo final demorava 6,5 horas. O pequeno número de fatores e níveis foi importante para uma análise consistente dos resultados. Esse fato é enfatizado pela principal referência metodológica usada neste trabalho [Jai91] e também foi sugerido para o autor deste trabalho em conversa com o pesquisador visitante no IME Jean-Marc Vincent, que possui grande experiência em estudos de desempenho.

O nível de confiança do estudo relativo ao tamanho da amostra está descrito na Seção 6.1, a Seção 6.2 mostra a análise dos tempos de resposta, a Seção 6.3, a análise dos conflitos e a Seção 6.4, a análise das migrações. A Seção 6.5 descreve as ameaças à validade levantadas e, por fim, a Seção 6.6 apresenta os trabalhos relacionados.

\subsection{Nível de Confiança, Exatidão, Tamanho da Amostra e Repli- cações}

O tamanho da amostra de um experimento é dado por [Jai91]:

$n=\left(\frac{100 * z * s}{r * \bar{x}}\right)^{2}$,

onde z é o valor z relativo do nível de confiança desejado, s é o erro padrão, $\mathrm{r}$ é a precisão desejada e $\bar{x}$ é a média da amostra.

O erro padrão indica o quão perto da média da população está a média da amostra, enquando o desvio padrão indica a variação dos indivíduos de uma amostra da média da mesma amostra. $\mathrm{O}$ erro padrão é dado por:

$s=\frac{\sigma}{\sqrt{n}}$,

onde $\sigma$ é o desvio padrão da média e $n$ é o tamanho da amostra.

O nível de confiança determina o intervalo de confiança, que é um intervalo de valores centrado na média e com uma probabilidade de que a média da população esteja incluída nele. Por exemplo, dada uma média $\bar{x}=100 \mathrm{~ms}$, um erro padrão $s=5 \mathrm{~ms}$ e nível de confiança de $95 \%(z=1,960)$, o intervalo de confiança é $(100-1,960 * 5,100+1,960 * 5)=(90,2,109,8)$, o que significa que existe 95\% de chance de a média da população estar nesse intervalo, ou que de cada 100 repetições do experimento, 95 terão a média dentro desse intervalo.

A exatidão indica qual a distância entre a média observada e a média da população. No caso, a exatidão é aplicada ao intervalo de confiança, portanto o cálculo do intervalo acima com uma exatidão de $1 \%$ passa a ser $(100 *(1-0,01)-1,960 * 5,100 *(1+0,01)+1,960 * 5)=(89,2,110,8)$.

O tamanho da amostra depende de conhecer a média e o erro padrão, portanto experimentos precisam ser feitos para uma estimativa desses valores. No caso deste estudo, o valor da média e do erro padrão variavam muito de um experimento para outro. Por exemplo, um experimento em que todas as requisições fossem locais apresentaria média e erro padrão menores do que um experimento em que houvesse um balanço entre requisições locais e remotas. Por isso, a opção foi executar todos os experimentos e depois verificar se o tamanho da amostra estava adequado para cada um deles. 
A configuração do benchmark era baseada em duração, e não em quantidade de requisições, por isso testes exploratórios foram feitos para identificar que duração deveria ser configurada para os experimentos. Com tempo de 3 min e repetindo os experimentos percebeu-se que havia pouca variação de média e erro padrão. O valor mínimo de quantidade de requisições de um experimento foi 76137 , para $l t$ _rec, localidade de $50 \%$ e latência de rede de $300 \mathrm{~ms}$.

Dados esses resultados, foram verificados os tamanhos da amostra dos experimentos. Com precisão de $1 \%$, apenas os experimentos para $l t_{-} r e c$, localidade de $50 \%$ e latência de rede $300 \mathrm{~ms}$ não tinham tamanho da amostra suficiente - para jitter de $0 \%$ o experimento precisaria de 127789 amostras mas tinha 115175, e para jitter de 60\% ele precisaria de 83030 mas tinha 76137 . Se considerado o mesmo nível de confiança, mas exatidão de $2 \%$, todos os experimentos tinham o tamanho da amostra suficiente.

Vale notar que o tamanho da amostra na maioria dos experimentos foi bem maior do que o necessário. Por exemplo, para ind1, localidade de $50 \%$ e latência de $300 \mathrm{~ms}$, foram observadas 358301 amostras quando apenas 933 seriam suficientes. Isso significa que os experimentos poderiam ser executados em bem menos tempo caso o benchmark fosse limitado por quantidade de requisições em vez de tempo ${ }^{1}$.

Normalmente, experimentos são replicados para estimar a variabilidade do fenômeno observado e calcular os erros experimentais. Replicação estatística costuma ser usada quando mais de um grupo é usado como objeto do estudo. Este não é o caso deste estudo, já que o objeto do estudo foi sempre o mesmo. Mas alguma variabilidade poderia ser causada por variação entre os nós usados. Outra causa seria variação no desempenho na LAN do Grid'5000 em diferentes momentos.

Assim, uma replicação do estudo foi feita para estimar a variabilidade dos experimentos. Isso foi feito calculando-se o coeficiente de variabilidade entre as duas replicações de cada experimento. A média dos CVs de todos os experimentos foi $1 \%$ para leituras e 0,8\% para escritas, e o máximo foi $8 \%$ para leituras e $5 \%$ para escritas.

\subsection{Análise dos Tempos de Resposta}

A principal métrica usada neste estudo foi o tempo de resposta. Tomou-se o cuidado de evitar sobrecarregar o sistema, de modo que os tempos de resposta representassem o comportamento do sistema no estado estacionário.

Os resultados para latências de $100 \mathrm{~ms}, 200 \mathrm{~ms}$ e $300 \mathrm{~ms}$ apresentam o mesmo comportamento, portanto a opção foi fazer a análise para um deles apenas. O boxplot para latência de rede de 200 ms está na Figura 6.1. Os casos em que a caixa não aparece indicam que todas as requisições delimitadas pelos bigodes eram locais.

No caso de leituras e localidade de $50 \%$, apenas $l t$ rec apresenta requisições remotas. Uma porção pequena dessas leituras tem tempo de resposta menor que a latência da rede, o que se explica pelo jitter de até $60 \%$.

Para leituras e localidade de $90 \%, l t_{-}$rec é beneficiado, mas continua apresentando requisições remotas (valores atípicos no gráfico).

No caso de escritas e localidade de $50 \%$, lt_ rec apresenta um desempenho um pouco melhor que ind2 e lt_qqer. A explicação provável para isso é o sistema estar menos carregado para esse modo do que os outros, o que acontece pois as leituras de $l t_{-} r e c$ são mais lentas. Esse fato é comprovado pela vazão dos modos $l t_{-}$rec, ev2 e $l t_{-} q q e r$, respectivamente, 594, 1072, 941 operações/s.

Para escritas e localidade de $90 \%$, lt_rec e $l t_{-}$qqer apresentam melhor desempenho devido à localidade, mas ainda apresentam requisições remotas (valores atípicos no gráfico). Já ind2 continua apresentando o mesmo perfil que para localidade de $50 \%$.

Os gráficos das FDAs para latência de rede de 200 ms estão na Figura 6.2. Eles mostram a proporção entre requisições locais e remotas, e confirmam que a localidade define essa proporção para $l t_{-} q q e r$ e $l t_{-}$rec.

\footnotetext{
${ }^{1}$ A limitação da quantidade de requisições foi implementada no benchmark pois era necessária para a etapa de aquecimento, mas não foi usada nos experimentos
} 


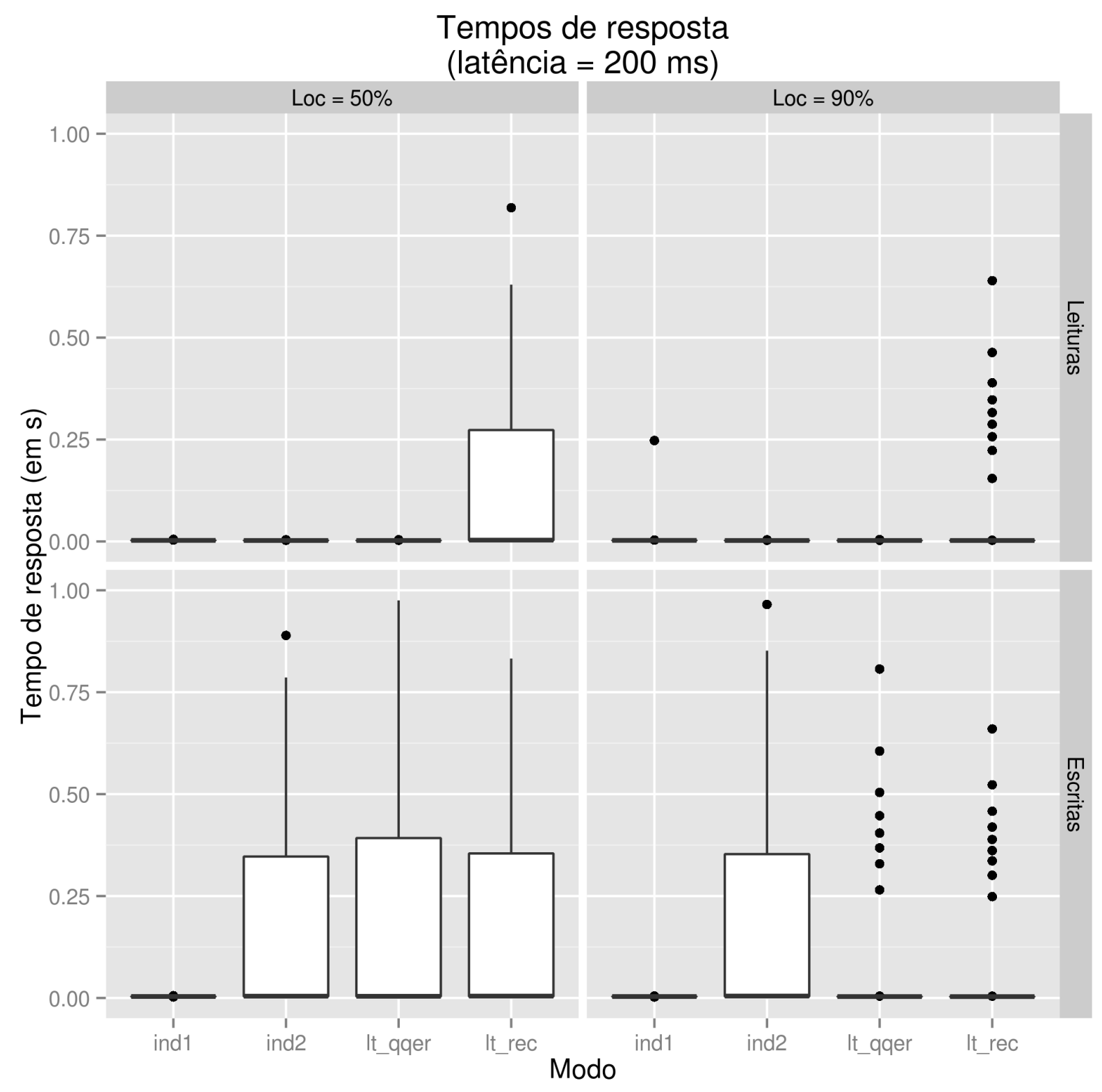

Figura 6.1: Boxplot dos tempos de resposta para latência de rede de $200 \mathrm{~ms}$. 
FDAs

(latência $=200 \mathrm{~ms}$ )

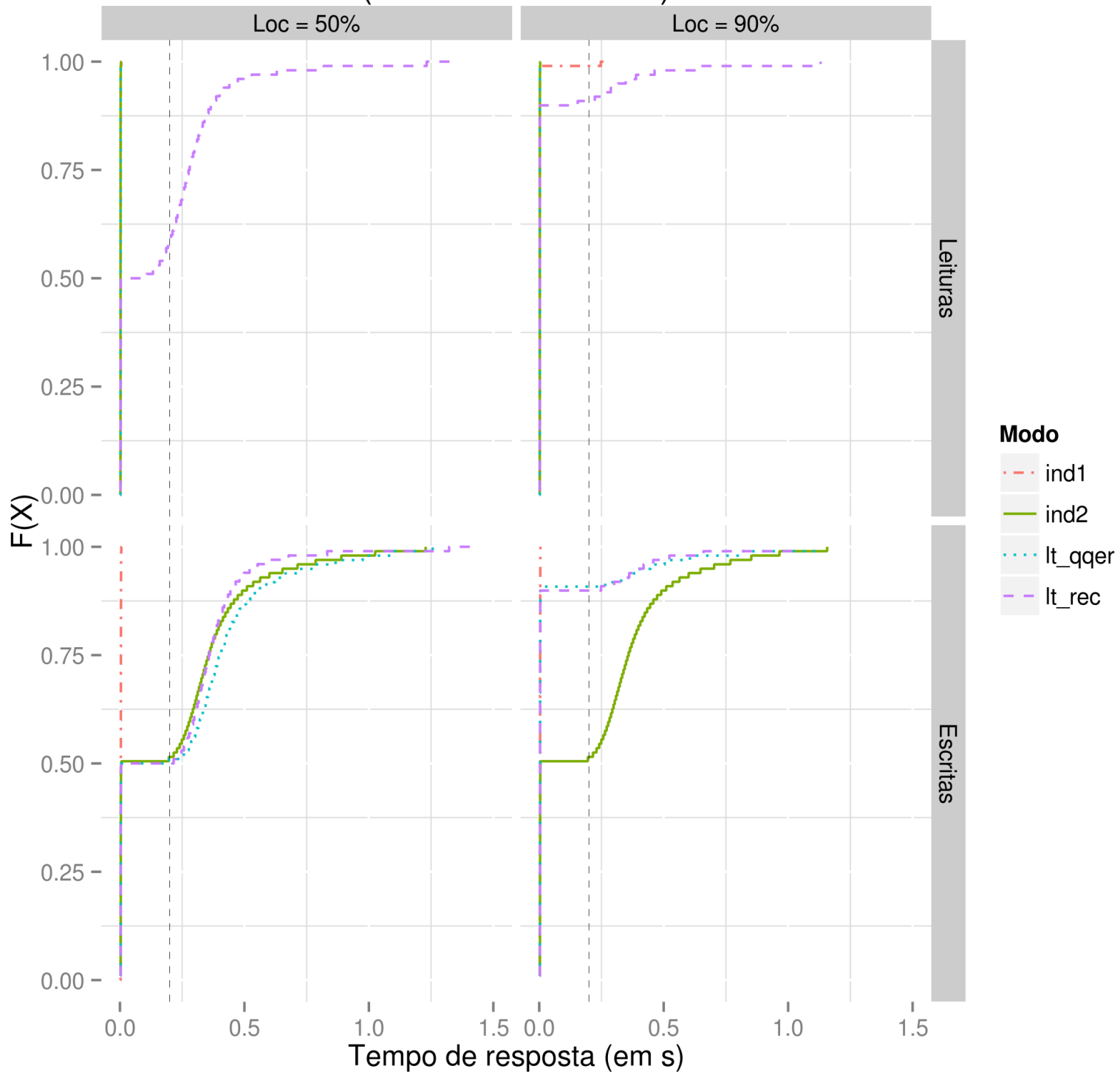

Figura 6.2: FDAs dos tempos de resposta para latência de rede de $200 \mathrm{~ms}$. A linha vertical tracejada indica a latência da rede (200 ms). 
Os ganhos para requisições remotas da consistência na linha do tempo com relação à consistência em momento indeterminado com $W=2$ e latência de rede de $200 \mathrm{~ms}$ se encontram na Tabela 6.1.

\begin{tabular}{|c|c|c|c|}
\hline Percentil & Localidade (\%) & $l t_{-} q q e r$ & $l t_{-} r e c$ \\
\hline 75 & 50 & 0,87 & 1,0 \\
\hline 75 & 90 & 92 & 97 \\
\hline 95 & 50 & 0,77 & 1,3 \\
\hline 95 & 90 & 1,4 & 1,6 \\
\hline
\end{tabular}

Tabela 6.1: Ganhos relativos dos tempos de resposta para os modos lt_qqer e lt_rec com relação a ind2 para latência de $200 \mathrm{~ms}$. O sinal negativo indica perdas.

O valor 1 significa que o desempenho é igual, valores menores que 1 indicam que ind2 apresenta melhor desempenho e valores maiores que 1 indicam que o modo comparado a ind2 apresenta melhor desempenho. Com relação ao percentil 75 e localidade de $50 \%$, os ganhos são altos pois as requisições são locais para $l t_{-} q q e r$ e $l t_{-} r e c$ e são remotas para ind2.

Para efeito de comparação, foi realizado um estudo em que a taxa de chegada era a máxima que o benchmark conseguia gerar (respeitando o número de threads configurado). A Figura 6.3 mostra que apesar de os tempos de resposta subirem em geral, os modos apresentam mesmo comportamento que para taxa de chegada de requisições controlada.

Os modos apresentaram o comportamento esperado. A hipótese de que a consistência na linha do tempo é competitiva em termos de desempenho com a consistência em momento indeterminado se confirma para o caso em que a localidade é alta e principalmente caso leituras de "qualquer versão" sejam usadas.

\subsection{Análise dos Conflitos}

A análise dos conflitos indicou uma proporção muito alta de conflitos, da ordem de $30 \%$, para todos os casos com latência diferente de $0 \mathrm{~ms}$ e variação de latência de $60 \%$. Para jitter de $0 \%$, os conflitos são da ordem de $0,1 \%$.

Esses números resultam da forma como conflitos são contabilizados no Riak. Sempre que uma leitura é feita, ela é enviada para todas as réplicas do objeto requerido. Mesmo após ter retornado uma resposta para o cliente, o coordenador espera as outras leituras para checar se houve conflito - e no caso da consistência em momento indeterminado acionar o mecanismo de resolução de conflitos. Durante os experimentos o mesmo mecanismo foi mantido na consistência na linha do tempo para a contagem de conflitos, mas sem acionar a resolução de conflitos.

No caso em que a latência é $0 \mathrm{~ms}$, as respostas das réplicas para o coordenador chegam em instantes muito próximos. Já quando existe latência, as réplicas no mesmo centro de processamento de dados respondem rapidamente, enquanto as remotas demoram centenas de milissegundos. Quando não há jitter, duas requisições saindo de um CPD chegam no outro CPD na ordem em que foram emitidas. Mas quando há jitter, é possível que a segunda chegue antes da primeira.

O benchmark emite uma leitura antes de toda escrita (ver Subseção 4.4.6). Considerando que o tempo de requisições locais é sempre muito baixo, algumas escritas emitidas pelo benchmark chegam ao outro centro de dados antes da leitura - o tempo de uma requisição local é de 2 a $4 \mathrm{~ms}$, e o tempo de uma requisição remota com latência de rede de $100 \mathrm{~ms}$, por exemplo, varia de 100 a 160 ms. No caso em que a escrita chega antes da leitura, a leitura retorna o valor que acabou de ser escrito para o coordenador, que por sua vez identifica o conflito.

Estudos foram feitos com outros valores de jitter de $5 \%, 15 \%, 30 \%$ e $45 \%$, e com exceção da variação de $5 \%$, que apresentou $17 \%$ de conflitos, todos apresentaram valores de conflitos acima de $30 \%$.

Esse comportamento é um problema para a consistência em momento indeterminado em uma WAN, pois muitas vezes ela vai acionar o mecanismo de resolução de conflitos desnecessariamente, 


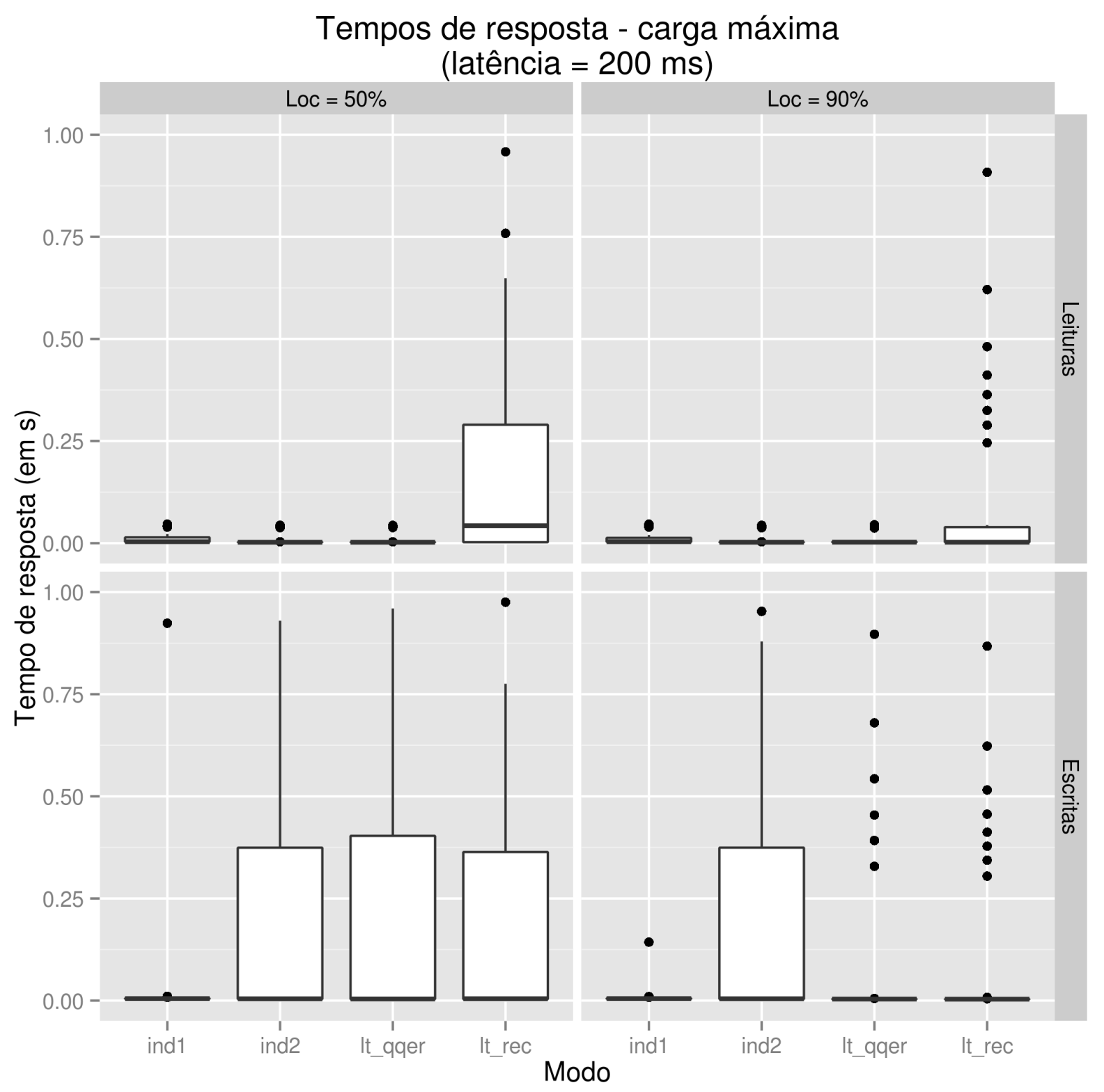

Figura 6.3: Boxplot dos tempos de resposta para latência de rede de 200 ms com taxa de chegada máxima. 
resultando em duas escritas consecutivas na réplica remota.

Apesar de as proporções de conflitos serem semelhantes para os dois modelos de consistência, não se pode dizer que a hipótese foi confirmada. A hipótese considerava que os conflitos seriam resultado da carga de trabalho, e não do fato de que toda escrita é precedida de uma leitura.

\subsection{Análise das Migrações}

A análise de migrações foi bastante simples, apenas confirmando o comportamento observado no aquecimento (ver Subseção 4.4.2). As migrações para consistência na linha do tempo para localidade de $50 \%$ são todas da ordem de $7,1 \%$ do total de requisições, enquanto para localidade de $90 \%$ são de $0,18 \%$.

\subsection{Ameaças à Validade}

Muitos parâmetros foram fixados e fatores tidos como influentes foram desconsiderados (ver Capítulo 4). Com isso, estudos que usem outros valores para os parâmetros ou considerem outros fatores podem apresentar resultados diferentes. Isso vale particularmente para a quantidade de nós do sistema, que apareceu com influência relativamente alta (ver Subseção 4.4.3). Além disso, um estudo é limitado pelos níveis usados [Jai91].Por exemplo, um estudo $2^{\mathrm{k}}$ havia mostrado influência alta da perda de pacotes usando $1 \%$ como nível (ver Subseção 4.4.5). Com isso, este estudo provavelmente apresentaria resultados diferentes caso fosse feito com taxas de perda de pacotes nesse nível.

Os experimentos consideraram que todos os nós sempre operaram sem falhas (ver Subseçao 3.2). Os resultados de experimentos com o sistema operando em algum modo de falha (desde a falha de um nó até de um centro de processamento de dados inteiro) devem ser diferentes dos obtidos nesse estudo.

O Riak usa uma arquitetura muito semelhante à descrita no artigo sobre o Dynamo. Com isso, os modelos de consistência usados nos experimentos podem apresentar resultados diferentes em sistemas que usem outras arquiteturas, embora o desempenho analisado neste estudo foi mais afetado for fatores de rede e carga de trabalho.

\subsection{Trabalhos Relacionados}

Uma abordagem comum na literatura de sistemas distribuídos é a proposta de um novo conceito e a implementação de um sistema que use esse conceito seguida de uma análise de seu desempenho. Tanto o artigo sobre o Dynamo [DHJ ${ }^{+} 07$ ] quanto o sobre o PNUTS [CRS ${ }^{+} 08$ ] apresentam análises de desempenho, sendo que apenas o segundo faz uma análise baseada na carga de trabalho. Há uma segunda publicação com experimentos com o PNUTS que analisa o consumo de banda de diferentes políticas de replicação em uma WAN [KCCL11].

Muitos trabalhos apresentam análises de desempenho de sistemas de armazenamento que usam replicação sobre WANs. Na maior parte dos casos, o objetivo desses sistemas é provar outros conceitos além da eficiência do modelo de consistência escolhido por eles. O COPS usa consistência causal+, que é semelhante à consistência causal com algumas garantia a mais, e implementa transações [LFKA11]. O Scatter propõe uma arquitetura ao mesmo tempo escalável e com consistência forte [GBKA11]. O Zeno usa consistência em momento indeterminado e é tolerante a falhas bizantinas ${ }^{2}$ [SFK $\left.{ }^{+} 09\right]$. O Windows Azure provê um sistema de armazenamento na nuvem com consistência forte $\left[\mathrm{CWO}^{+} 11\right]$. O Megastore usa Paxos para implementar consistência forte $\left[\mathrm{BBC}^{+} 11\right]$. Nenhum desses trabalhos apresenta comparações com outros sistemas ou com outros

\footnotetext{
${ }^{2}$ Falhas bizantinas fazem com que o sistema falhe de uma forma diferente que apenas parar de responder requisições. O envio de respostas com valores errados para os clientes é um exemplo de falha bizantina.
} 
modelos de consistência. Como eles não usam uma aplicação para execução de testes ou ambiente comum, é difícil fazer qualquer comparação a partir desses trabalhos.

Beyer et al. realizaram testes para analisar a relação entre as diferentes configurações de consistência no Cassandra e sua disponibilidade e desempenho [BKS $\left.{ }^{+} 11\right]$. Como esperado, eles notam que configurações que oferecem consistência mais rígida apresentam pior desempenho. Renesse e Schneider apresentam resultados experimentais comparando desempenho e disponibilidade de replicação mestre-escravo e replicação em cadeia, cada uma delas usando consistência forte e consistência em momento indeterminado [vRS04]. Nenhum desses estudos leva em consideração operação sobre WAN nem diferentes cargas de trabalho. Yu e Vahdat realizaram uma análise sobre a relação entre disponibilidade e níveis de consistência em sistemas replicados em WANs [YV01]. Eles comparam a disponibilidade de um sistema usando consistência forte e consistência contínua, usando diferentes protocolos de consistência como cópia primária e votação, por exemplo. Esse trabalho não testa consistência em momento indeterminado nem consistência na linha do tempo e não observa o desempenho dos modelos de consistência analisados.

Uma publicação com uma proposta mais próxima da deste trabalho é a comparação feita entre Cassandra, HBase, PNUTS e MySQL particionado horizontalmente usando diferentes cargas de trabalho $\left[\mathrm{CST}^{+} 10\right]$. Os resultados servem como uma comparação entre esses sistemas, mas dizem menos sobre seus modelos de consistência, dado que os sistemas apresentam arquiteturas e configurações diferentes. Além disso, os testes são feitos em uma rede local, não em uma WAN. 


\section{Capítulo 7}

\section{Conclusões}

Este trabalho comparou o desempenho de um mesmo sistema de armazenamento usando consistência em momento indeterminado e consistência na linha do tempo operando em uma WAN. A consistência na linha do tempo se mostrou competitiva com a consistência em momento indeterminado quando a localidade de escritas é alta e quando as leituras são de "qualquer versão" (ver Seção 6.2).

As principais vantagens da linha do tempo sobre a consistência em momento indeterminado são a garantia de que as réplicas não são atualizadas com valores divergentes e a existência de uma réplica mestre que corresponde à versão mais recente. Com isso, desenvolvedores não precisam implementar resolução de conflitos ou ações de compensação na aplicação (ver Seção 2.2). Um cenário particularmente interessante para o uso da consistência na linha do tempo é o caso em que a aplicação tolera inconsistências na maioria das leituras, mas em algumas poucas situações precisa da versão consistente.

A principal desvantagem da consistência na linha do tempo com relação à consistência em momento indeterminado é o fato de a indisponibilidade da réplica mestre por falha do nó ou particionamento da rede impedir escritas e leituras consistentes. Uma outra desvantagem é que mesmo sendo competitiva, ela apresenta variabilidade relativamente alta nos tempos de resposta. Por exemplo, a localidade $90 \%$ implica que $10 \%$ das escritas e $10 \%$ das leituras consistentes são remotas, com tempos de resposta da ordem da latência da rede. Para aplicações em que os requisitos de tempos de resposta são dados pelo percentil 99,9, como é o caso da Amazon [DHJ ${ }^{+}$07], a consistência na linha do tempo não é adequada.

Além da comparação do desempenho, este trabalho apresentou resultados sobre a infuência que diversos fatores têm sobre o desempenho de um sistema de armazenamento operando sobre WAN. Por meio dos experimentos fatoriais $2^{\mathrm{k}}$, descobriu-se quais fatores são mais ou menos influentes para o desempenho desse tipo de sistema (ver Seção 4.4). Por exemplo, verificou-se que a quantidade de objetos armazenados não afeta o desempenho do sistema. Vale notar que as constatações feitas são válidas para o conjunto de valores de parâmetros e níveis testados. Por exemplo, caso o mecanismo de armazenamento fosse disco e não memória, o resultado para influência da quantidade de objetos armazenados provavelmente seria diferente devido à interação entre disco, cache de disco e memória.

Por último, uma consideração sobre a reprodutibilidade deste estudo. Caso um pesquisador queira reproduzir o estudo no Grid'5000, ele tem disponíveis os recursos necessários para tal. Caso ele queira reproduzi-lo em outra plataforma (AWS, por exemplo), ele precisará criar uma nova imagem, o que é simples, dado que a imagem usada neste estudo tem poucos aplicativos e ferramentas instalados e está documentada (ver Seção 5.3). Além disso, alguns poucos scripts para execução do estudo precisariam ser alterados.

\subsection{Contribuições}

As principais contribuições deste trabalho são: 
Comparativo de desempenho entre modelos de consistência A principal contribuição é a constatação de que a consistência na linha do tempo é competitiva em termos de desempenho com a consistência em momento indeterminado em um sistema operando sobre uma WAN e que apresente localidade alta. Quando possível, o uso da consistência na linha do tempo no lugar da consistência em momento indeterminado torna o desenvolvimento do sistema mais simples.

Influência de fatores em sistemas de armazenamento Conhecer quais fatores afetam ou não o desempenho de um sistema de armazenamento ajuda desenvolvedores e administradores de sistemas em decisões sobre planejamento de capacidade e desenvolvimento do sistema (como otimizações, por exemplo).

Infraestrutura de experimentos A infraestrutura de experimentos pode ser reaproveitada (especialmente se o Riak for usado), aumentando a produtividade de pesquisadores realizando estudos semelhantes.

\subsection{Lições Aprendidas}

Além dos conceitos aprendidos sobre sistemas distribuídos, experimentação e análise de desempenho, a implementação e execução deste trabalho também resultou em lições e reflexões:

A arte da análise de desempenho A principal referência metodológica usada neste trabalho considera que a análise de desempenho é uma arte, sugerindo que existem atividades envolvidas nesse tipo de análise que não são facilmente tratáveis metodologicamente. Um exemplo disso é a experiência do autor deste trabalho com a operação no Grid'5000 influenciar a decisão sobre o tamanho do sistema, uma limitação que não foi mensurada com exatidão, mas sim percebida pelo trabalho diário na plataforma (ver Subseção 4.4.3).

O método na análise de desempenho Apesar de a atividade de análise de desempenho possuir características de arte, muito dela é passível de ser sistematizada, importante para a confiabilidade dos resultados e produtividade na execução do estudo. Um exemplo disso foi uma versão anterior do estudo que havia sido executada com problemas não percebidos e foi descartada. Essa primeira versão não usava o método e as técnicas apresentadas em [Jai91]. Ela usava fatores que na segunda versão se mostraram pouco influentes (popularidade dos objetos, por exemplo) e ignorava outros que eram influentes (jitter, por exemplo). Além disso, era composta por 420 experimentos que demoravam aproximadamente $24 \mathrm{~h}$ para serem executados, contra os 64 experimentos e $6,5 \mathrm{~h}$ da segunda versão do estudo, redução que aconteceu pelo uso de experimentos $2^{\mathrm{k}}$ (ver Seção 4.4).

Reprodutibilidade Além de importante para a qualidade da pesquisa, a reprodutibilidade do estudo facilitou executá-lo muitas vezes para comparações e análises. Isso foi consequência de ter o processo automatizado e, portanto, reprodutível. Uma execução completa do estudo consistia em usar um script para a reserva dos nós, outro para a implantação da imagem e um terceiro para executar um estudo.

Importância de ferramentas para pesquisa na área de sistemas Muitas tecnologias foram usadas neste trabalho. Além das linguagens de programação - Erlang, bash, Ruby e R - entender o funcionamento do Linux foi importante. Primeiro, pela questão do gerenciamento do hardware, o que foi importante, por exemplo, para a discussão sobre a relação entre disco, cache de disco e memória (ver Subseção 4.3.1). Depois, pelas suas ferramentas para tarefas de administração de sistema, como top, vmstat, iostat, bwm-ng, etc., que possibilitam um maior entendimento do sistema durante o processo de análise de desempenho. 


\subsection{Produções ao Longo do Mestrado}

As principais produções ao longo do mestrado foram:

- Seminário "NoSQL: Vantagens, desvantagens e compromissos"1 apresentado para o departamento de Ciência da Computação do IME.

- Apresentação "NoSQL: Perdas e Ganhos"² na The Developer’s Conference 2010.

- Artigo curto "NoSQL na Web 2.0: Um Estudo Comparativo de Bancos Não-Relacionais para Armazenamento de Dados na Web 2.0" aceito no Workshop de Teses e Dissertações em Bancos de Dados 2010 (WTDBD’2010), dentro do Simpósio Brasileiro de Bancos de Dados (SBBD).

- Artigo "Mitigating Network Impacts in Large Scale DFSs", recusado no Euro-par 2012, relacionado ao estágio de quatro meses no INRIA em Nantes, França, sobre análise de desempenho de sistemas de arquivos distribuídos.

- Relatório de desempenho da DHT chamada BlobSeer, produzido em estágio de um mês no INRIA em Rennes, França, sobre análise de desempenho desse sistema.

- Código para consistência na linha do tempo no Riak (a implementação ainda não está pronta para uso em produção).

- Infraestrutura de experimentos, comentada na Seção 7.1.

\subsection{Trabalhos Futuros}

Um dos trabalhos futuros mais interessantes seria a validação ou refutação das conclusões deste estudo em uma outra plataforma, de preferência uma que seja usada por aplicações web de produção, como o AWS, por exemplo. Os resultados poderiam ser diferentes por influência da virtualização, devido a latência da rede não variar necessariamente seguindo uma distribuição normal, dentre outros fatores.

Outro tipo de trabalho poderia considerar diferentes discos, incluindo discos de estado sólido (Solid State Drives - SSDs), cujo uso em centros de processamento de dados vem crescendo. Seria interessante analisar e comparar a influência de cada um dos dois tipos de $\mathrm{E} / \mathrm{S}$ - rede e disco - no desempenho do sistema.

Enquanto este trabalho era realizado, modelos de consistência com maiores garantias de consistência com foco em WANs foram desenvolvidos, como os propostos por Google [BBC $\left.{ }^{+} 11\right]$ e Berkeley / MIT [KPFM12]. Seriam interessantes comparações dos desempenhos desses e de outros modelos de consistência.

\footnotetext{
${ }^{1}$ Slides disponíveis em http://www.slideshare.net/mdediana/no-sql-vantagensdesvantagensecompromissos.

${ }^{2}$ Slides disponíveis em http://www.slideshare.net/mdediana/no-sql-perdaseganhos.
} 


\section{Referências Bibliográficas}

[Aba10] Daniel J. Abadi. Problems with CAP, and Yahoo's little known NoSQL system. http:// dbmsmusings.blogspot.com/2010/04/problems-with-cap-and-yahoos-little.html, 2010. [Último Acesso em 01/02/2013.].

[AD76] P.A. Alsberg e J.D. Day. A principle for resilient sharing of distributed resources. Em Proceedings of the 2nd international conference on Software engineering, páginas 562-570. IEEE Computer Society Press, 1976.

[AG95] Sarita V Adve e Kourosh Gharachorloo. Shared Memory Consistency Models: A Tutorial. Computer Engineering, 1995.

[All08] John Allspaw. The Art of Capacity Planning: Scaling Web Resources. O'Reilly Media, 2008.

$\left[\mathrm{ANB}^{+} 95\right]$ M. Ahamad, G. Neiger, J.E. Burns, P. Kohli e P.W. Hutto. Causal memory: Definitions, implementation, and programming. Distributed Computing, 1995.

[And06] Chris Anderson. The Long Tail: Why the Future of Business is Selling Less of More. Hyperion, 2006.

[AW94] Fiagit Attiya e Jennifer L Welch. Sequential Consistency versus Linearizability. Computer, 1994.

[AW96] Yair Amir e A. Wool. Evaluating quorum systems over the internet. Em Proceedings of Annual Symposium on Fault Tolerant Computing, páginas 26-35. IEEE, 1996.

[AXF12] Berk Atikoglu, Y Xu e E Frachtenberg. Workload analysis of a large-scale key-value store. Em Proceedings of the 2012 ACM SIGMETRICS International Conference on Measurement and Modeling of Computer Systems, 2012.

[Bas] Basho Bench. http://wiki.basho.com/Benchmarking.html. [Último Acesso em 01/02/2013.].

$\left[\mathrm{BBC}^{+} 11\right]$ Jason Baker, Chris Bond, J.C. Corbett, JJ Furman, Andrey Khorlin, James Larson, J.M. Léon, Yawei Li, Alexander Lloyd e Vadim Yushprakh. Megastore: providing scalable, highly available storage for interactive services. Em Conference on Innovative Data Systems Research (CIDR), páginas 223-234, 2011.

[BDH03] Luiz André Barroso, Jeffrey Dean e Urs Hölzle. Web Search for a Planet: The Google Cluster Architecture. IEEE Micro, 23(2):22-28, 2003.

[BG81] Philip A. Bernstein e Nathan Goodman. Concurrency control in distributed database systems. ACM Computing Surveys (CSUR), 1981.

[BG83] P.A. Bernstein e N Goodman. The failure and recovery problem for replicated databases. Em Proceedings of the second annual ACM symposium on Principles of distributed computing, páginas 114-122. ACM, 1983. 
BKS $\left.^{+} 11\right]$ Felix Beyer, Arne Koschel, Christian Schulz, Michael Schäfer, Irina Astrova, Alexander Reich, Stella Gatziu Grivas e Marc Schaaf. Testing the Suitability of Cassandra for Cloud Computing Environments Consistency, Availability and Partition Tolerance. Computing, páginas 86-91, 2011.

[Bre00] Eric A. Brewer. Towards Robust Distributed Systems. Annual ACM Symposium on Principles of Distributed Computing, 2000.

[Bre01] Eric A. Brewer. Lessons from giant-scale services. IEEE Internet Computing, 5(4):46$55,2001$.

$\left[\mathrm{CDG}^{+} 06\right]$ Fay Chang, Jeffrey Dean, Sanjay Ghemawat, W.C. Hsieh, D.A. Wallach, Mike Burrows, Tushar Chandra, Andrew Fikes e R.E. Gruber. Bigtable: A Distributed Storage System for Structured Data. Em Proceedings of the 7th USENIX Symposium on Operating Systems Design and Implementation (OSDI 06), volume 26, 2006.

[CR10] Marta Carbone e Luigi Rizzo. Dummynet Revisited. ACM SIGCOMM Computer Communication Review, 2010.

[CRS ${ }^{+}$08] Brian F. Cooper, Raghu Ramakrishnan, Utkarsh Srivastava, Adam Silberstein, Philip Bohannon, Hans-arno Jacobsen, Nick Puz, Daniel Weaver e Ramana Yerneni. PNUTS: Yahoo!'s Hosted Data Serving Platform. Em Proceedings of the VLDB Endowment. VLDB Endowment, 2008.

$\left[\mathrm{CST}^{+} 10\right]$ Brian Cooper, Adam Silberstein, Erwin Tam, Raghu Ramakrishnan e Russell Sears. Benchmarking cloud serving systems with YCSB. ACM Symposium on Cloud Computing (SOCC 2010), página 143, 2010.

$\left[\mathrm{CWO}^{+} 11\right]$ Brad Calder, Ju Wang, Aaron Ogus, Niranjan Nilakantan, Arild Skjolsvold, S. McKelvie, Yikang Xu, Shashwat Srivastav, Jiesheng Wu, Huseyin Simitci e Others. Windows Azure Storage: a highly available cloud storage service with strong consistency. Em Proceedings of the Twenty-Third ACM Symposium on Operating Systems Principles, páginas 143-157. ACM, 2011.

[DGMS85] Susan B. Davidson, Hector Garcia-Molina e Dale Skeen. Consistency in Partitioned Networks. Computing Surveys, 17(3), 1985.

$\left[\mathrm{DHJ}^{+}\right.$07] Giuseppe DeCandia, Deniz Hastorun, Madan Jampani, Gunavardhan Kakulapati, Avinash Lakshman, Alex Pilchin, Swaminathan Sivasubramanian, Peter Vosshall e Werner Vogels. Dynamo: Amazon's Highly Available Key-value Store. ACM SIGOPS Operating Systems Review, (6):205-220, 2007.

[Dyn] Dynomite. http://github.com/cliffmoon/dynomite. [Último Acesso em 01/06/2012.].

[EpNm03] Ricardo J I M Enez-peris e M Pati No-mart. Are Quorums an Alternative for Data Replication? Computer, 28(3):257-294, 2003.

[ESN] Host Tuning. http://fasterdata.es.net/host-tuning/background/. [Último Acesso em 01/02/2013.].

$\left[\mathrm{FGL}^{+} 99\right]$ Alan Fekete, D. Gupta, V. Luchangco, N. Lynch e A. Shvartsman. Eventuallyserializable data services. Theoretical Computer Science, 220(1):113-156, 1999.

[Fid88] Colin J. Fidge. Timestamps in Message-Passing Systems That Preserve the Partial Ordering. Em Proc. of the 11th Australian Computer Science Conference (ACSC'88), páginas 56-66, 1988. 
[FM05] Kevin Fall e Steve McCanne. You don't know jack about network performance. Queue, $3(4): 54,2005$.

$\left[\mathrm{FML}^{+}\right.$10] Daniel A Freedman, Tudor Marian, Jennifer H Lee, Ken Birman, Hakim Weatherspoon e Chris Xu. Exact Temporal Characterization of 10 Gbps Optical Wide-Area Network. Em IMC '10 Proceedings of the 10th ACM SIGCOMM conference on Internet measurement, 2010.

[GBKA11] Lisa Glendenning, I. Beschastnikh, A. Krishnamurthy e Thomas Anderson. Scalable consistency in Scatter. Em Proceedings of the Twenty-Third ACM Symposium on Operating Systems Principles, páginas 15-28. ACM, 2011.

[GHOS96] Jim Gray, Pat Helland, Patrick O’Neil e Dennis Shasha. The dangers of replication and a solution. Em Proceedings of the 1996 ACM SIGMOD international conference on anagement of data, páginas 173-182, 1996.

[Gif79] David K. Gifford. Weighted Voting for Replicated Data. Em Proceedings of the Seventh Symposium on Operating Systems Principles - SOSP 'ry, páginas 150-162, 1979.

[GL02] Seth Gilbert e Nancy Lynch. Brewer's Conjecture and the Feasibility of Consistent, Available, Partition-tolerant Web Services. ACM SIGACT News, 33(2):51, 2002.

[GN95] R. Gallersdörfer e Matthias Nicola. Improving performance in replicated databases through relaxed coherency. Em Proceedings of the 21st VLDB Conference, páginas 445-456, 1995.

[Gra81] Jim Gray. The Transaction Concept: Virtues and Limitations. Em Proceedings of the seventh international conference on Very Large Data Bases, number 1, 1981.

[Gur01] Andrei Gurtov. Effect of delays on TCP performance. Em In Proceedings of IFIP Personal Wireless Communications, páginas 87-108, 2001.

[Hal10] Coda Hale. You Can’t Sacrifice Partition Tolerance. http://codahale.com/ you-cant-sacrifice-partition-tolerance/, 2010. [Último Acesso em 01/02/2013.].

[HC09] Pat Helland e Dave Campbell. Building on quicksand. Em 4th Biennial Conf. on Innovative Data Systems Research (CIDR), 2009.

[Hel07] Pat Helland. Life beyond distributed transactions: an apostate's opinion. Em Proceedings on Conference on Innovative DataSystems Research, páginas 132-141, 2007.

[Hen06] Cal Henderson. Building Scalable Web Sites: Building, Scaling, and Optimizing the Next Generation of Web Applications. O'Reilly Media, 2006.

[Hoh04] Gregor Hohpe. Starbucks Does Not Use Two-Phase Commit. http://eaipatterns.com/ ramblings/18_starbucks.html, 2004. [Último Acesso em 01/02/2013.].

[Hoo10] Stu Hood. Making Massive Manageable: Hadoop and Cassandra (at Rackspace). http://www.slideshare.net/stuhood/hadoop-and-cassandra-at-rackspace, 2010. [Último Acesso em 01/02/2013.].

[HR83] Theo Haerder e Andreas Reuter. Principles of transaction-oriented database recovery. ACM Computing Surveys, páginas 287-317, 1983.

[HRX08] S Ha, Injong Rhee e Lisong Xu. CUBIC: a new TCP-friendly high-speed TCP variant. ACM SIGOPS Operating Systems Review, 2008. 
[HW90] Maurice P. Herlihy e Jeannette M. Wing. Linearizability: a correctness condition for concurrent objects. ACM Transactions on Programming Languages and Systems, 12(3):463-492, 1990.

[Jac88] Van Jacobson. Congestion Avoidance and Control. SIGCOMM Comput. Commun. Rev., 1988.

[Jai91] Raj Jain. The Art of Computer Systems Performance Analysis: Techniques for Experimental Design, Measurements, Simulation, and Modeling. Wiley Computer Publishing, John Wiley \& Sons, Inc., 1991.

[JD05] Hao Jiang e Constantinos Dovrolis. Why is the internet traffic bursty in short time scales? ACM SIGMETRICS Performance Evaluation Review, 33(1):241, 2005.

[Jon06] M. Tim Jones. Boost socket performance on Linux. http://www.ibm. com/developerworks/linux/library/l-hisock/index.html, 2006. [Último Acesso em 01/02/2013.].

[JT75] Paul R. Johnson e Robert H. Thomas. RFC 677 - The Maintenance of Duplicate Databases. Relatório técnico, 1975.

[KCCL11] Sudarshan Kadambi, Jianjun Chen, Brian Cooper e David Lomax. Where in the World is My Data? Em Proceedings of the VLDB Endowment, páginas 1040-1050, 2011.

[Kin10a] David King. She who entangles men. http://blog.reddit.com/2010/03/ she-who-entangles-men.html, 2010. [Último Acesso em 01/02/2013.].

[Kin10b] Ryan King. Cassandra at Twitter Today. http://engineering.twitter.com/2010/07/ cassandra-at-twitter-today.html, 2010. [Último Acesso em 01/02/2013.].

[KLL $\left.{ }^{+} 97\right]$ D. Karger, E. Lehman, T. Leighton, R. Panigrahy, M. Levine e D. Lewin. Consistent hashing and random trees: Distributed caching protocols for relieving hot spots on the World Wide Web. Em Proceedings of the twenty-ninth annual ACM symposium on Theory of computing, páginas 654-663. ACM, 1997.

[KPFM12] Tim Kraska, Gene Pang, MJ Franklin e Samuel Madden. MDCC: Multi-Data Center Consistency. Relatório técnico, 2012.

[Lam78] Leslie Lamport. Time, clocks, and the ordering of events in a distributed system. Communications of the ACM, 21(7):558-565, 1978.

[Lam97] L. Lamport. How to make a correct multiprocess program execute correctly on a multiprocessor. IEEE Transactions on Computers, 46(7):779-782, 1997.

[LFKA11] Wyatt Lloyd, M.J. Freedman, Michael Kaminsky e D.G. Andersen. Don't Settle for Eventual: Scalable Causal Consistency for Wide-Area Storage with COPS. Lloydia (Cincinnati), páginas 1-16, 2011.

[Li105] David J. Lilja. Measuring Computer Performance: A Practitioner's Guide. Cambridge University Press, 2005.

[LM10] Avinash Lakshman e Prashant Malik. Cassandra: a decentralized structured storage system. ACM SIGOPS Operating Systems Review, 44(2):35-40, 2010.

[LO09] Ling Liu e M. Tamer Özsu, editors. Encyclopedia of Database Systems. Springer, 2009.

[LS04] D Leith e R Shorten. H-TCP: TCP for high-speed and long-distance networks. Proceedings of PFLDnet, páginas 1-16, 2004. 
[Mos93] David Mosberger. Memory consistency models. ACM SIGOPS Operating Systems Review, 27(1):18-26, 1993.

[Pin13] PingER (Ping End-to-end Reporting). http://www-iepm.slac.stanford.edu/pinger/, 2013. [Último Acesso em 01/02/2013.].

$\left[\mathrm{PPR}^{+} 83\right]$ D.S. Parker, G.J. Popek, G. Rudisin, a. Stoughton, B.J. Walker, E. Walton, J.M. Chow, D. Edwards, S. Kiser e C. Kline. Detection of Mutual Inconsistency in Distributed Systems. IEEE Transactions on Software Engineering, (3):240-247, 1983.

[PPR ${ }^{+}$09] Andrew Pavlo, Erik Paulson, Alexander Rasin, Daniel J. Abadi, David .J. DeWitt, Samuel Madden e Michael Stonebraker. A Comparison of Approaches to Large-Scale Data Analysis. Em Proceedings of the 35th SIGMOD International Conference on Management of Data, volume 2, páginas 165-178. ACM, 2009.

[Pri08] Dan Pritchett. BASE: An Acid Alternative. Queue, 6(3):48-55, 2008.

[Puj12] Josep M. Pujol. Having fun with Redis Replication between Amazon and Rackspace. http://3scale.github.com/2012/07/25/fun-with-redis-replication/, 2012. [Último Acesso em 01/02/2013.].

[RFC09] RFC5681 - TCP Congestion Control. Relatório técnico, 2009.

[Ria] Riak. http://wiki.basho.com/Riak.html. [Último Acesso em 01/02/2013.].

[RST11] Jun Rao, E.J. Shekita e Sandeep Tata. Using paxos to build a scalable, consistent, and highly available datastore. Proceedings of the VLDB Endowment, 4(4):243-254, 2011.

[SFK $\left.{ }^{+} 09\right]$ Atul Singh, Pedro Fonseca, Petr Kuznetsov, Rodrigo Rodrigues e Petros Maniatis. Zeno: eventually consistent byzantine-fault tolerance. Em Proceedings of the 6th USENIX symposium on Networked systems design and implementation, páginas 169184. USENIX Association, 2009.

[Sha11] Marc Shapiro. A comprehensive study of Convergent and Commutative Replicated Data Types. Relatório técnico, 2011.

$\left[\mathrm{SMA}^{+} 07\right]$ Michael Stonebraker, Samuel Madden, Daniel J. Abadi, Stavros Harizopoulos, Nabil Hachem e Pat Helland. The End of an Architectural Era (It's Time for a Complete Rewrite). Em Proceedings of the 33rd International Conference on Very Large Data Bases, volume 07pp, páginas 1150-1160. VLDB Endowment, 2007.

[SPAL11] Yair Sovran, R. Power, M.K. Aguilera e J. Li. Transactional storage for geo-replicated systems. Em Proceedings of the Twenty-Third ACM Symposium on Operating Systems Principles, páginas 385-400, 2011.

[SPBZ] Marc Shapiro, Nuno Preguiça, Carlos Baquero e Marek Zawirski. Conflict-free Replicated Data Types. Proceeding of SSS'11 Proceedings of the 13th international conference on Stabilization, safety, and security of distributed systems, páginas 1-17.

[SS05] Yasushi Saito e Marc Shapiro. Optimistic replication. ACM Computing Surveys (CSUR), 37(1):42-81, 2005.

[SW93] W. Richard Stevens e Gary R Wright. Tcp/Ip Illustrated: The Protocols - Volume 1. Addison-Wesley Professional, 1993.

[Tho79] Robert H. Thomas. A Majority consensus approach to concurrency control for multiple copy databases. ACM Transactions on Database Systems, 4(2):180-209, 1979. 
[Tho07] Thorsten. Network performance within Amazon EC2 and to Amazon S3. http://blog.rightscale.com $/ 2007 / 10 / 28 /$ network-performance-within-amazon-ec2-and-to-amazon-s3/, 2007. [Último Acesso em 01/02/2013.].

[TS06] Andrew S. Tanenbaum e Maarten Van Steen. Distributed Systems: Principles and Paradigms. Prentice Hall, 2006.

[Vog07] Werner Vogels. Amazon's Dynamo. http://allthingsdistributed.com/2007/10/ amazons_dynamo.html, 2007. [Último Acesso em 01/02/2013.].

[Vog09] Werner Vogels. Eventually Consistent. Communications of the ACM, 52(1):40-44, 2009.

[Vol] Project Voldemort. http://project-voldemort.com/. [Último Acesso em 01/02/2013.].

[vRS04] R. van Renesse e F.B. Schneider. Chain replication for supporting high throughput and availability. Em Proceedings of the 6th conference on Symposium on Opearting Systems Design 63 Implementation-Volume 6, página 7. USENIX Association, 2004.

[WLL04] Yi Wang, Guohan Lu e Xing Li. A study of internet packet reordering. Em Information Networking, Networking Technologies for Broadband and Mobile Networks, International Conference ICOIN 2004, páginas 350-359, 2004.

[YV01] Haifeng Yu e A. Vahdat. The costs and limits of availability for replicated services. Em ACM SIGOPS Operating Systems Review, volume 35, páginas 29-42. ACM, 2001. 